US Army Corps of Engineers ${ }_{\circledast}$

Engineer Research and

Development Center

U.S. Air Force Rapid Airfield Damage Recovery (RADR) Program

Full-Scale Testing of Commercially Available Cementitious Backfill and Surface Capping Materials for Crater Repairs

William D. Carruth
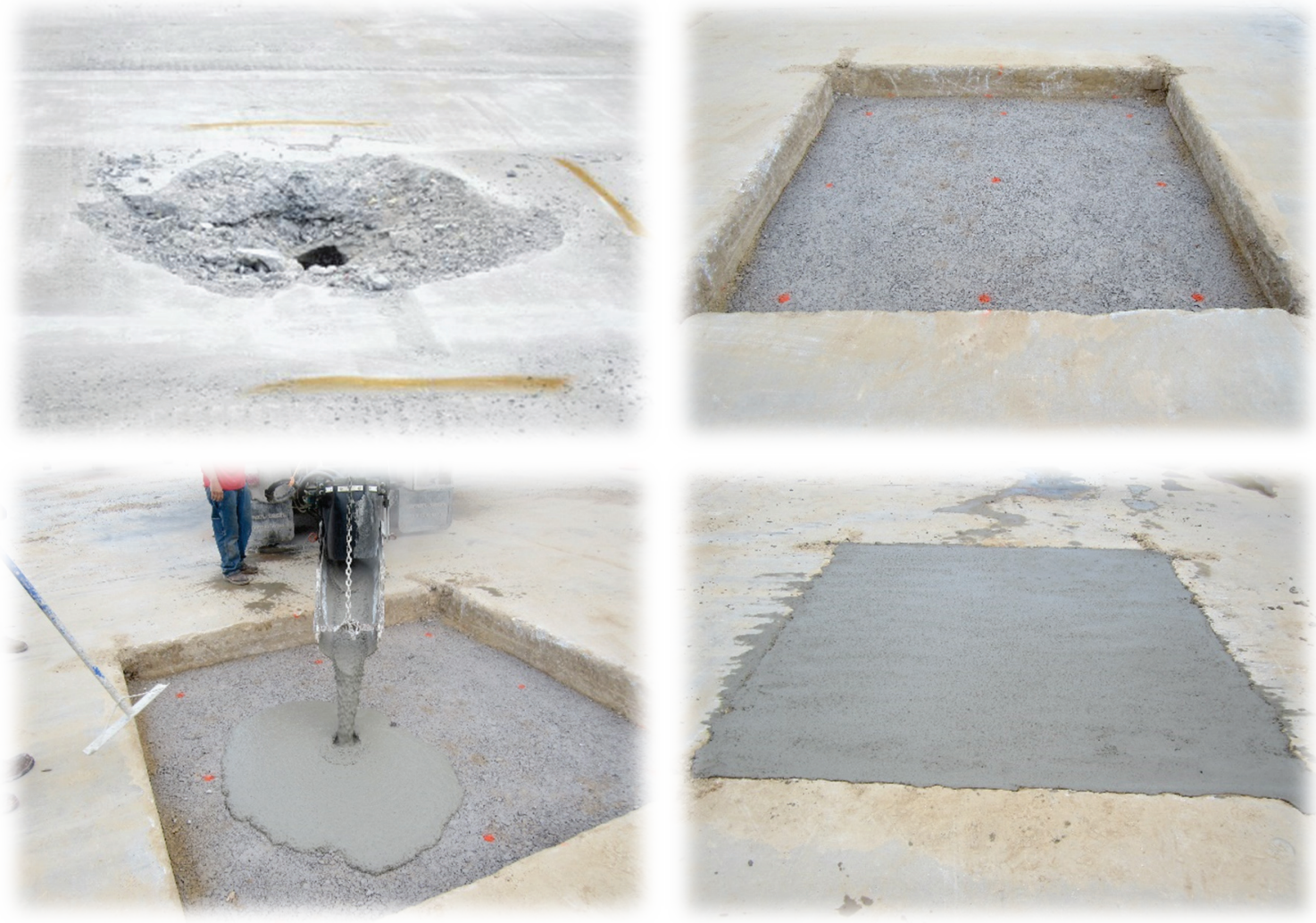
The U.S. Army Engineer Research and Development Center (ERDC) solves the nation's toughest engineering and environmental challenges. ERDC develops innovative solutions in civil and military engineering, geospatial sciences, water resources, and environmental sciences for the Army, the Department of Defense, civilian agencies, and our nation's public good. Find out more at www.erdc.usace.army.mil.

To search for other technical reports published by ERDC, visit the ERDC online library at http://acwc.sdp.sirsi.net/client/default. 


\title{
Full-Scale Testing of Commercially Available Cementitious Surface Capping Materials for Crater Repairs
}

\author{
William D. Carruth, P.E \\ Geotechnical and Structures Laboratory \\ U.S. Army Engineer Research and Development Center \\ 3909 Halls Ferry Road \\ Vicksburg, MS 39180-6199
}

Final report

Approved for public release; distribution is unlimited.

\author{
Prepared for U.S. Air Force Civil Engineer Center \\ 139 Barnes Drive, Suite 1 \\ Tyndall AFB, FL 32403 \\ Under Rapid Airfield Damage Recovery (RADR) Program \\ MIPR F4ATA77242GW01
}




\section{Abstract}

The Air Force Civil Engineer Center (AFCEC) Rapid Airfield Damage Recovery (RADR) program currently utilizes rapid-setting flowable fill (RSFF) and rapid-setting concrete (RSC) for backfilling and capping crater repairs. These materials have been proven successful through many fullscale tests, troop demonstrations, and live flight trafficking. However, only one proprietary product is currently approved for each material. Two candidate capping materials and one backfill material were evaluated by conducting simulated crater repairs and collecting appropriate data. For capping products, both small $(8.5 \mathrm{ft} \times 8.5 \mathrm{ft})$ and large $(15 \mathrm{ft} \times 15 \mathrm{ft})$ repairs were conducted and trafficked with simulated F-15E aircraft traffic. For the backfill material, three small repairs were backfilled and the California Bearing Ratio (CBR) was estimated at cure times of 0.5, 2, and $24 \mathrm{hr}$. Overall, repairs capped with Western Materials Fastrac 246 failed after only 2,000 passes, so the material is not currently recommended for approval. Repairs capped with Buzzi Unicem Ulti-Pave $3^{\circledR}$ were able to sustain 3,500 passes before trafficking was ceased, so this material is recommended for approval as a crater repair capping material. CTS rapidsetting flowable fill backfill exhibited lower than expected CBR values and did not allow timely percolation of mix water, so it is not currently recommended for approval at this time.

DISCLAIMER: The contents of this report are not to be used for advertising, publication, or promotional purposes. Citation of trade names does not constitute an official endorsement or approval of the use of such commercial products. All product names and trademarks cited are the property of their respective owners. The findings of this report are not to be construed as an official Department of the Army position unless so designated by other authorized documents. 


\section{Contents}

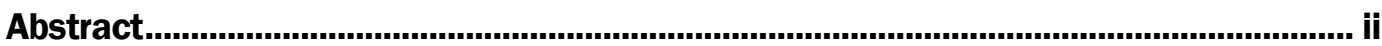

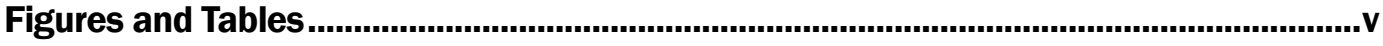

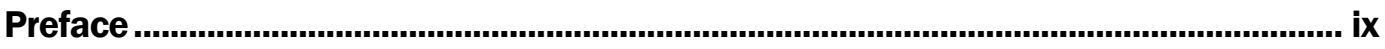

1 Introduction ........................................................................................................1

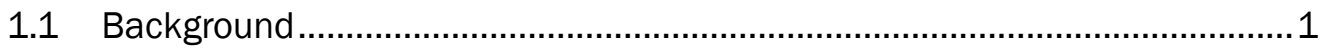

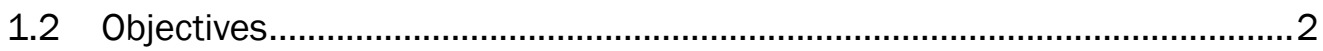

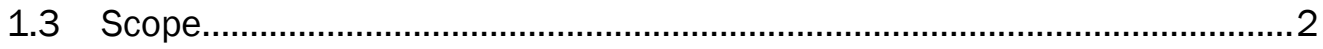

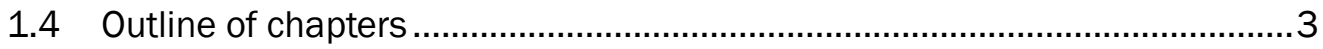

2 Test Site, Equipment, and Materials Description........................................... 4

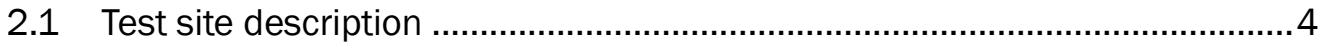

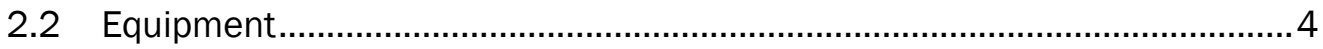

2.2.1 Compact track loader and wheel saw attachment ............................................... 4

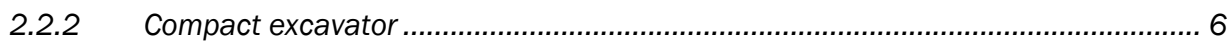

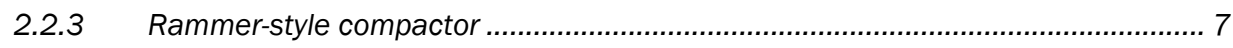

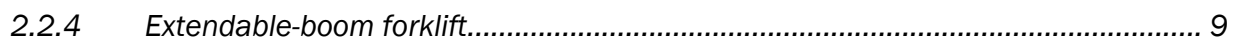

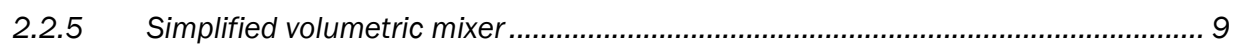

2.3 Materials .................................................................................... 10

2.3.1 Natural subgrade and crushed stone backfill material ...................................... 10

2.3.2 Rapid-setting flowable fill ................................................................................ 11

2.3.3 Rapid-setting concrete................................................................................... 12

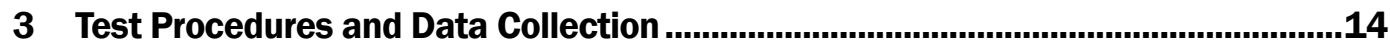

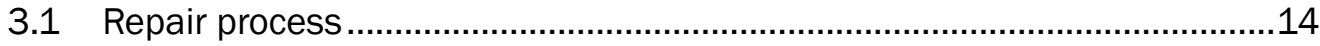

3.1.1 Marking, saw cutting, breaking, and excavation processes.................................. 14

3.1.2 Backfill process ............................................................................................. 14

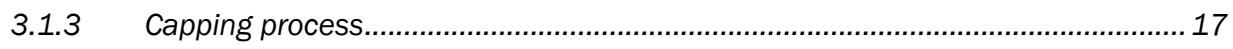

3.2 Data collection ............................................................................ 19

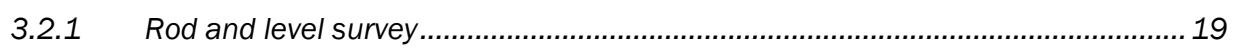

3.2.2 Material strength property testing .................................................................... 21

3.2.3 Repair distress photographs and documentation ............................................ 21

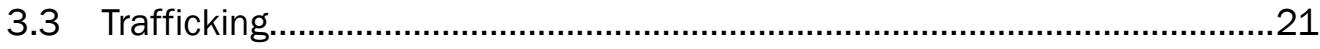

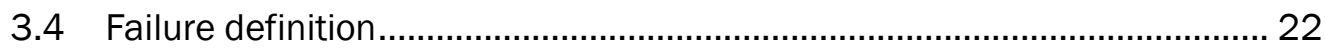

4 Results and Discussion ...............................................................................23

4.1 Rapid-setting concrete results and discussion..................................... 23

4.1.1 Subgrade and backfill California bearing ratio (CBR) results................................ 23

4.1.2 Backfill and cap thickness results ................................................................... 24

4.1.3 Tri-service spall repair certification protocol results ............................................. 24

4.1.4 Compressive strength sample results .............................................................. 25

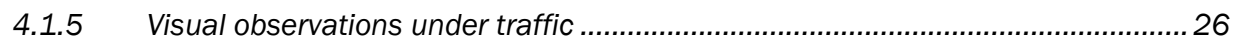




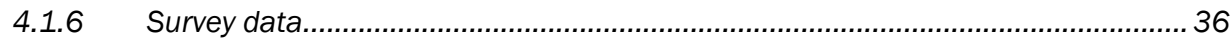
4.2 Rapid-setting flowable fill results and discussion ................................ 40
4.2.1 Previous wet method testing ............................................................................ 40

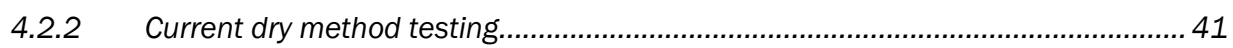

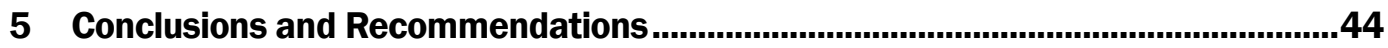

5.1 Conclusions......................................................................................... 44

5.2 Recommendations ....................................................................... 45

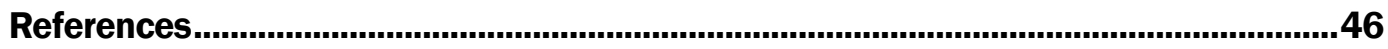

Appendix A: Repair Material Certification Results....................................................48

Appendix B: Dynamic Cone Penetrometer (DCP) Data .............................................51

Unit Conversion Factors....................................................................................... 106

Acronyms ................................................................................................................. 107

\section{Report Documentation Page}




\section{Figures and Tables}

\section{Figures}

Figure 1. Caterpillar 279C CTL...................................................................................... 5

Figure 2. Caterpillar 279C CTL with SW45 wheel saw attachment. .................................... 6

Figure 3. Bobcat E45 compact excavator............................................................................ 7

Figure 4 . Mutiquip Mikasa MTX-70 rammer-style compactor. ….......................................... 8

Figure 5. Caterpillar 1055C extendable boom forklift....................................................... 9

Figure 6. Simplified volumtric mixer. ............................................................................10

Figure 7. Compaction of brown CL clay subgrade. ...............................................................11

Figure 8. Compacted crushed stone backfill material......................................................11

Figure 9. Placement of rapid-setting flowable fill material.....................................................16

Figure 10. Leveling of dry rapid-setting flowable fill material. .............................................16

Figure 11. Metering of water over dry rapid-setting flowable fill. ........................................17

Figure 12. Completed rapid-setting flowable fill placement after 30 min of cure time

Figure 13. Placement of rapid-setting concrete capping material....................................18

Figure 14. Screeding of rapid-setting concrete capping material......................................19

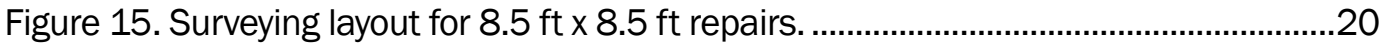

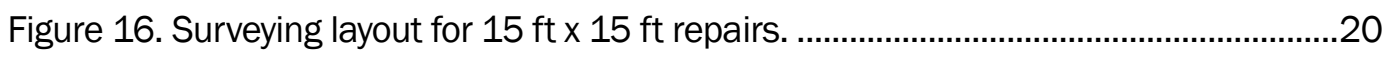

Figure 17. F-15 load cart.............................................................................................22

Figure 18. F-15 load cart trafficking pattern.......................................................................2

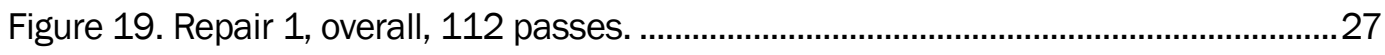

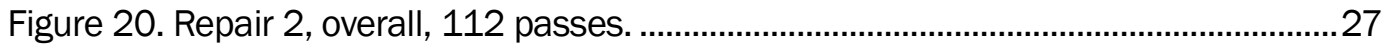

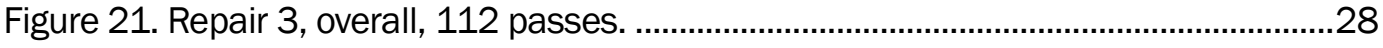

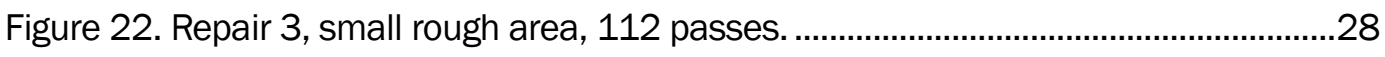

Figure 23. Repair 1, rear edge deterioration, 1,000 passes................................................29

Figure 24. Repair 2, rear edge deterioration, 1000 passes. .................................................29

Figure 25. Repair 3, Spalling and cracking on rear edge, 1,000 passes.........................30

Figure 26. Repair 1, overall, 2,000 passes...........................................................................

Figure 27. Repair 1, front edge, 2,000 passes......................................................................31

Figure 28. Repair 1, rear edge, 2,000 passes. ...........................................................32

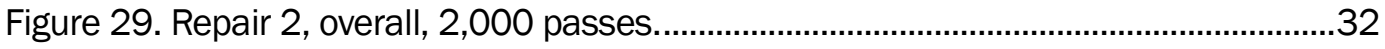

Figure 30. Repair 2, rear edge, 2,000 passes. ................................................................32

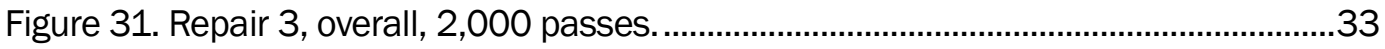

Figure 32. Repair 3, high-severity joint spalling on rear edge, 2,000 passes.....................33

Figure 33. Repair 4, overall, 112 passes. ........................................................................3

Figure 34. Repair 5, overall, 112 passes. .............................................................................34

Figure 35. Repair 4, rear edge, 2,000 passes. ..............................................................34 


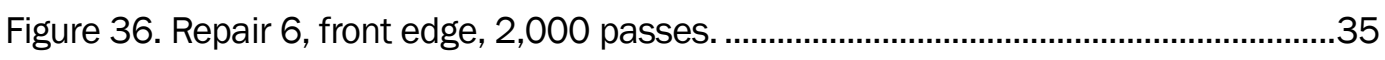

Figure 37. Repair 4, medium-severity spalling, 3,500 passes. ..........................................35

Figure 38. Repair 5, low-severity spalling, 3,500 passes. .................................................36

Figure 39. Repair 6 , high- severity spalling, 3,500 passes..................................................36

Figure 40. CTS rapid-setting flowable fill after 30 min cure time. ....................................43

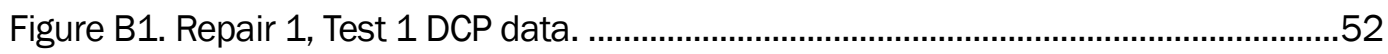

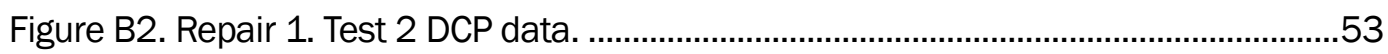

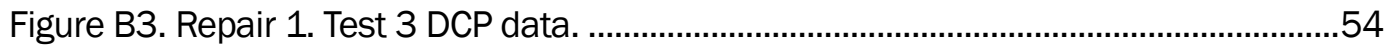

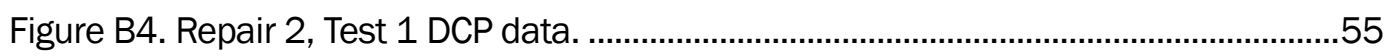

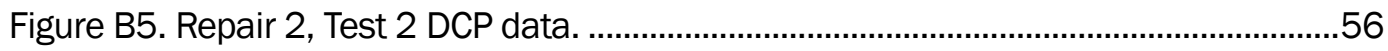

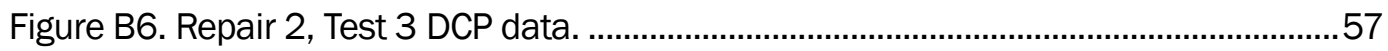

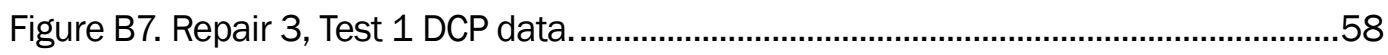

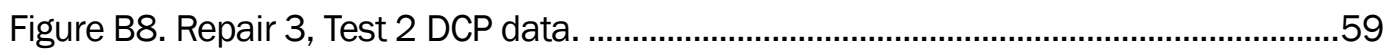

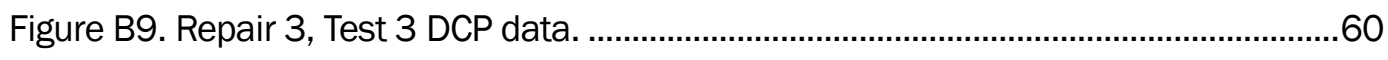

Figure B10. Repair 4, Test 1 DCP data........................................................................61

Figure B11. Repair 4, Test 2 DCP data.........................................................................62

Figure B12. Repair 4, Test 3 DCP data............................................................................63

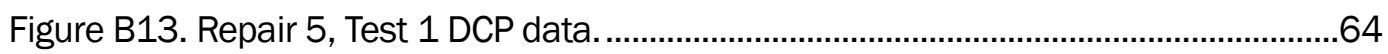

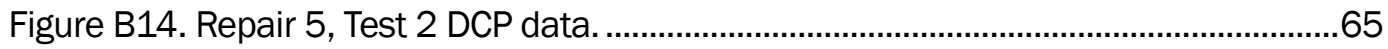

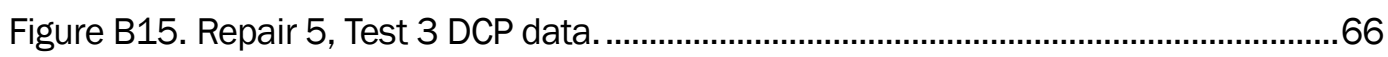

Figure B16. Repair 6, Test 1 DCP data.......................................................................67

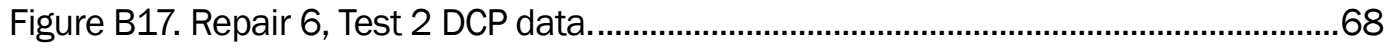

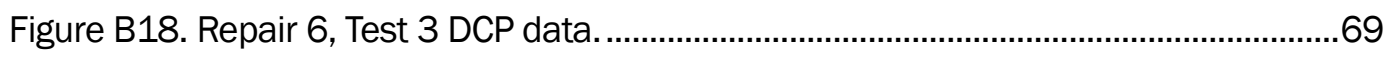

Figure B19. Repair FF-1, Test 1, DCP data at 30 min cure time.........................................70

Figure B20. Repair FF-1, Test 2, DCP data at 30 min cure time........................................ 71

Figure B21. Repair FF-1, Test 1, DCP data at 30 min cure time......................................72

Figure B22. Repair FF-2, Test 1, DCP data at 30 min cure time........................................73

Figure B23. Repair FF-2, Test 2, DCP data at 30 min cure time....................................... 74

Figure B24. Repair FF-2, Test 3, DCP data at 30 min cure time........................................75

Figure B25. Repair FF-3, Test 1, DCP data at 30 min cure time......................................... 76

Figure B26. Repair FF-3, Test 2, DCP data at 30 min cure time....................................... 77

Figure B27. Repair FF-3, Test 3, DCP data at 30 min cure time. .......................................78

Figure B28. Repair FF-1, Test 1, DCP data at $1 \mathrm{hr}$ cure time. ............................................79

Figure B29. Repair FF-1, Test 2, DCP data at $1 \mathrm{hr}$ cure time. .........................................80

Figure B30. Repair FF-1, Test 3, DCP data at $1 \mathrm{hr}$ cure time. ............................................81

Figure B31. Repair FF-2, Test 1, DCP data at $1 \mathrm{hr}$ cure time.............................................82

Figure B32. Repair FF-2, Test 2, DCP data at $1 \mathrm{hr}$ cure time. ...........................................83

Figure B33. Repair FF-2, Test 3, DCP data at $1 \mathrm{hr}$ cure time. ...........................................84

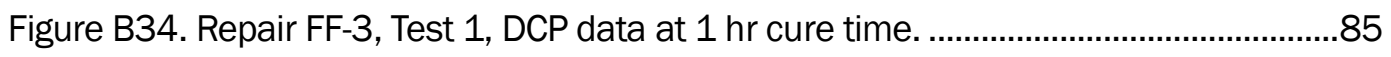




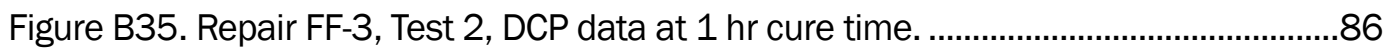

Figure B36. Repair FF-3, Test 3, DCP data at $1 \mathrm{hr}$ cure time........................................... 87

Figure B37. Repair FF-1, Test 1, DCP data at $2 \mathrm{hr}$ cure time. ...........................................8

Figure B38. Repair FF-1, Test 2, DCP data at $2 \mathrm{hr}$ cure time. .............................................89

Figure B39. Repair FF-1, Test 3, DCP data at $2 \mathrm{hr}$ cure time. .........................................90

Figure B40. Repair FF-2, Test 1, DCP data at $2 \mathrm{hr}$ cure time. ...........................................

Figure B41. Repair FF-2, Test 2, DCP data at $2 \mathrm{hr}$ cure time............................................92

Figure B42. Repair FF-2, Test 3, DCP data at $2 \mathrm{hr}$ cure time. ..........................................93

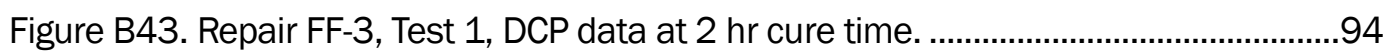

Figure B44. Repair FF-3, Test 2, DCP data at $2 \mathrm{hr}$ cure time. ............................................95

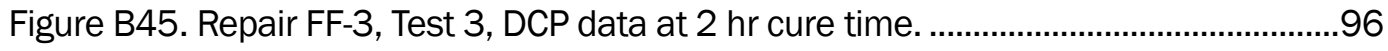

Figure B46. Repair FF-1, Test 1, DCP data at $24 \mathrm{hr}$ cure time........................................97

Figure B47. Repair FF-1, Test 2, DCP data at $24 \mathrm{hr}$ cure time.......................................98

Figure B48. Repair FF-1, Test 3, DCP data at $24 \mathrm{hr}$ cure time...........................................99

Figure B49. Repair FF-2, Test 1, DCP data at 24 hr cure time....................................... 100

Figure B50. Repair FF-2, Test 2, DCP data at $24 \mathrm{hr}$ cure time......................................... 101

Figure B51. Repair FF-2, Test 3, DCP data at $24 \mathrm{hr}$ cure time........................................ 102

Figure B52. Repair FF-3, Test 1, DCP data at 24 hr cure time........................................ 103

Figure B53. Repair FF-3, Test 2, DCP data at $24 \mathrm{hr}$ cure time....................................... 104

Figure B54. Repair FF-3, Test 3, DCP data at 24 hr cure time....................................... 105

\section{Tables}

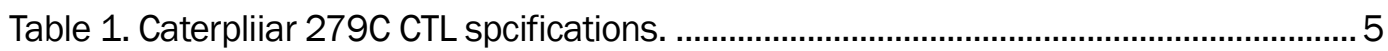

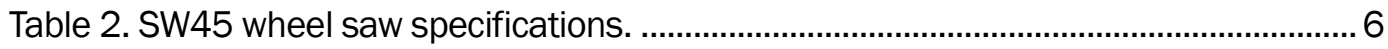

Table 3. Bobcat E45 compact excavator specifications.................................................... 7

Table 4. Mutiquip Mikasa MTX-70 specifications. ........................................................... 8

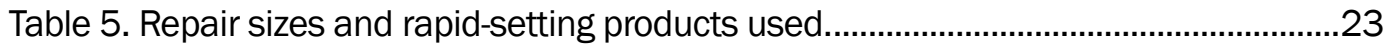

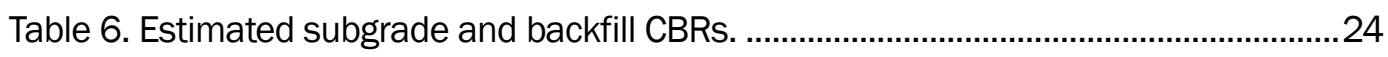

Table 7. Average repair backfill and cap thicknesses. ........................................................ 24

Table 8. RSC compressive strength results. .......................................................................26

Table 9. Repairs 1, 2, and 3 joint spall dimensions after 2,000 passes. ............................30

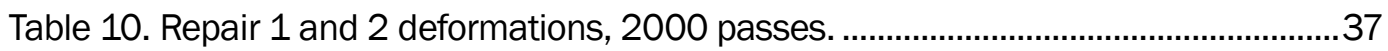

Table 11. Repair 3 deformations, 2,000 passes. ..............................................................38

Table 12. Repair 4 and 5 deformations, 3,500 passes. ....................................................39

Table 13. Repair 6 deformations, 3,500 passes. .............................................................40

Table 14. Compressive strength results from Cox and Hoffman (2019)...........................41

Table 15. CTS rapid-setting flowable fill dry method CBR results. ......................................42

Table 16. Summary of CBR results. ..................................................................................43

Table A1. Fastrac \#246 Laboratory repair material certification protocol results. .............49 
Table A2. Ulti-Pave3 Laboratory repair material certification protocol results. ...................50 


\section{Preface}

This study was conducted for the U.S. Air Force (USAF) Civil Engineer Center (AFCEC) under the U.S. Air Force Rapid Airfield Damage Recovery (RADR) program. The AFCEC technical monitor was Dr. Robert Diltz. Mr. Jeb S. Tingle provided technical oversight.

The work was performed by the Airfields and Pavements Branch (GMA) of the Engineering Systems and Materials Division (GM), U.S. Army Engineer Research and Development Center, Geotechnical and Structures Laboratory (ERDC-GSL). At the time of publication, Dr. Timothy W. Rushing was Chief, CEERD-GMA; Justin S. Strickler was Chief, CEERDGM; and R. Nicholas Boone, CEERD-GZT, was the Technical Director for Force Projection and Maneuver Support. The Deputy Director of ERDCGSL was Mr. Charles W. Ertle, III, and the Director was Mr. Bartley P. Durst.

COL Teresa A. Schlosser was the Commander of ERDC, and Dr. David W. Pittman was the Director. 


\section{Introduction}

\subsection{Background}

In order to address the operational limitations of legacy repair methods, the Critical Runway AssessmenT and Repair (CRATR) Joint Capabilities Technology Demonstration (JCTD) was initiated in 2006. The CRATR JCTD intended to provide a method of rapidly assessing and repairing damage to an airfield. The JCTDs goal was to develop capabilities to return damaged runways to full operational sortie production in a timely manner. The CRATR JCTD included three major technology demonstrations, which included two limited operational utility assessments (LOUA) and one operational utility assessment (OUA). LOUA1 was conducted to evaluate materials, tactics, techniques, and procedures (TTPs), and prototype equipment for rapid automated airfield damage assessment and crater repair (Tingle et al. 2009). Following material and equipment modifications, LOUA2 was conducted during April 2009 (Priddy et al. 2013a) so further evaluation of materials, TTPs, and prototype equipment for crater repair could take place.

Successfully demonstrated technologies from LOUA2 were down selected and refined for a final OUA demonstration, which was conducted at Avon Park Air Force Range, FL, during August 2009 (Priddy et al. 2011; Priddy et al. 2013b). In general, the OUA demonstration verified new materials, equipment, and procedures are capable of meeting the required Airfield Damage Repair (ADR) timeline and sustaining live aircraft traffic. Based on the results of the OUA, the decision to begin refinement and procurement of the new crater repair technologies was made by the U.S. Air Force (USAF).

Since the OUA was conducted, numerous troop demonstrations and other full-scale tests have been conducted. These include conducting repairs in cold weather (Edwards et al. 2013, 2018), wet weather (Bell et al. 2013, Bell 2017, and Bell et. al 2018), and performing large crater repairs (Carruth et al. 2015). Additional work has also been performed on equipment refinement (Bell et al. 2015, Bell and Rowland 2018) and examining the structural performance of rapid-setting concrete (RSC) (Priddy et al. 2016) and rapid-setting flowable fill (RSFF) (Carruth and Howard 2016). 
A description of the crater repair process is well documented in many of the references cited above (Bell et al. 2013, Priddy et al. 2013b, Edwards et al. 2013, and Carruth et al. 2015). First, large debris is removed with track loaders and large front end loaders. Next, the stanchion method is used (USAF 1992) to mark the extent of upheaval before a square repair area on the pavement is marked. The marked area is then saw-cut, followed by breaking and removal of the existing material with wheeled excavators. Once the repair is excavated, it is backfilled typically with RSFF or compacted crushed stone. The repair is capped with RSC using the USAF simplified Volumetric Mixer (SVM).

Currently, only two commercially available materials are recommended for the backfill and capping tasks within the rapid airfield damage recovery (RADR) scenario. Buzzi Unicem Utility Fill One-Step 750 is a rapid-setting flowable fill recommended for backfilling and CTS Rapid Set ${ }^{\circledR}$ concrete mix is recommended for capping repairs. Both materials were recommended after passing initial laboratory testing and then performing well during numerous full-scale tests and troop demonstrations (Bell et. al 2013, Carruth et al. 2015, Edwards et. al 2013, Edwards et. al 2018, Priddy et al. 2013a, and Priddy et al. 2013b). A few other commercially available products have met laboratory requirements, but need to be tested in a fullscale environment so a recommendation could be developed as to whether these materials are suitable for backfilling or capping crater repairs.

\subsection{Objectives}

The objective of the testing described in this report was to evaluate commercially available RSFF and RSC materials by performing full-scale simulated crater repairs. Additional commercially available RSFF and RSC materials are needed that can meet USAF requirements for RADR operations. Although the materials have met laboratory requirements, fullscale testing is required before a recommendation can be developed.

\subsection{Scope}

The scope of the work described herein involved evaluating two proprietary RSC materials (Western Materials Fastrac 246 and Buzzi Unicem Ulti-Pave ${ }^{\circledR}$ ) and one RSFF material (CTS Rapid Setting Flowable Fill) via full-scale testing. Construction timing data was not reported since civilian engineering technicians performed the work, in lieu of enlisted 
airmen. Trafficking was ceased after failure or 3,500 passes was reached, since continuing above that pass level was outside the scope of this report.

\subsection{Outline of chapters}

Chapter 2 describes the equipment, materials, and test site, and Chapter 3 presents the test procedures. Chapter 4 contains test results along with discussion and analysis of the results. Conclusions and recommendations are presented in Chapter 5, followed by references used in preparing this report. Appendix A contains laboratory data for the two RSC products, and Appendix B provides complete Dynamic Cone Penetrometer (DCP) test results. 


\section{Test Site, Equipment, and Materials Description}

\subsection{Test site description}

Simulated crater repairs were conducted on a full-scale portland cement concrete (PCC) test section that was constructed in March 2016 on the east campus at ERDC's Vicksburg, MS site. The test section consisted of 15 and 18 in. thick airfield designed PCC pavement with a target flexural strength of 650 psi. The base consisted of compacted \#610 crushed limestone that was 6 in. thick under the 18 in. thick PCC and 9 in. thick under the 15 in. PCC. The existing subgrade beneath the base material was classified as a low plasticity clay (CL) according to the Unified Soil Classification System (USCS). The test site was originally constructed to provide a testing area for evaluating a variety of concrete sawing equipment for crater repairs. Additional information concerning construction procedures and material characterization can be found in Bell and Rowland (2017).

\subsection{Equipment}

Several different pieces of equipment were utilized to complete simulated crater repairs. Equipment was utilized for breaking, sawing, and excavating the repaired areas, along with placing and compacting the subgrade and base materials. Volumetric mixing equipment was used to place rapid-setting materials. A description of the equipment used and the corresponding specifications are provided in this section.

\subsubsection{Compact track loader and wheel saw attachment}

A Caterpillar $279 \mathrm{C}$ compact track loader (CTL), or skid steer, is a highflow, rubber-tracked machine with quick-disconnect fittings that are used extensively in the modernized RADR process (Figure 1). The quick disconnect allows attachments to be switched out rapidly without the use of tools. Specifications for the machine can be found in Table 1. 
Figure 1. Caterpillar 279C CTL.

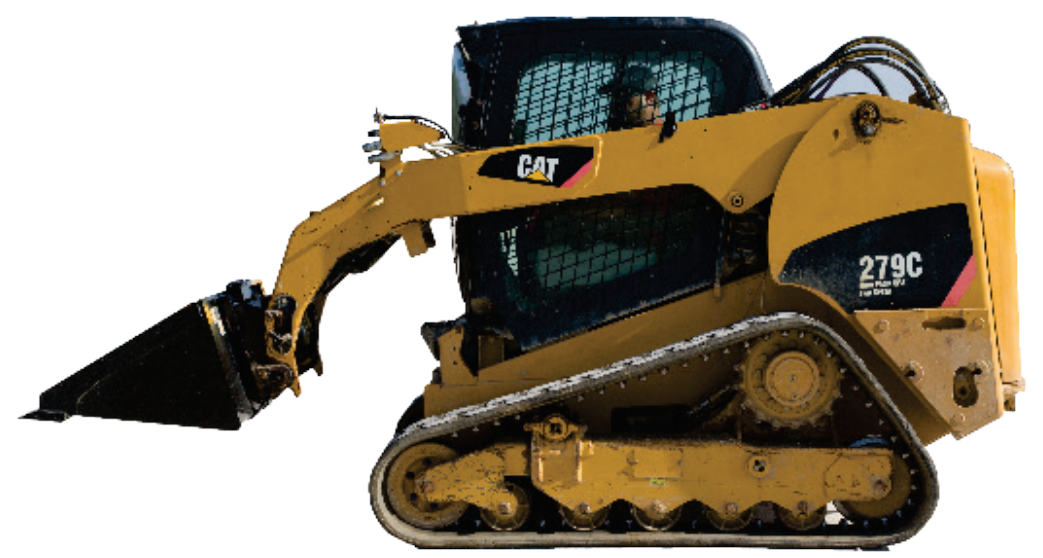

Table 1. Caterpliiar 279C CTL spcifications.

\begin{tabular}{|l|l|}
\hline Specification & Value \\
\hline Net power & $82 \mathrm{hp}$ \\
\hline Operating weight & $9,495 \mathrm{lbs}$ \\
\hline Rated operating capacity & $3,200 \mathrm{lbs}$ at 50\% tipping load \\
\hline Travel speed & $5.0 \mathrm{mph}$ \\
\hline Tipping load & $6,483 \mathrm{lbs}$ \\
\hline Breakout force, tilt cylinder & $7,308 \mathrm{lbs}$ \\
\hline Maximum loader hydraulic pressurea & $4,061 \mathrm{psi}$ \\
\hline Maximum loader hydraulic flow & \\
\hline
\end{tabular}

aFor high flow XPS models

For the RADR mission, the track loader is a multi-purpose machine that is employed for rapidly cutting around the upheaval using the wheel saw attachment, removing debris using the bucket attachment, or cleaning up with the broom attachment. For the testing described in this report, the SW45 attachment was utilized to sawcut around repairs, remove excavated material, and place subgrade and backfill materials. The $279 \mathrm{C}$ CTL with the wheel saw attachment is shown in Figure 2 and specifications can be found in Table 2. 
Figure 2. Caterpillar 279C CTL with SW45 wheel saw attachment.

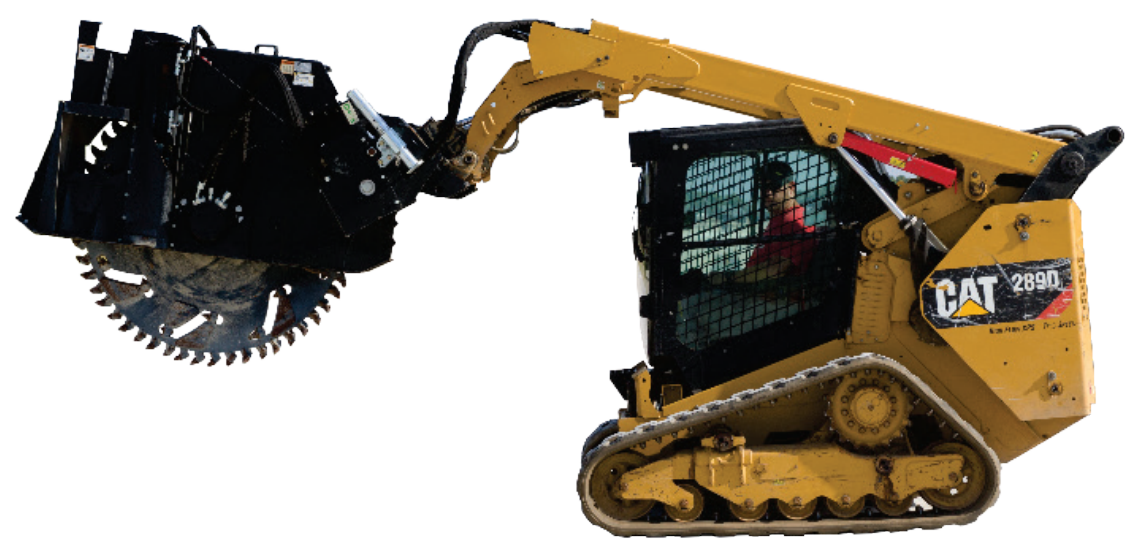

Table 2. SW45 wheel saw specifications.

\begin{tabular}{|l|l|}
\hline Specification & Value \\
\hline Overall width & 71 in. \\
\hline Overall height & 57 in. \\
\hline Length & 78 in. \\
\hline Weight & $2,295 \mathrm{lbs}$ \\
\hline Wheel width & $3.5 \mathrm{in}$. \\
\hline Required hydraulic flow range & $24-42$ gpm \\
\hline Optimal hydraulic pressure range & 2,611 to $4,351 \mathrm{psi}$ \\
\hline Wheel torque at maximum pressure & $4,944 \mathrm{lb} \bullet \mathrm{ft}$ \\
\hline Wheel speed at maximum flow & $115 \mathrm{rpm}$ \\
\hline Number of teeth & 64 per wheel \\
\hline Maximum depth of cut & 18 in. \\
\hline Sideshift travel & 26 in. \\
\hline
\end{tabular}

\subsubsection{Compact excavator}

A compact excavator, shown in Figure 3, was used to break out and remove the existing concrete, base, and subgrade material so the repairs could be completed for testing. The Bobcat E45 model was used and specifications are provided in Table 3. A compact excavator was used in lieu of a larger excavator since the smaller bucket and reach are easier to maneuver during excavation and backfilling of smaller repairs. 
Figure 3. Bobcat E45 compact excavator.

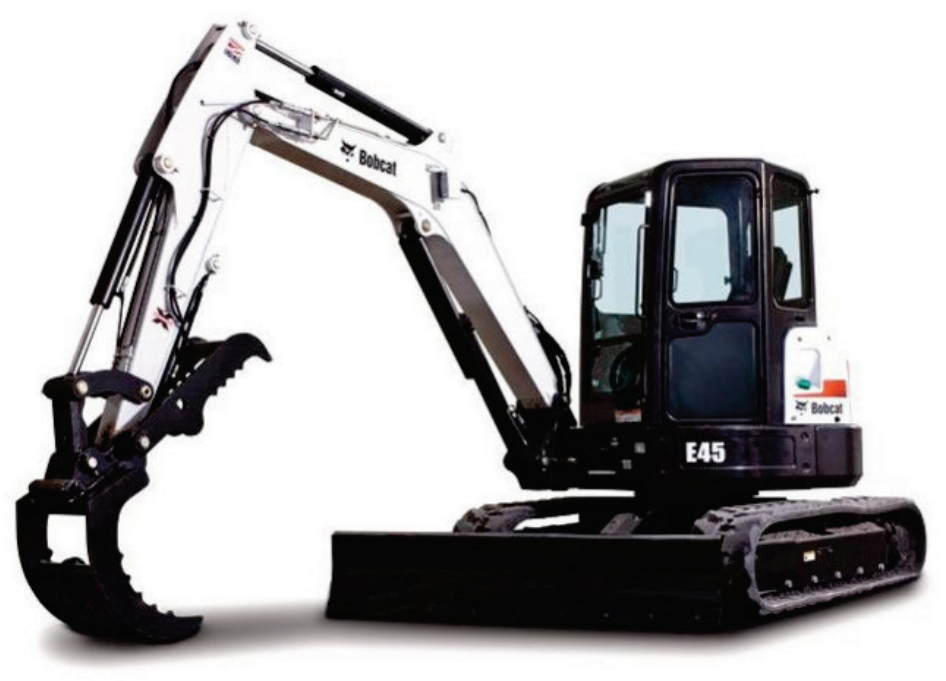

Table 3. Bobcat E45 compact excavator specifications.

\begin{tabular}{|l|l|}
\hline Specification & Value \\
\hline Overall width & $77.2 \mathrm{in}$. \\
\hline Overall height & $99.7 \mathrm{in}$. \\
\hline Length & $210.8 \mathrm{in}$. \\
\hline Operating weight & $10,077 \mathrm{lbs}$ \\
\hline Engine fuel & Diesel \\
\hline Horsepower & $42.7 \mathrm{hp}$ \\
\hline Maximum travel speed & $2.6 \mathrm{mph}$ \\
\hline Arm digging force & $5,332 \mathrm{lbf}$ \\
\hline Bucket digging force & $7,650 \mathrm{lbf}$ \\
\hline Rated lift capacity & $5,131 \mathrm{lbs}$ \\
\hline Hydraulic auxiliary pressure & $3,045 \mathrm{psi}$ \\
\hline Hydraulic auxiliary flow rate & $20 \mathrm{gal} / \mathrm{min}$ \\
\hline
\end{tabular}

\subsubsection{Rammer-style compactor}

A small rammer-style compactor was used to compact the natural subgrade and crushed stone backfill material during testing. The compactor used was a Multiquip Mikasa MTX-70 (Figure 4), which has a 2.8-hp motor capable of providing 3,350 lbf of impact force. Additional specifications are displayed in Table 4. A smaller compactor was employed since larger compaction equipment would be difficult to maneuver inside smaller craters. 
Figure 4 . Mutiquip Mikasa MTX-70 rammer-style compactor.

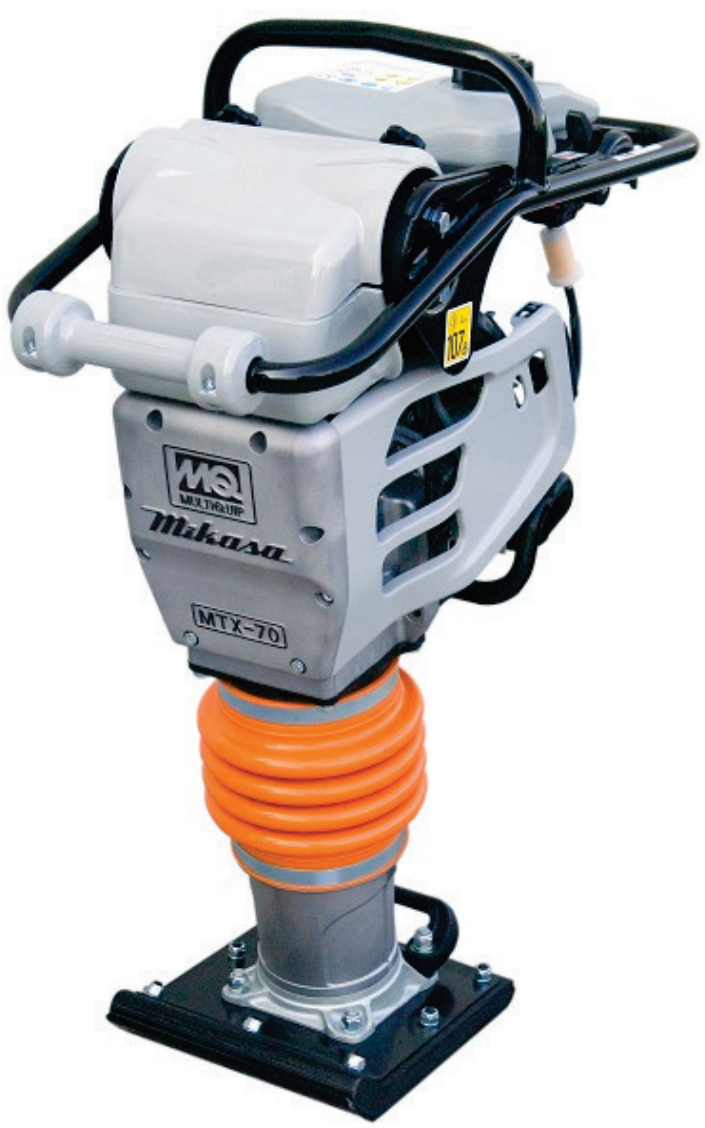

Table 4. Mutiquip Mikasa MTX-70 specifications.

\begin{tabular}{|l|l|}
\hline Specification & Value \\
\hline Operating weight & $165 \mathrm{lbs}$ \\
\hline Blows per min. & 690 \\
\hline Impact force & $3,350 \mathrm{lbf}$ \\
\hline Shoe jump height & $3.1 \mathrm{in}$. \\
\hline Shoe dimensions & $13.4 \mathrm{in}$. by $11.2 \mathrm{in}$. \\
\hline Engine make/model & Honda GX100 \\
\hline Engine power & $2.8 \mathrm{hp}$ \\
\hline
\end{tabular}




\subsubsection{Extendable-boom forklift}

An extendable-boom forklift was used to move the 3,00o lb super sacks of materials. The extendable boom used was a Caterpillar TL1055c telehandler (Figure 5), which is capable of lifting 10,00o lbs and exhibited a maximum forward reach of $40 \mathrm{ft}$ and a maximum reach height of $55 \mathrm{ft}$. The extendable boom is needed so the large super sacks of pre-blended materials can be loaded into the SVM or extended over an excavation for placement. Smaller forklifts with at least a $6,500 \mathrm{lbs}$ lifting capacity are capable of lifting and loading supersacks, but the TL1055c was used since it was available during testing.

Figure 5. Caterpillar 1055C extendable boom forklift.

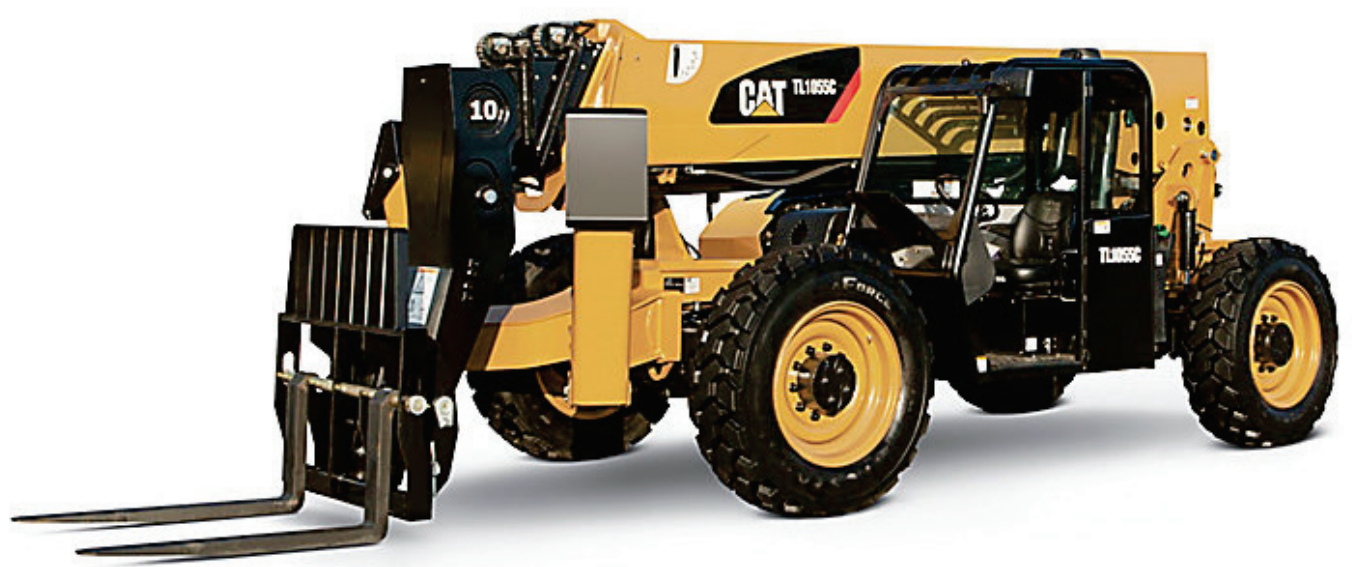

\subsubsection{Simplified volumetric mixer}

A specially designed tow-behind simplified volumetric concrete mixer (Figure 6) was previously designed by CemenTech, Inc. in consultation with the ERDC for use in the RADR modernization program. The SVM is pre-calibrated for rapid-setting cementitious repair materials to include flowable fill and concrete capping material. The mixer is towed with a vehicle capable of pulling at least 20 tons. The mixer consists of a single dry-material hopper with a capacity of approximately $7 \mathrm{yd} 3$, a conveyor belt feed system, a positive displacement water pump to meter mix water according to a fixed pump speed, two 200-gal water tanks on each side of the mixer, a washout tank with pressure washer, and a replaceable mixing auger mounted in a discharge boom at the rear of the machine. The machine is outfitted with two retractable catwalk platforms, a bin entry platform, a replacement auger, and two super sack piercing points. The only means of controlling the water-to-cement $(\mathrm{w} / \mathrm{c})$ ratio is by adjusting a 
strike-off gate, which can change the height of the dry material on the conveyor belt feeding the mix auger. Allowing more dry material to enter the mix auger results in a mix with a lower $\mathrm{w} / \mathrm{c}$ ratio. The wheel for adjusting the gate height has a scale from 1 to 12 , where 1 allows the least amount of material to enter the mix auger and 12 allows the most. However, typical strike-off gate settings used during production of RSFF or RSC range from 4 to 8.

Figure 6. Simplified volumtric mixer.

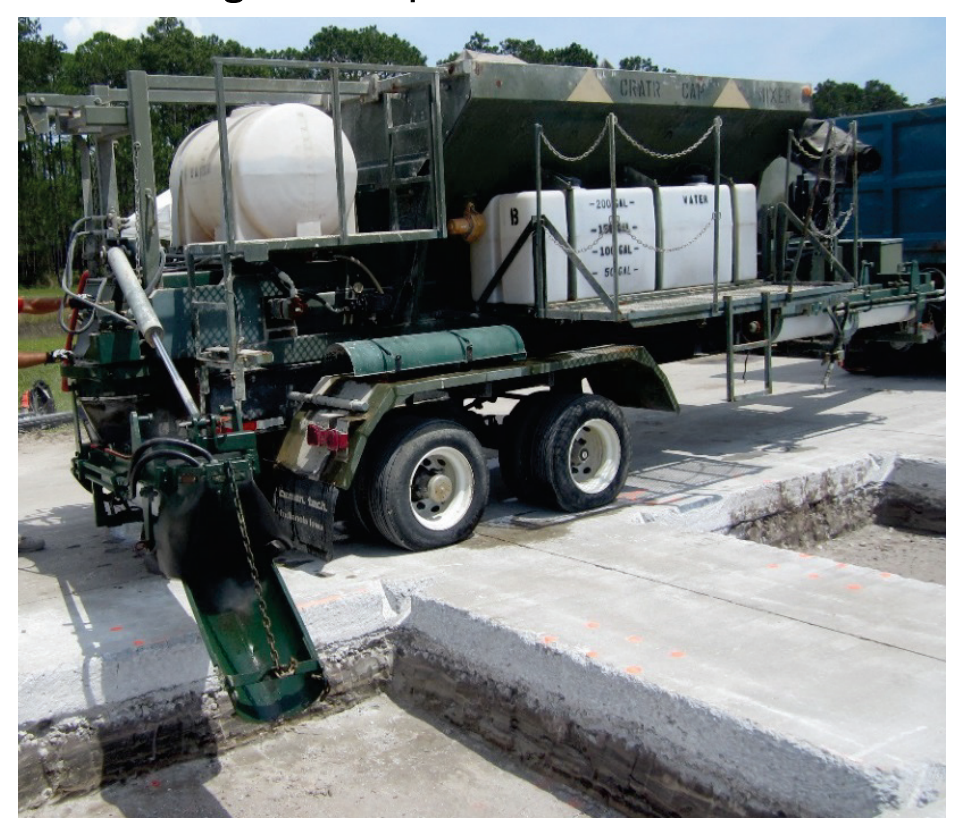

\subsection{Materials}

\subsubsection{Natural subgrade and crushed stone backfill material}

The natural subgrade shown in Figure 7 is classified as a brown, low plasticity clay (CL) according to the USCS. The subgrade was exposed after excavation and was re-compacted before backfill placement. Crushed limestone, purchased from a local vendor, was used as a backfill material for test craters capped with RSC (Figure 8). Crushed stone was selected, since it is one of the preferred backfill materials for RADR operations, the other being dry-placed RSFF that is discussed in Section 2.3.2. Crushed stone is more economical than RSFF and could be reused for several crater repairs after re-compaction. The maximum aggregate size of the material was 1 in. 
Figure 7. Compaction of brown CL clay subgrade.

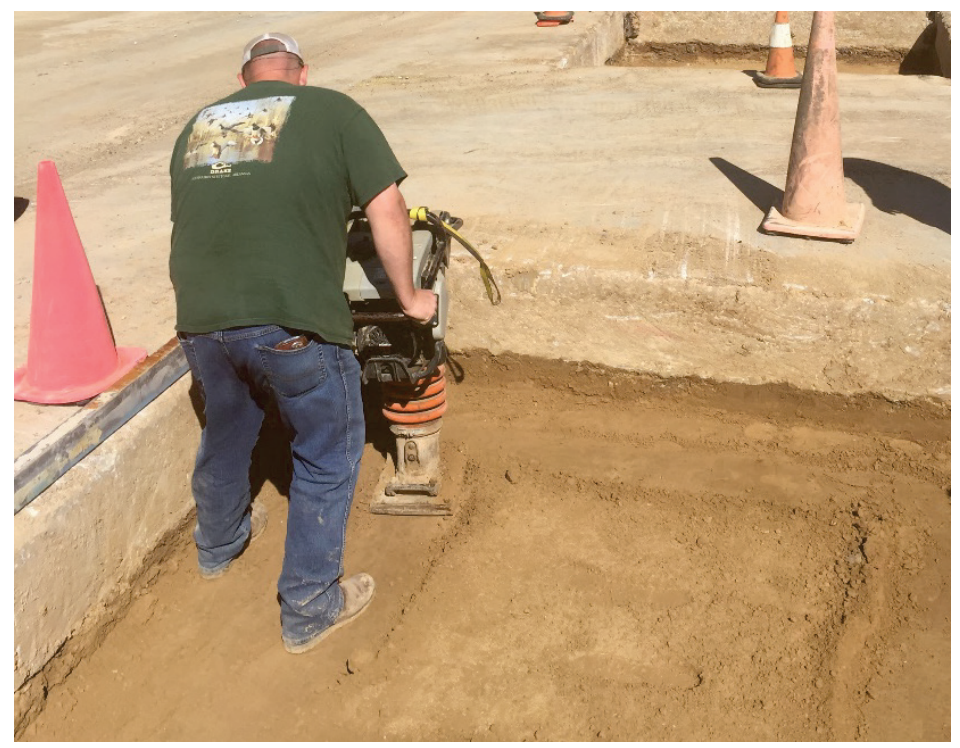

Figure 8. Compacted crushed stone backfill material.

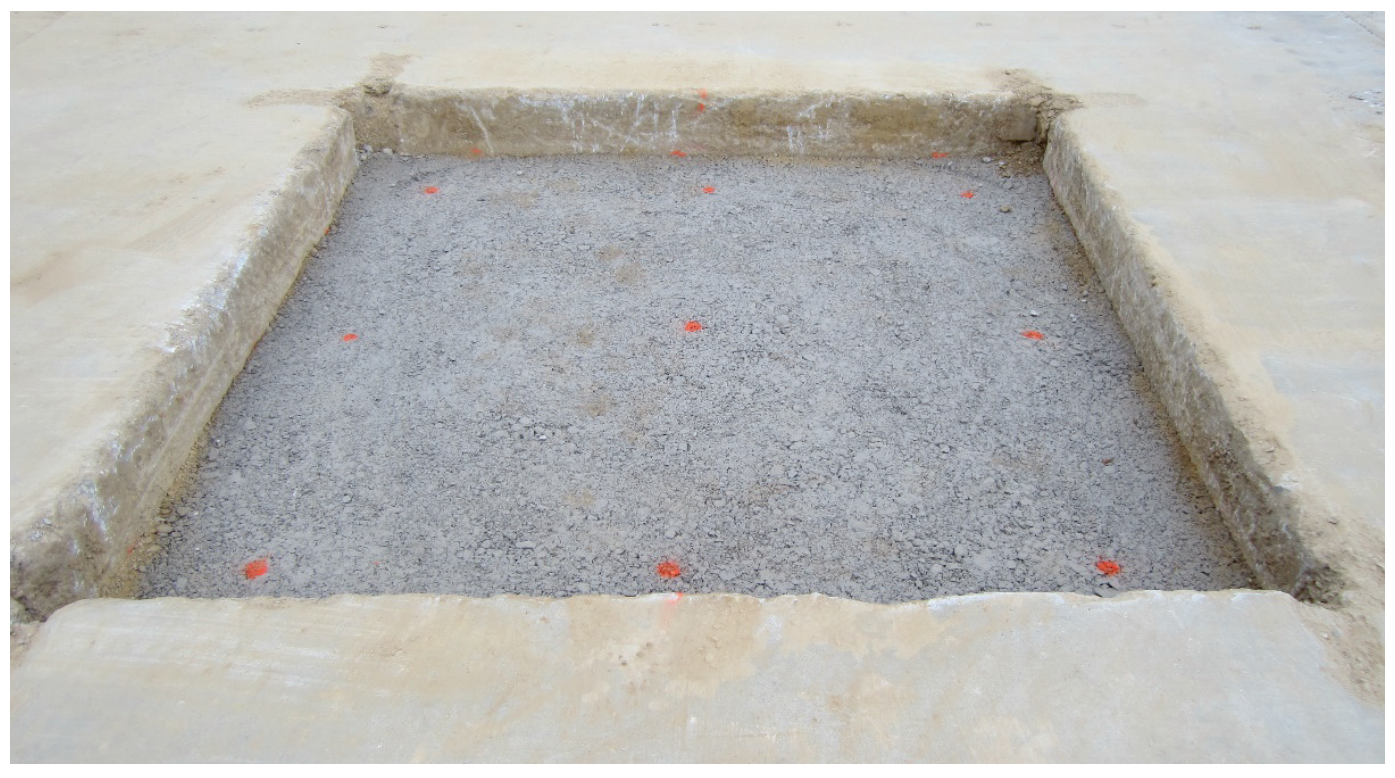

\subsubsection{Rapid-setting flowable fill}

In general, traditional flowable fill is a low-viscosity, grout-like, cementitious blend commonly composed of portland cement, fine aggregate, and water. Other materials such as fly ash, slag, foundry sand, bottom ash, and chemical admixtures can also employed in flowable fill blends. Flowable fills can be designed for traditional and rapid set times, depending on the type and amount of cementitious materials and chemical admixtures used. The material is self-leveling, self-compacting, and flows under gravity to fill the desired volume. 
Material properties established to accommodate rapid ADR include an unconfined compressive strength of $250 \mathrm{psi}$ after $30 \mathrm{~min}$ of cure, $750 \mathrm{psi}$ after $3 \mathrm{hr}$ of cure, being optimally flowable as indicated by 8 to 12 in. of flow consistency as per ASTM D6103 (ASTM 2017) and exhibiting minimal shrinkage and subsidence potential.

Flowable fill is traditionally placed using a standard transit truck or the SVM. This technique is referred to as the "wet method" and uniformly distributes moisture resulting in optimal flowability and achievement of ultimate compressive strength. An alternative method is referred to as the "dry method," which is an expedient placement technique where the preblended dry material is dispensed directly into the excavation, alleviating the requirement for a dedicated mixer. Following the placement of thin 4 to 6 in. lifts of dry material, water is metered onto the surface and allowed to percolate through the dry material. Placement using the dry method sacrifices some of the beneficial properties of flowable fill including its self-leveling behavior, uniformity, and a considerable reduction in compressive strength. However, the material can be placed expediently without the use of additional equipment and provides sufficient bearing capacity for heavy aircraft pavement applications. The dry method is typically used when flowable fill is used as a base material beneath a rapidsetting concrete cap as described in Edwards et al. (2013), Bell et al. (2013), and Carruth et al. (2015).

Utility Fill 1-Step $750^{\circledR}$ is a RSFF material that has been selected for rapid ADR operations as discussed previously in this report. The material differs from traditional flowable fill material in that it contains calcium sulfoaluminate (CSA) cement, which provides faster set times. An additional vendor for rapid-setting flowable fill is desired as discussed in Chapter 1 of this report. CTS Rapid Set flowable fill was previously tested using the "wet" method and was selected for testing using the "dry" method for this study.

\subsubsection{Rapid-setting concrete}

RSC has been established as a preferred surface material for crater repairs during RADR operations. The material is typically packaged and shipped in 3,00o lb supersacks and mixed using the SVM. CTS Rapid Set Concrete Mix ${ }^{\circledR}$ has been used extensively during RADR testing as discussed in Chapter 1. Two alternate propriety products were selected for full-scale testing and are described in this section. 


\subsubsection{Fastrac 246}

Fastrac 246, manufactured by Western Materials, is a proprietary, preblended mixture of cement, aggregates, and performance enhancing chemical admixtures available in a range of quantities from $60 \mathrm{lb}$ bags up to $3,000 \mathrm{lb}$ supersacks. Fastrac 246 requires only the addition of water to be mixed and placed. The material previously passed tri-service spall repair certification testing protocol as shown in Table A1 of Appendix A. Results from the certification testing are further discussed in Section 4.1.3.

\subsubsection{Ulti-Pave3 ${ }^{\circledR}$}

Ulti-Pave $3^{\circledR}$, manufactured by Buzzi Unicem USA, is a proprietary blend of aggregates, CSA cement, and fibers that is mixed with water to create a rapid-setting pavement repair material. The material is available in $50 \mathrm{lb}$ bags as well as larger bulk quantities. Supersacks weighing 2,00o lbs were used for this study since that is the typical bulk packaging quantity for the manufacturer; however, 3,00o lb supersacks are desired for any future procurements in order to maintain consistency with current USAF storage and reduce the number of supersacks required to be loaded during mixing. The manufacturer indicates that approximately 20 to 30 min of working is available after the material is mixed before it reaches initial set and begins to behave plastically. Ulti-Pave $3{ }^{\circledR}$ previously passed the tri-service spall repair certification testing protocol as shown in Table A2 of Appendix A. Results from the certification testing are further discussed in Section 4.1.3. 


\section{Test Procedures and Data Collection}

\subsection{Repair process}

The procedure used to conduct the crater repairs described in this report was intended to match the standard crater repair process within the RADR base recovery scenario. One main exception was the use of crushed stone backfill material in lieu of rapid-setting flowable fill placed using the dry method. Crushed stone was used to provide cost savings and is an acceptable alternate backfill material as described in the USAF RADR interim tactics, techniques, and procedures (TTPs) (USAF 2019). The following sections describe each step in the crater repair process. The pertinent details of each repair and the overall test matrix are discussed in the next chapter.

\subsubsection{Marking, saw cutting, breaking, and excavation processes}

The standard RADR base recovery processes of marking, saw cutting, breaking, and excavation were carried out as described in previous RADR reports (Edwards et al. 2012, Bell et al. 2013, and Carruth et al. 2015). These processes were not timed since the work was not performed by airmen nor were the appropriate amount of personnel used for the various crater repair teams (marking, saw-cutting, breaking, excavation, backfill, and capping teams). For marking, the target size of the finished crater repair $(8.5 \mathrm{ft} \times 8.5 \mathrm{ft}$ or $15 \mathrm{ft} \times 15 \mathrm{ft}$ ) was measured and marked with a string line and marking paint. Since no upheaval was present, stanchions were not used in the marking process. Saw cutting was conducted using the CTL with a wheel saw attachment. For breaking and excavating, the compact excavator with the appropriate attachment (hammer or bucket) was used. Great care was taken during excavation since the thicknesses of each layer of the crater repair structure was critical to the objective of this study. A tolerance of +/- 0.5 in. for each layer was imposed.

\subsubsection{Backfill process}

\subsubsection{Crushed stone backfill}

Once excavation of the crater repairs was complete, the natural subgrade was compacted with the rammer-style compactor. Two coverages were performed during compaction and the target backfill strength was a California Bearing Ratio (CBR) of greater than 4 percent. Crushed stone 
backfill was placed in two 6 in. lifts for a target total layer thickness of 12 in. The CTL and hand tools were used to place and level the material before two coverages of compaction with the rammer-style compactor were applied. The target strength for the backfill was a CBR of 30 to $40 \%$. Crushed stone backfill can typically exhibit CBR values of 60 to $80 \%$ with larger compaction equipment. However, due to the confined space of the repair, only smaller compaction equipment could be used so the target strength values were reduced.

\subsubsection{Rapid-setting flowable fill backfill}

For rapid-setting flowable fill backfill dry method placement, a target thickness of 14 in. was used to match the standard thickness in the interim RADR TTPs. The typical dry placement method was used, which involves lifting a supersack over the repair and cutting the bottom to allow dry material to fall into the repair (Figure 9). The dry material is then spread evenly with hand tools (Figure 10) and 40 gal of water is metered evenly over the surface and allowed to percolate through the material (Figure 11). The process is repeated until the target thickness has been reached. If partial supersacks are required, the amount of water used is adjusted accordingly. Only 30 gal are used for the final supersack to limit the amount of standing water on the backfill surface so the subsequent RSC material will not be diluted. Figure 12 shows a repair with rapid-setting flowable fill placement complete after $30 \mathrm{~min}$ of cure time. 
Figure 9. Placement of rapid-setting flowable fill material.

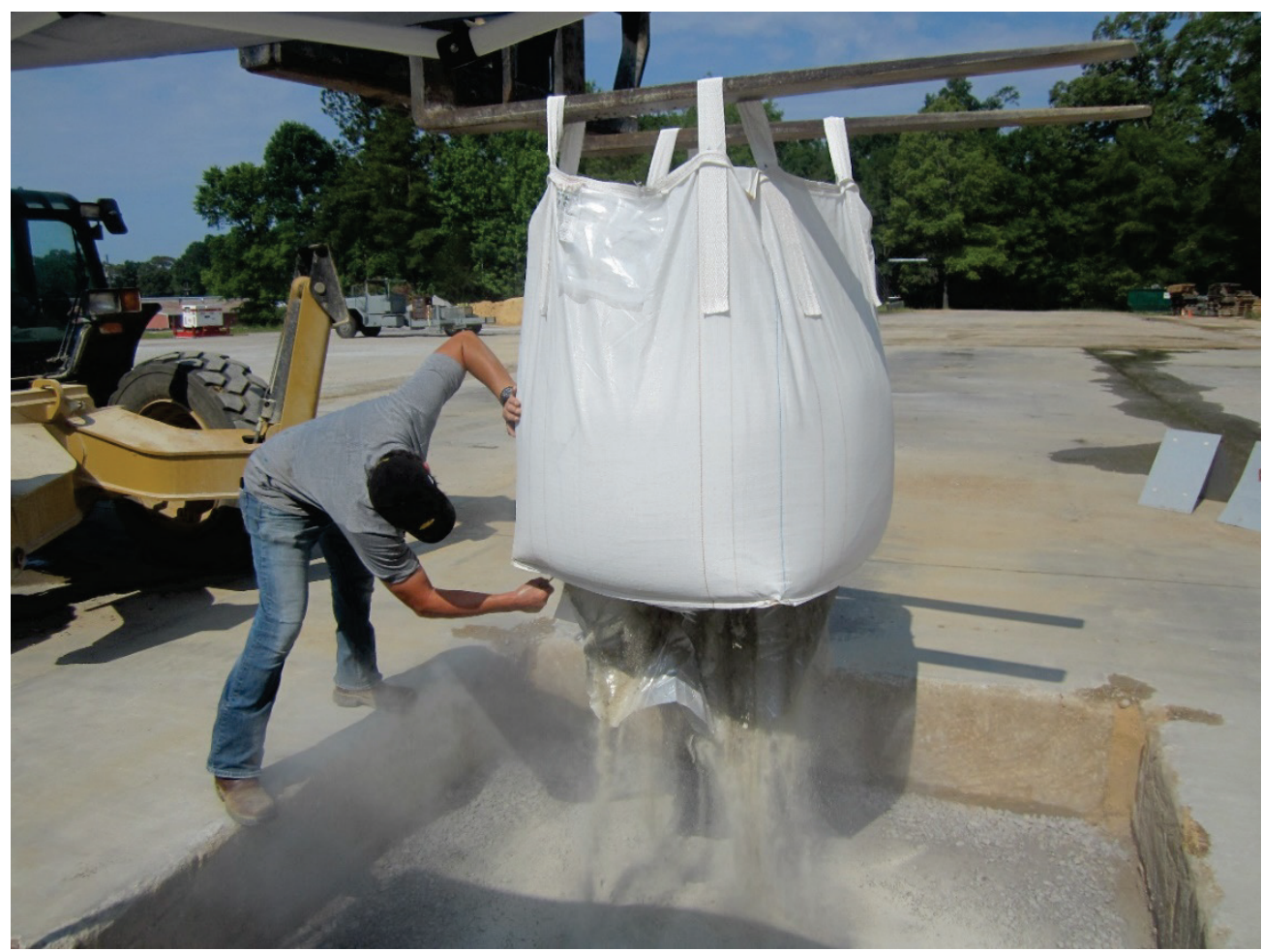

Figure 10. Leveling of dry rapid-setting flowable fill material.

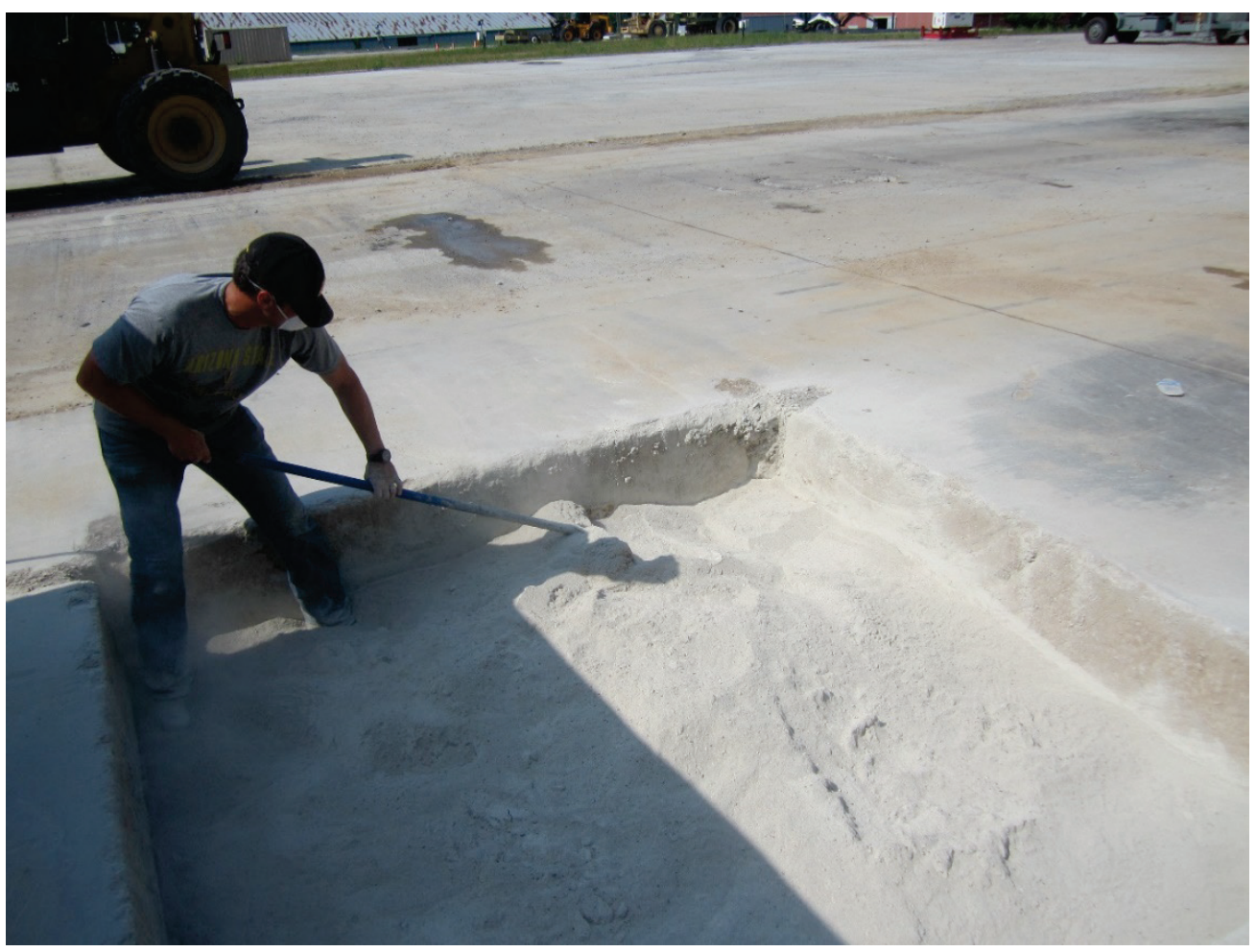


Figure 11. Metering of water over dry rapid-setting flowable fill.

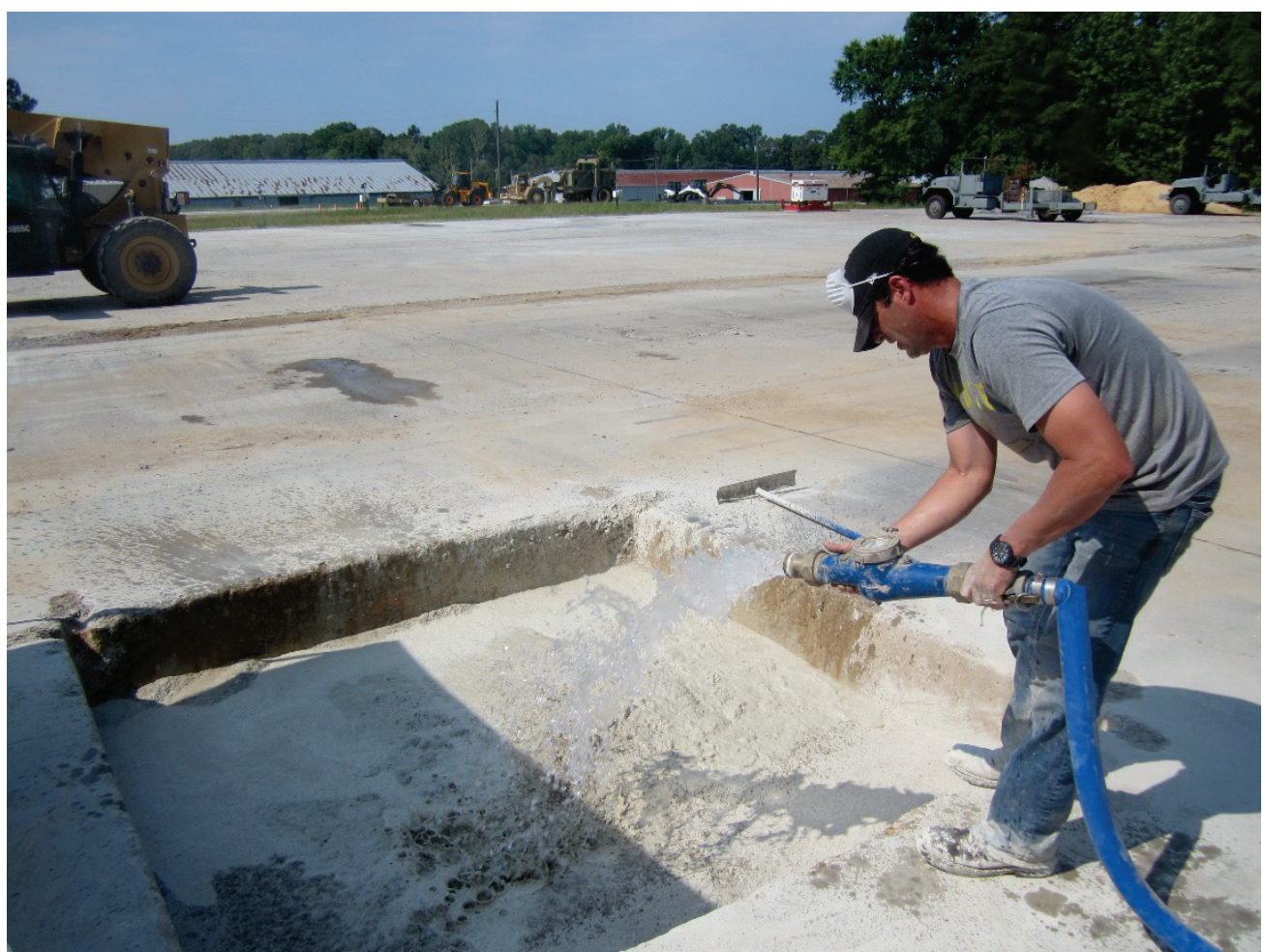

Figure 12. Completed rapid-setting flowable fill placement after $30 \mathrm{~min}$ of cure time.

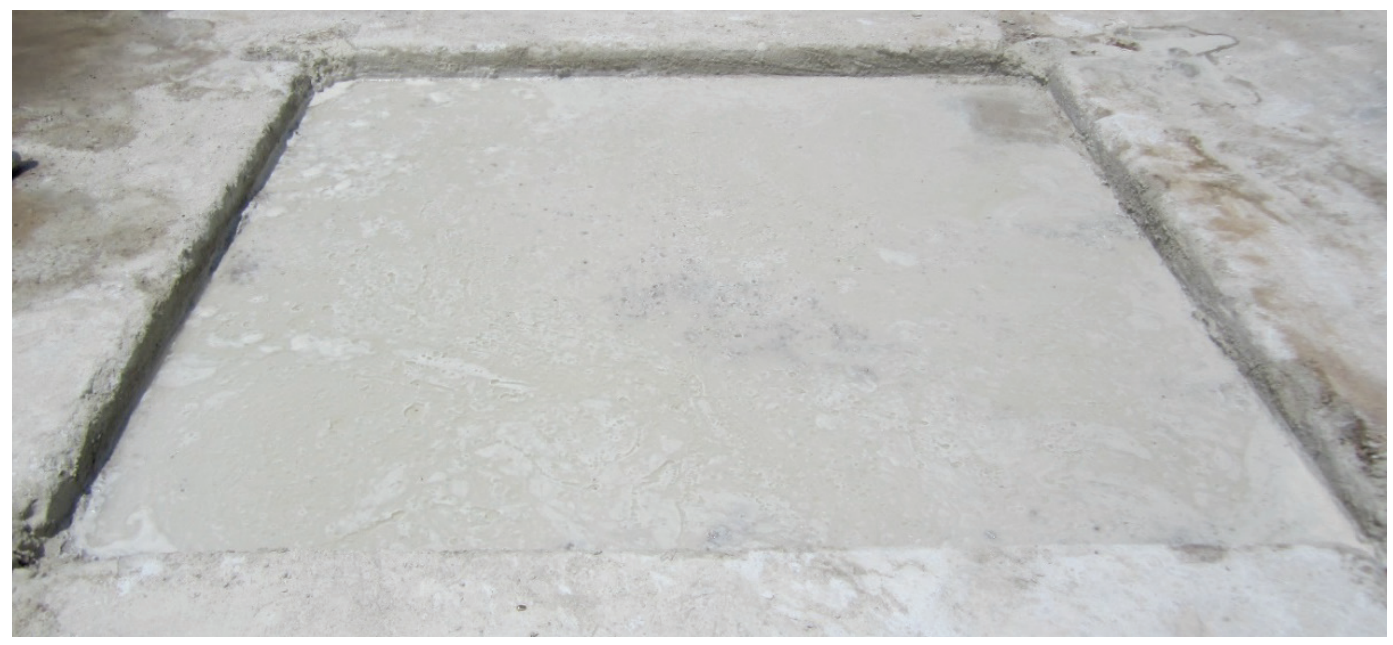

\subsubsection{Capping process}

To begin the capping process, the SVM was prepared for standard operation. Supersacks were loaded into the dry material bin, the mix water and washout tanks were filled, and the mix auger and concrete tools were sprayed with concrete release agent. The water pump gear controls were set to "Rapid Set," which is the lower gear. The SVM was previously factory calibrated to provide the optimum amount of water for CTS Rapid Set 
Concrete $\mathrm{Mix}^{\circledR}$ since it is currently the preferred proprietary rapid-setting concrete product (approximately 50 gal per supersack at a gate setting of 6). Since this was the first time conducting a relatively large placement of the two new rapid-setting concrete products, placement began with a gate setting of 6 and was adjusted until a reasonably workable consistency was achieved. Figure 13 shows placement of Fastrac 246. Sufficient material was placed and distributed evenly using hand tools. The material was struck off using a magnesium bar screed (Figure 14) and any excess material was removed from the edges using trowels as necessary.

During placement, the fibers present in the Ulti-Pave ${ }^{\circledR}$ dry mix appeared to collect on the grate in the SVM material bins causing movement of dry material from the material bins to the conveyor belt to be partially interrupted. This issue was solved by engaging the bins vibrators manually until the dry material flow was no longer interrupted. While the fibers may have contributed to the materials durability, evaluation of an Ulti-Pave ${ }^{\circledR}$ mixture without fibers could be warranted.

Figure 13. Placement of rapid-setting concrete capping material.

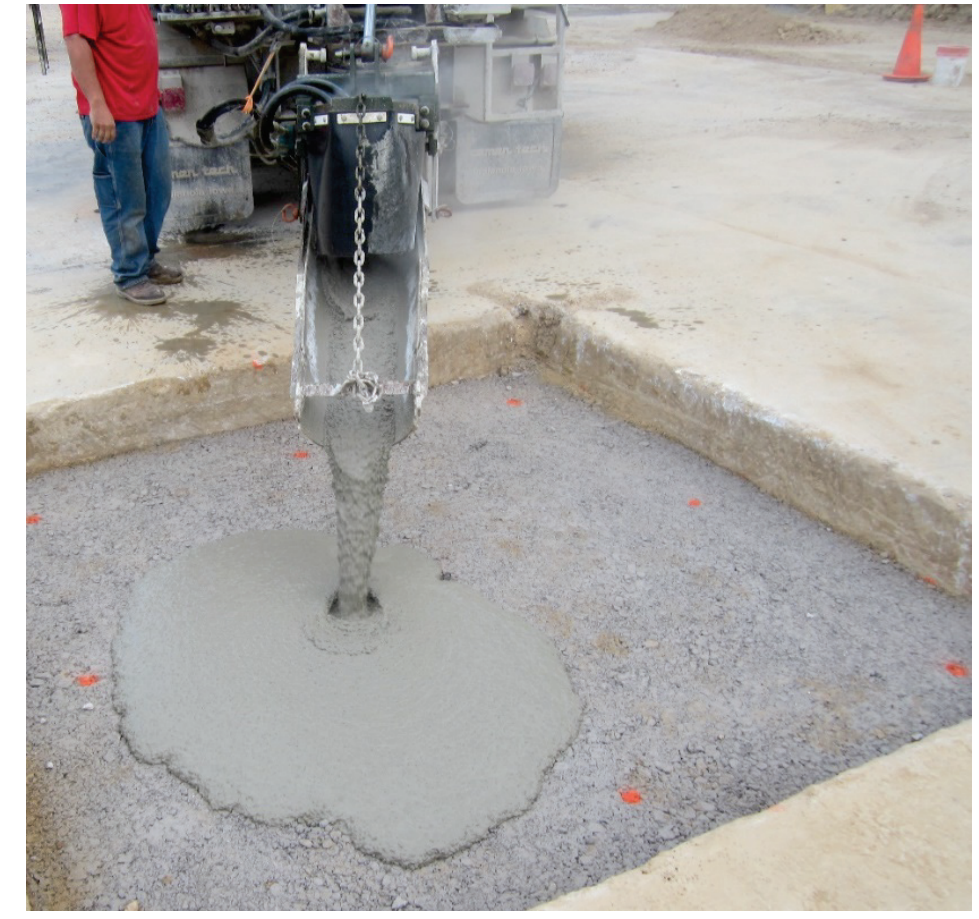


Figure 14. Screeding of rapid-setting concrete capping material.

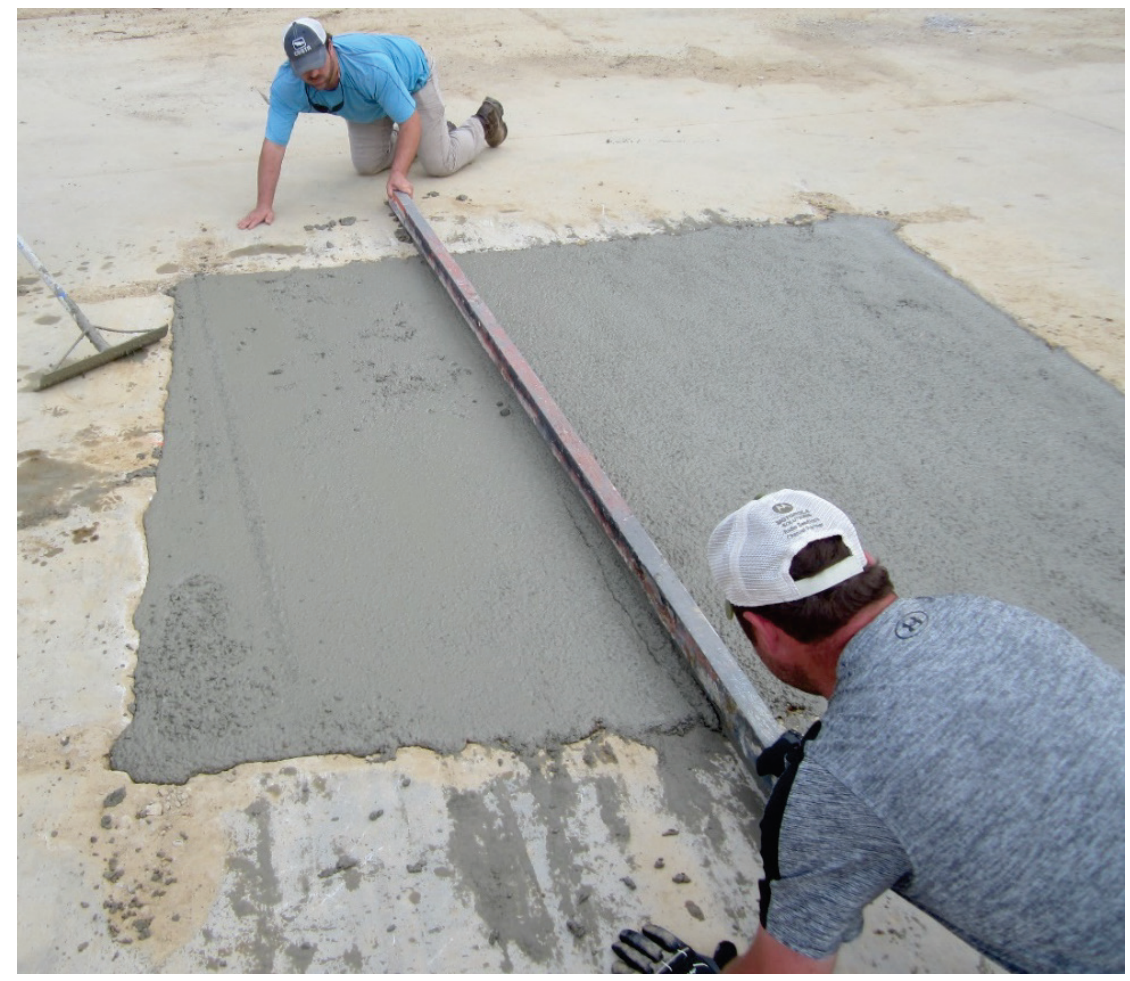

\subsection{Data collection}

Several types of data were collected to achieve the overall objectives for this study. Data were collected to 1) confirm the thickness of each layer of the pavement structure, 2) estimate the strength of the subgrade, backfill, and surface cap materials, and 3) monitor the performance of each repair under traffic. This section describes the test methods and types of data collected.

\subsubsection{Rod and level survey}

For the RSC repairs, the top of the subgrade, backfill, and repair surface were surveyed with a rod and level to measure the thickness of each layer of the pavement structure. Subsequent surveys of the repair surface were conducted periodically during trafficking to monitor any deformation of the repairs. The layout for small repairs $(8.5 \mathrm{ft} \times 8.5 \mathrm{ft})$ and larger repairs $(15 \mathrm{ft} \times 15 \mathrm{ft})$ are shown in Figure 15 and Figure 16, respectively. 
Figure 15. Surveying layout for $8.5 \mathrm{ft}$ x $8.5 \mathrm{ft}$ repairs.

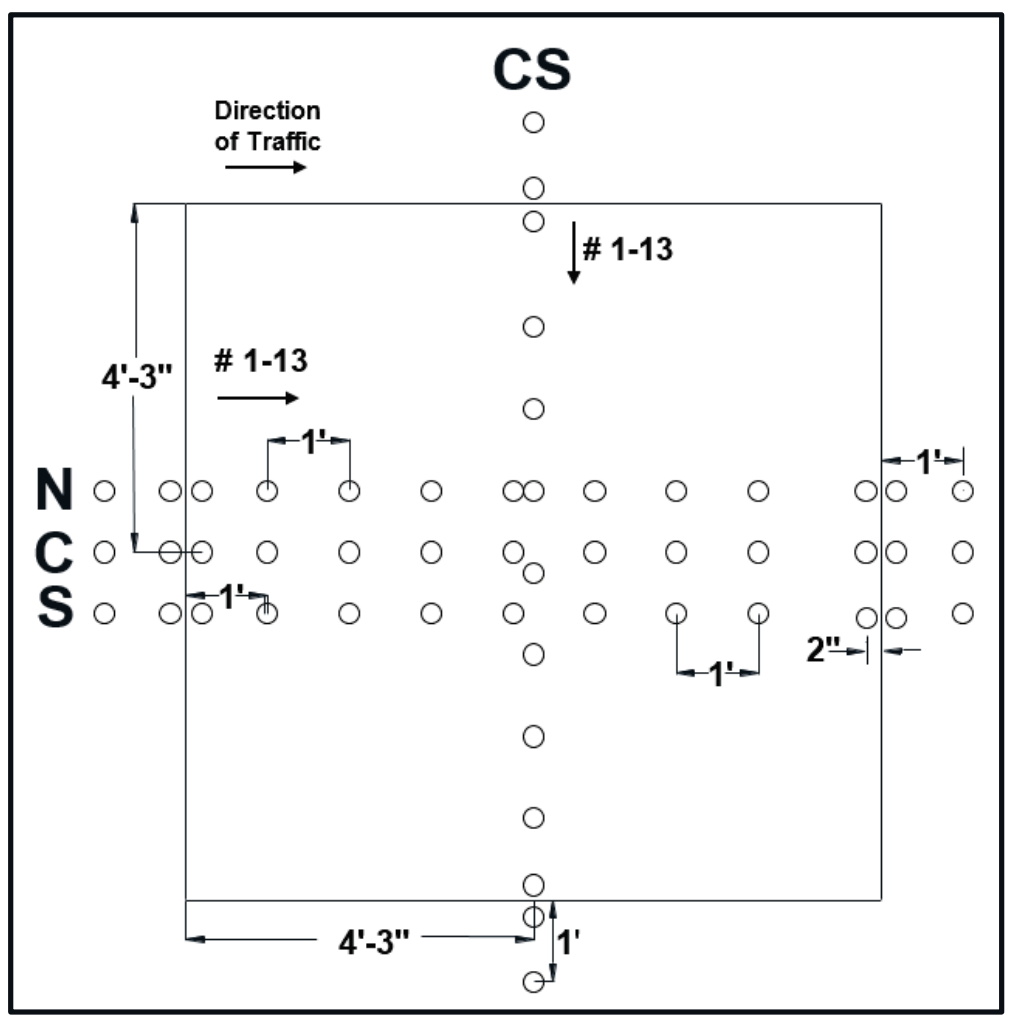

Figure 16. Surveying layout for $15 \mathrm{ft}$ x $15 \mathrm{ft}$ repairs.

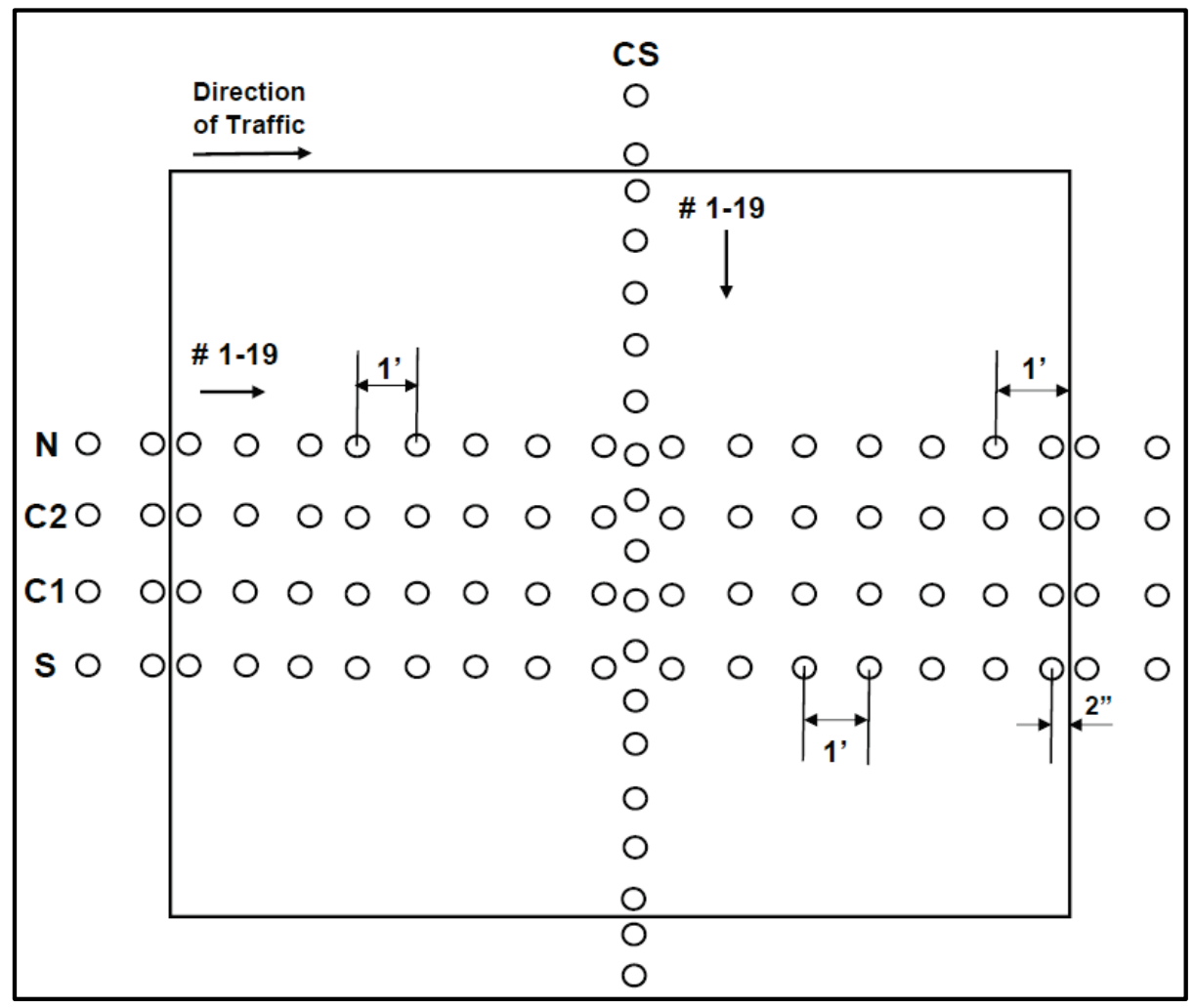




\subsubsection{Material strength property testing}

The strength of the subgrade and crushed stone backfill materials was estimated by measuring penetration resistance using a dynamic cone penetrometer (DCP) before capping the repairs. The DCP was also used to estimate the strength of dry-placed rapid-setting flowable fill at cure times of $30 \mathrm{~min}, 1 \mathrm{hr}, 2 \mathrm{hr}$, and $24 \mathrm{hr}$. Three replicates were conducted for each repair. DCP testing followed ASTM D6951 (ASTM 2009). A $17.6 \mathrm{lb}$ hammer was used for all testing and DCP penetration versus blow count data were converted to CBR values using equation 1 of ASTM D6951 throughout this effort. During placement of capping materials, 4 in. $x 8$ in. cylindrical samples were obtained to ensure the material placed reasonably matched laboratory results. Samples were tested in triplicate for compressive strength after $2 \mathrm{hr}, 1$ day, and 7 days of curing time per ASTM C39 (ASTM 2018). Samples tested at $2 \mathrm{hr}$ were cured on site, while the 1 day and 7 day specimens were cured at room temperature $\left(73^{\circ} \mathrm{F}\right)$ in $100 \%$ humidity until testing. Specimens were demolded at the time of compressive strength testing except for the 7 day samples, which were demolded after 1 day of curing time.

\subsubsection{Repair distress photographs and documentation}

Photographs were taken of each rapid-setting concrete repair before traffic was applied and at regular intervals during trafficking to document any distresses. Spalls and any other types of cracking that occurred during traffic were measured and documented also.

\subsection{Trafficking}

Trafficking of each repair was conducted using a simulated F-15E aircraft load cart. The single-wheel F-15E load cart was loaded to 35,235 lbs and a 325-psi tire pressure (Figure 17). The F-15 traffic pattern was an approximate normal distribution as shown in (Figure 18), resulting in a pass-to-coverage ratio of 4 . 
Figure 17. F-15 load cart.

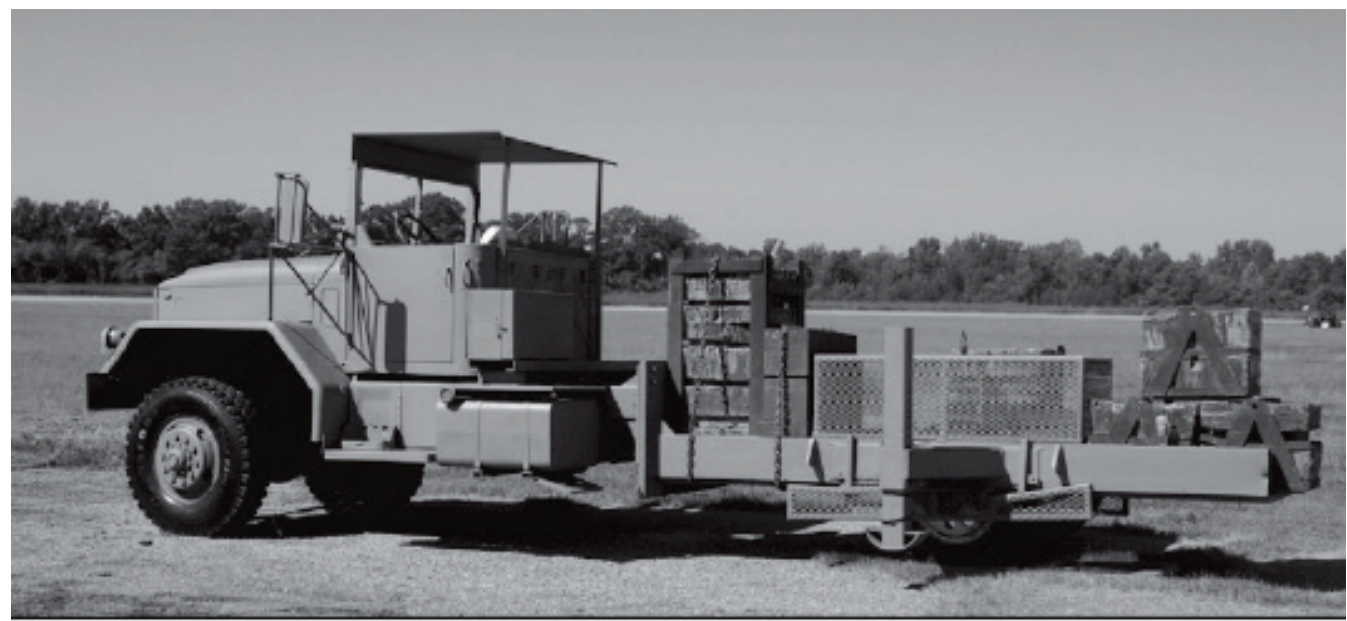

Figure 18. F-15 load cart trafficking pattern.

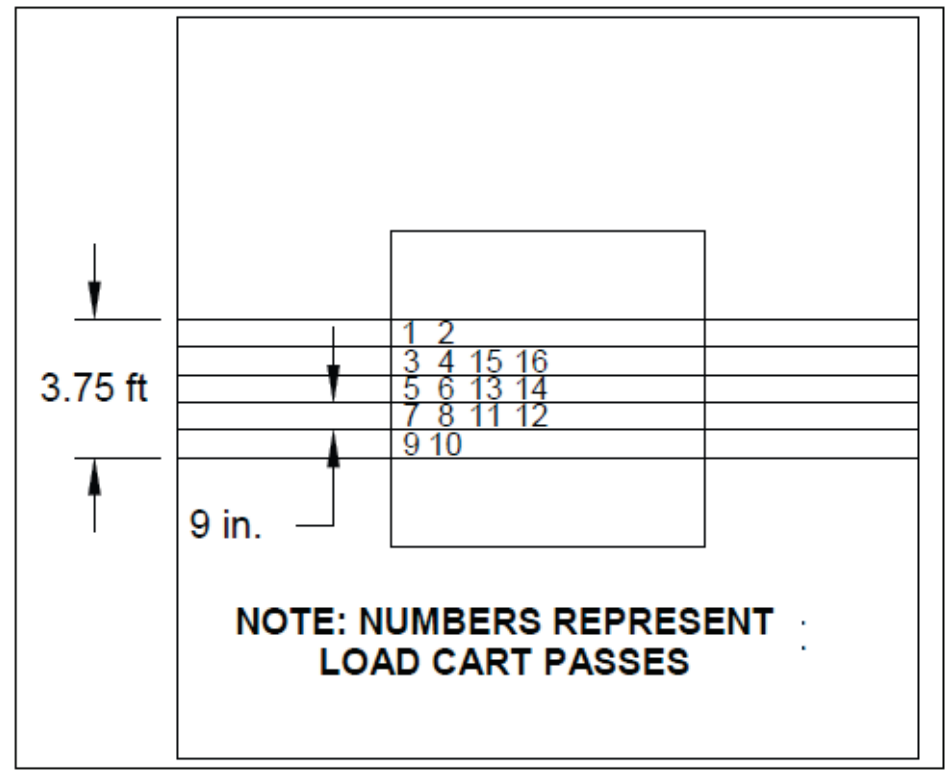

\subsection{Failure definition}

Failure of a crater repair was defined as observing a measurement in the interior of the repair greater than 0.75 in. above or below the surrounding pavement, presence of a severe tire hazard, or failing the high-severity joint spall criterion described in Priddy et al. (2016). The criteria defines failure of a joint as exhibiting a high-severity joint spall with a length of at least $2 \mathrm{ft}$, a width of at least 6 in., and a depth of at least 2 in. over at least 50 percent of the spall length. The criteria was used since a structural failure, e.g. shattered slab or faulting, is rarely observed in repairs following the RADR process, but spalling along the edges of the repair perpendicular to traffic occurs frequently. 


\section{Results and Discussion}

\subsection{Rapid-setting concrete results and discussion}

Table 5 shows the size of each repair and which rapid-setting concrete product was used for capping. DCP testing was conducted for the subgrade and backfill and cylindrical samples were obtained during placement to determine the compressive strength of each product tested. Photographs and survey data were obtained periodically during trafficking to determine if repairs had met the failure criteria. The following sections provide these data along with a discussion of the results.

Table 5. Repair sizes and rapid-setting products used.

\begin{tabular}{|c|c|c|c|}
\hline Repair & $\begin{array}{c}\text { Repair Size }(\mathrm{ft} \\
\text { by ft) }\end{array}$ & Product & $\begin{array}{c}\text { Ambient } \\
\text { Temperature }\left({ }^{\circ} \mathrm{F}\right)\end{array}$ \\
\hline $\mathbf{1}$ & 8.5 by 8.5 & Fastrac 246 & 70 \\
\hline $\mathbf{2}$ & 8.5 by 8.5 & Fastrac 246 & 70 \\
\hline $\mathbf{3}$ & 15 by 15 & Fastrac 246 & 50 \\
\hline $\mathbf{4}$ & 8.5 by 8.5 & Ulti-Pave3 $^{\circledR}$ & 56 \\
\hline $\mathbf{5}$ & 8.5 by 8.5 & Ulti-Pave3 $^{\circledR}$ & 56 \\
\hline $\mathbf{6}$ & 15 by 15 & Ulti-Pave3 $^{\circledR}$ & 73 \\
\hline
\end{tabular}

\subsubsection{Subgrade and backfill California bearing ratio (CBR) results}

Raw data for DCP tests conducted on the backfill and subgrade of RSC repairs can be found in Figures B1 through B18 in Appendix B. A summary of CBR values estimated from DCP testing are displayed in Table 6. All subgrade CBRs were greater than the target of 4 . The estimated CBRs for the backfill layer beneath Repairs 1, 2, and 3 were just below the target value of 30 to $40 \%$. The use of small compaction equipment likely caused the failure to reach target CBRs. Placement and trafficking of Repairs 1, 2, and 3 continued since the values were very close to the target and it was not believed that further compaction would result in increased CBR values. Repairs 4 and 5 backfill CBRs met the target, while the CBR for repair 6 was much lower. Repair 6 behaved similarly to Repairs 4 and 5 during trafficking, so the lower backfill CBR was not considered a major issue. 
Table 6. Estimated subgrade and backfill CBRs.

\begin{tabular}{|c|c|c|}
\hline Repair & Subgrade CBR & Backfill CBR \\
\hline 1 & 16 & 25 \\
\hline 2 & 7 & 24 \\
\hline 3 & 19 & 24 \\
\hline 4 & 7 & 35 \\
\hline 5 & 10 & 36 \\
\hline 6 & 14 & 19 \\
\hline
\end{tabular}

\subsubsection{Backfill and cap thickness results}

Table 7 shows backfill and cap thicknesses averaged from survey results. Note that the subgrade was not surveyed for Repairs 4, 5, and 6, since these repairs were created by removing the RSC material from Repairs 1 , 2, and 3 and re-compacting the backfill. Without the subgrade measurements, the backfill thicknesses could not be estimated. As shown, all thicknesses were within $0.5 \mathrm{in}$. or less of the target thicknesses for the backfill (12 in.) and cap (10 in.).

Table 7. Average repair backfill and cap thicknesses.

\begin{tabular}{|c|c|c|}
\hline Repair & $\begin{array}{c}\text { Average Backfill } \\
\text { Thickness (in.) }\end{array}$ & $\begin{array}{c}\text { Average Cap } \\
\text { Thickness (in.) }\end{array}$ \\
\hline $1^{\mathrm{a}}$ & 11.85 & 10.16 \\
\hline $\mathbf{2}^{\mathrm{a}}$ & 12.28 & 9.64 \\
\hline $\mathbf{3}^{\mathrm{c}}$ & 12.50 & 9.50 \\
\hline $\mathbf{4}^{\mathrm{b}}$ & $\mathrm{d}_{--}$ & 10.13 \\
\hline $\mathbf{5}^{\mathrm{b}}$ & $\mathrm{d}_{--}$ & 9.56 \\
\hline $\mathbf{6}^{\mathrm{c}}$ & $\mathrm{d}_{-}-$ & 9.74 \\
\hline
\end{tabular}

aThicknesses calculated from 9 evenly spaced survey points within repair.

bThicknesses calculated from survey points indicated in Figure 16.

cThicknesses calculated from survey points indicated in Figure 17.

dMeasurements unavailable due to reuse of backfill.

\subsubsection{Tri-service spall repair certification protocol results}

Fastrac 246 and Ulti-Pave $3^{\circledR}$ were previously evaluated in the laboratory using the tri-service spall repair certification protocol. Results from protocol testing are shown in Tables A1 and A2 in Appendix A for Fastrac 246 and Ulti-Pave $3{ }^{\circledR}$, respectively. As shown, Fastrac 246 passed all requirements with the exception of $2 \mathrm{hr}$ compressive strength and final set 
time. However, Ramsey et al. (2019) suggests reducing the $2 \mathrm{hr}$ compressive strength requirement to $2,500 \mathrm{psi}$ and the final set time range to $15-90$ min. The results in Table A2 indicate that Fastrac 246 would pass all tests using the new criteria. Ulti-Pave $3{ }^{\circledR}$ (Table A2) met all requirements except for the final set time requirement of 15 to $35 \mathrm{~min}$ and the 14-day shrinkage potential requirement of less than 40 microstrains. However, Ramsey et al. (2019) recommends that the set time requirement be changed to 15 to 90 min and the shrinkage potential requirement be removed and the microstrains only be recorded at 14 and 28 days, while limiting the requirement to no observed cracking at 28 days. Under this new guidance, Ulti-Pave $3{ }^{\circledR}$ would pass all tests in the protocol.

\subsubsection{Compressive strength sample results}

Compressive strength samples were obtained during one placement per product to ensure that field strengths produced from the selected SVM settings were similar to those obtained during tri-service spall repair certification program testing. Results averaged from three samples per cure time are displayed in Table 8. As shown, all compressive strength results met the newly proposed minimum requirements. Most of the compressive strengths were higher for the laboratory produced specimens than those sampled during field testing. The difference is likely due to the placement of the material at a slightly more fluid consistency in the field to increase workability.

\footnotetext{
* Ramsey, M. A., J. S. Tingle, and C. A. Rutland. DRAFT. Evaluation of Rapid-Setting Cementitious Materials and Testing Protocol for Airfield Spall Repair. ERDC/GSL TR-19-DRAFT. Vicksburg, MS: U.S. Army Engineer Research and Development Center.
} 
Table 8. RSC compressive strength results.

\begin{tabular}{|c|c|c|c|c|c|}
\hline Product & $\begin{array}{l}\text { Cure } \\
\text { time }\end{array}$ & $\begin{array}{l}\text { aCompressive } \\
\text { strength (psi) }\end{array}$ & $\begin{array}{l}\text { aAverage } \\
\text { (psi) }\end{array}$ & $\begin{array}{l}\text { bLaboratory } \\
\text { Results (psi) }\end{array}$ & $\begin{array}{l}\text { cRecommened } \\
\text { minimum } \\
\text { criteria (psi) }\end{array}$ \\
\hline \multirow{9}{*}{$\begin{array}{c}\text { Fastrac } \\
246\end{array}$} & \multirow{3}{*}{$2 \mathrm{hr}$} & 2,960 & \multirow{3}{*}{3,007} & \multirow{3}{*}{2,620} & \multirow{3}{*}{$\geq 2,500 \mathrm{psi}$} \\
\hline & & 2,930 & & & \\
\hline & & 3,130 & & & \\
\hline & \multirow{3}{*}{1 day } & 4,880 & \multirow{3}{*}{4,970} & \multirow{3}{*}{6,070} & \multirow{3}{*}{$\geq 4,000$ psi } \\
\hline & & 4,960 & & & \\
\hline & & 5,070 & & & \\
\hline & \multirow{3}{*}{7 day } & 6,000 & \multirow{3}{*}{5,937} & \multirow{3}{*}{7,290} & \multirow{3}{*}{$\geq 5,000$ psi } \\
\hline & & 5,930 & & & \\
\hline & & 5,880 & & & \\
\hline \multirow{9}{*}{$\begin{array}{c}\text { Ulti- } \\
\text { Pave3 }^{\circledR}\end{array}$} & \multirow{3}{*}{$2 \mathrm{hr}$} & 3,700 & \multirow{3}{*}{3,827} & \multirow{3}{*}{4,630} & \multirow{3}{*}{$\geq 2,500 \mathrm{psi}$} \\
\hline & & 3,830 & & & \\
\hline & & 3,950 & & & \\
\hline & \multirow{3}{*}{1 day } & 5,890 & \multirow{3}{*}{6,097} & \multirow{3}{*}{7,880} & \multirow{3}{*}{$\geq 4,000$ psi } \\
\hline & & 6,730 & & & \\
\hline & & 5,670 & & & \\
\hline & \multirow{3}{*}{7 day } & 6,850 & \multirow{3}{*}{7,080} & \multirow{3}{*}{8,740} & \multirow{3}{*}{$\geq 5,000$ psi } \\
\hline & & 7,170 & & & \\
\hline & & 7,220 & & & \\
\hline
\end{tabular}

aCompressive strength results from field sampling.

bCompressive strength results from laboratory testing.

cMinimum laboratory requirement from new tri-service spall repair certification protocol. *

\subsubsection{Visual observations under traffic}

\subsubsection{Fastrac 246 repairs}

The repair's ability to withstand loading at an early age is essential to support the RADR mission. An important data collection interval is after 7 full traffic patterns have been applied (112 passes). Seven patterns are generally completed in the first 30-60 min after the material has cured for $2 \mathrm{hr}$. Repairs 1 and 2 were conducted at the same time and trafficked

* Ramsey, M. A., J. S. Tingle, and C. A. Rutland. DRAFT. Evaluation of Rapid-Setting Cementitious Materials and Testing Protocol for Airfield Spall Repair. ERDC/GSL TR-19-DRAFT. Vicksburg, MS: U.S. Army Engineer Research and Development Center. 
simultaneously, and Repair 3 was completed separately. Figures 19, 20, and 21 show Repairs 1, 2, and 3, respectively, after 112 passes. The boundaries of Repair 3 are outlined in orange. As shown, no notable distresses were observed for Repair 1. Repair 2 showed only some debris near the front right edge that was due to cured, excess material around the repair breaking up under traffic. Repair 3 exhibited no distresses with the exception of a small rough area that was not finished before the material reached initial set (Figure 22). This area did not appear to deteriorate under traffic.

Figure 19. Repair 1, overall, 112 passes.

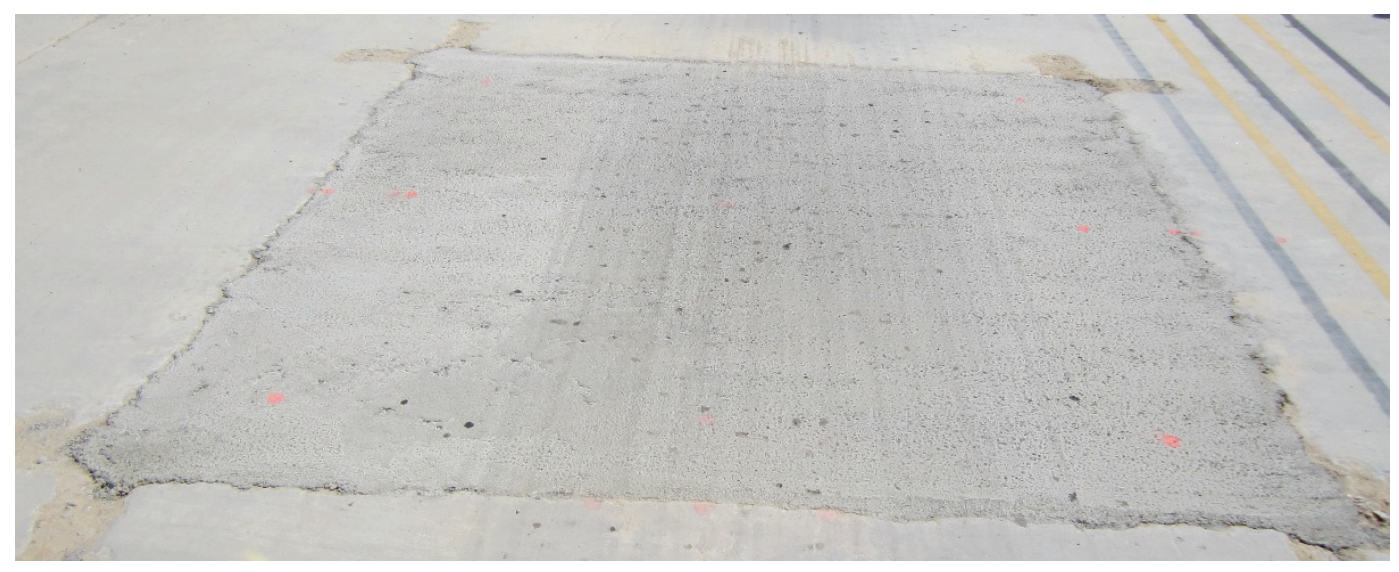

Figure 20. Repair 2, overall, 112 passes.

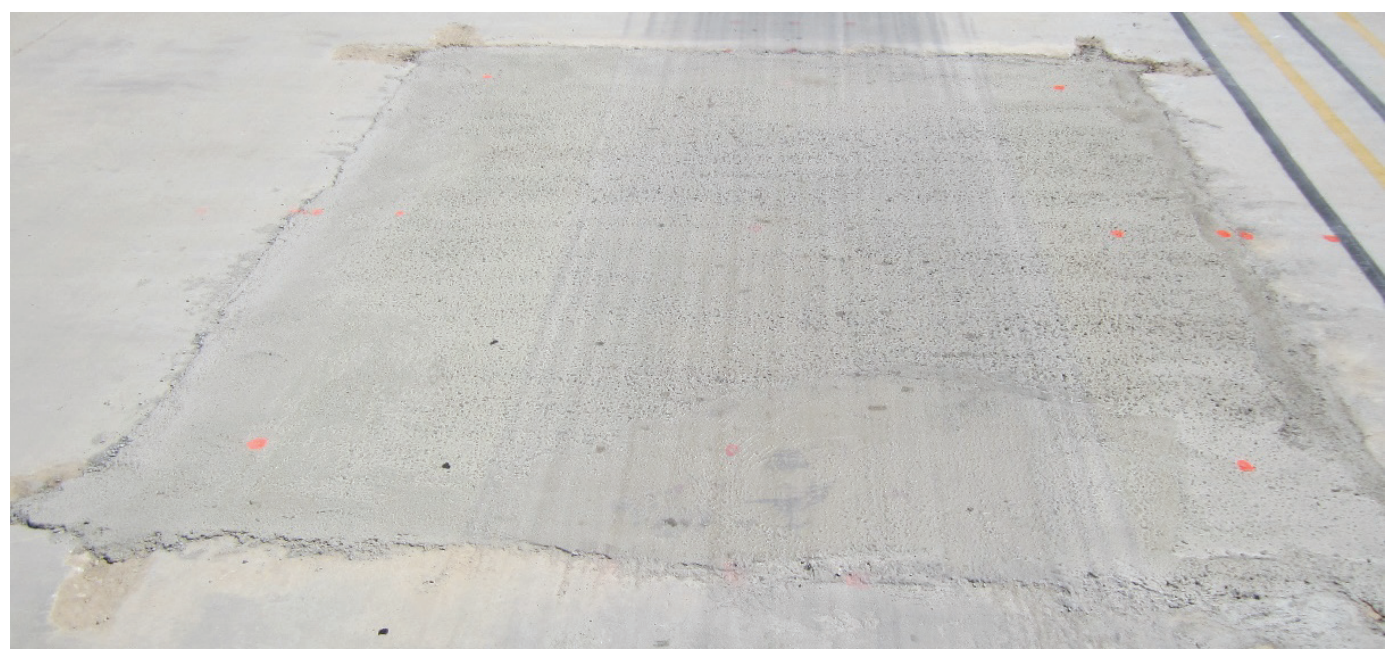


Figure 21. Repair 3, overall, 112 passes.

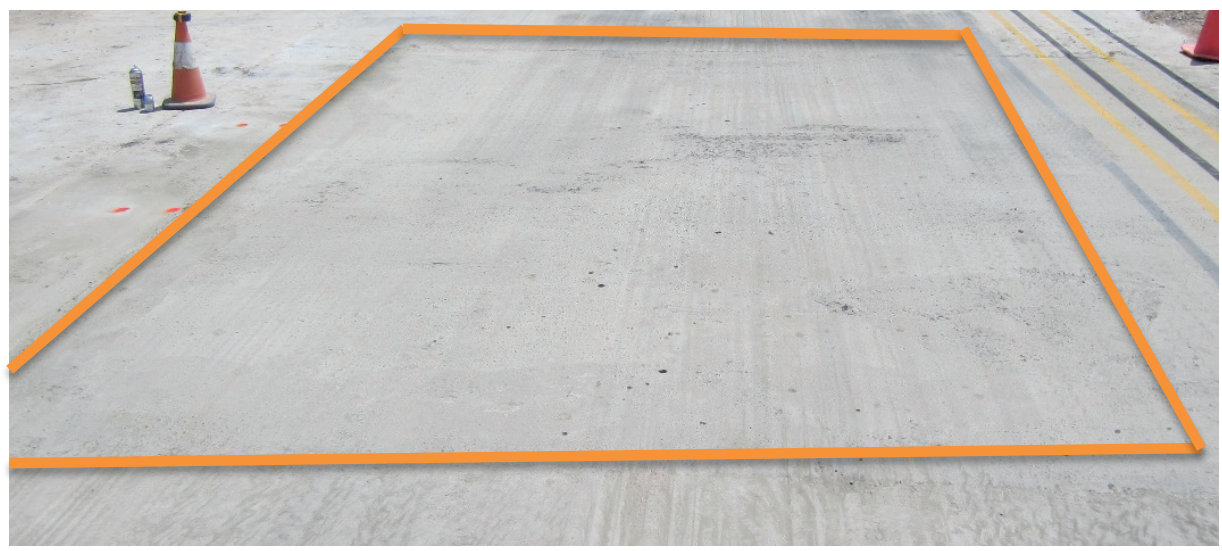

Figure 22. Repair 3, small rough area, 112 passes.

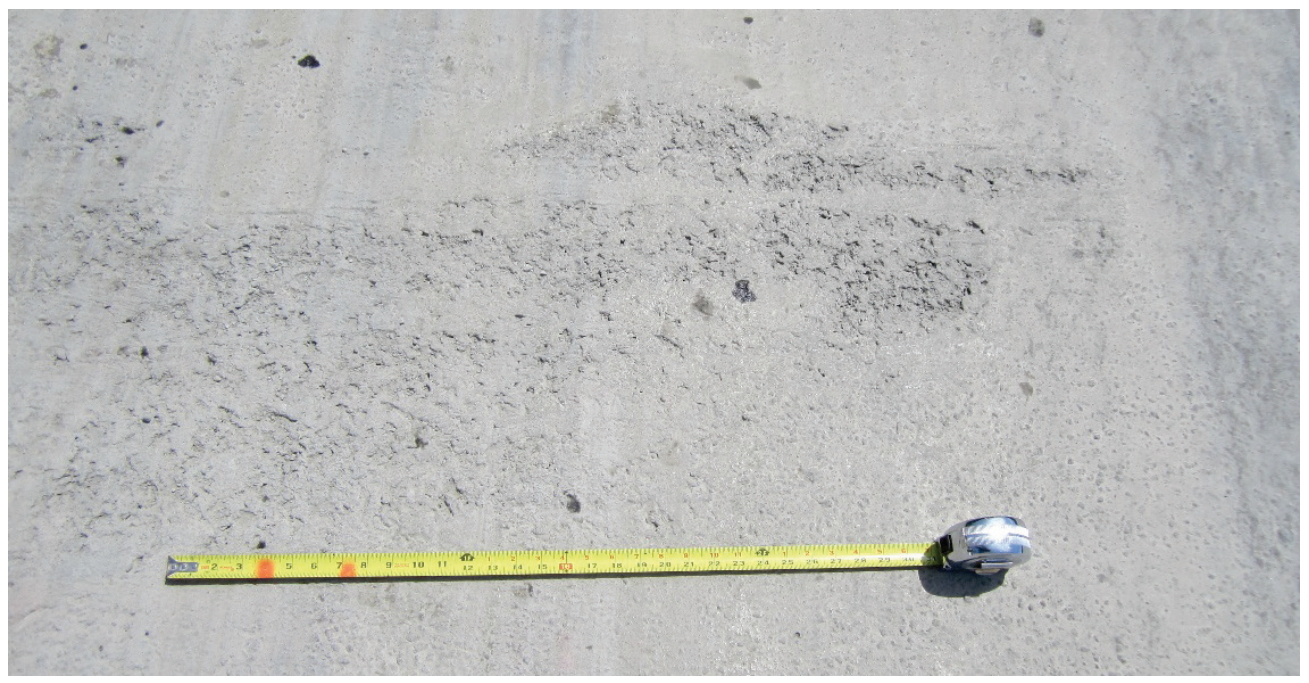

After 1,00o passes, none of the repairs exhibited any major distresses, but some deterioration near the edges was apparent. Figures 23 and 24 show the rear edges of Repairs 1 and 2, respectively. For repair 3, some mediumseverity spalling and cracking was observed on the rear edge (Figure 25). 
Figure 23. Repair 1, rear edge deterioration, 1,000 passes.

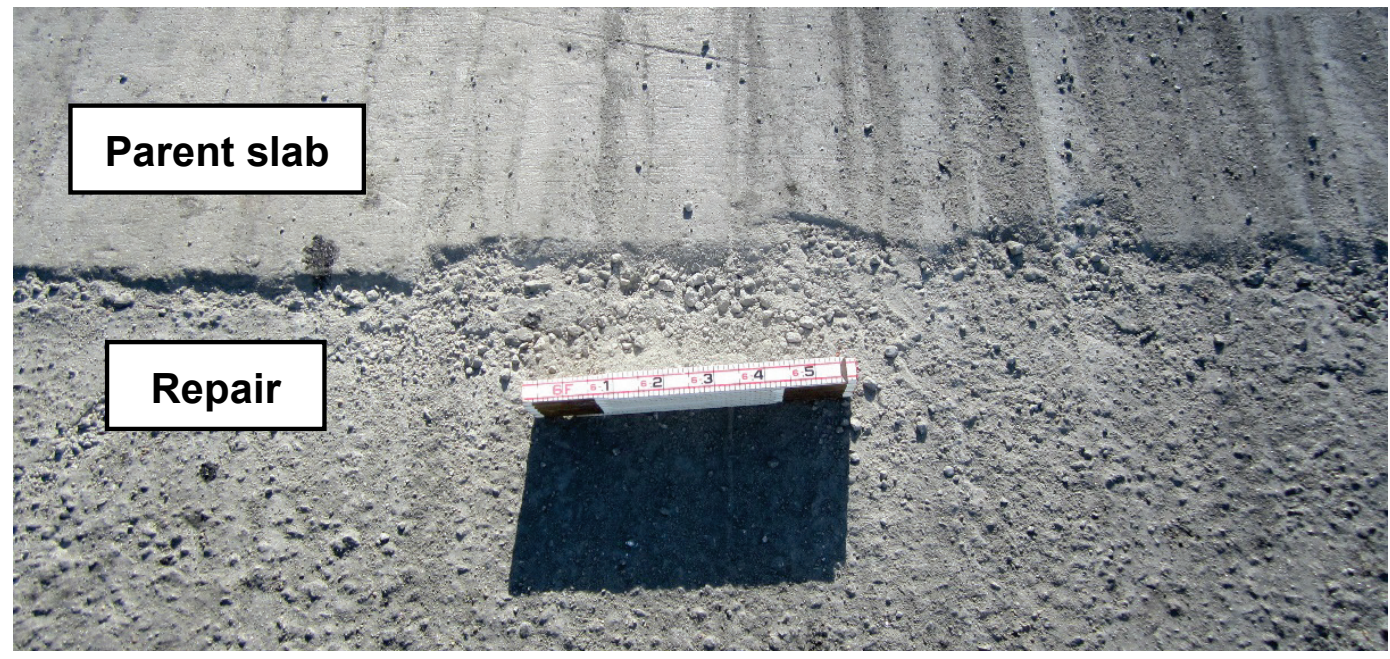

Figure 24. Repair 2, rear edge deterioration, 1000 passes.

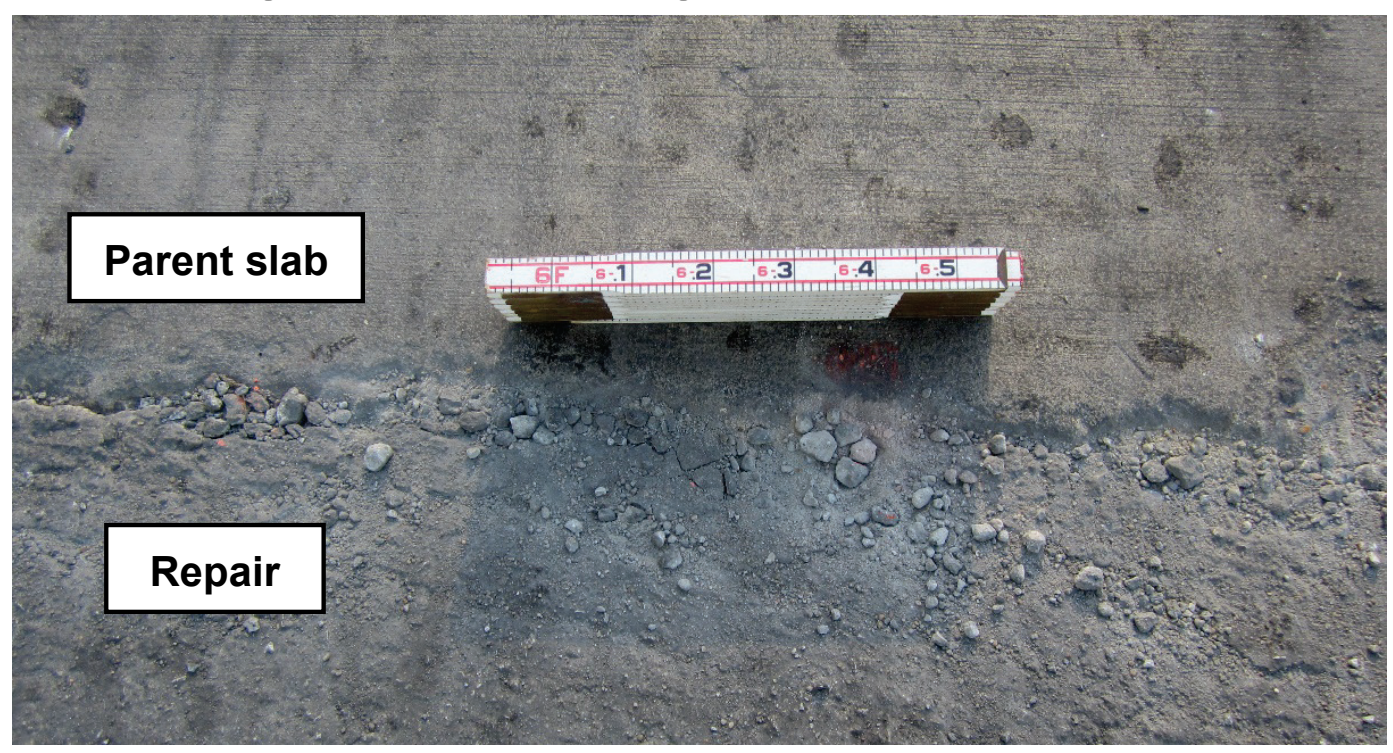


Figure 25. Repair 3, Spalling and cracking on rear edge, 1,000 passes.

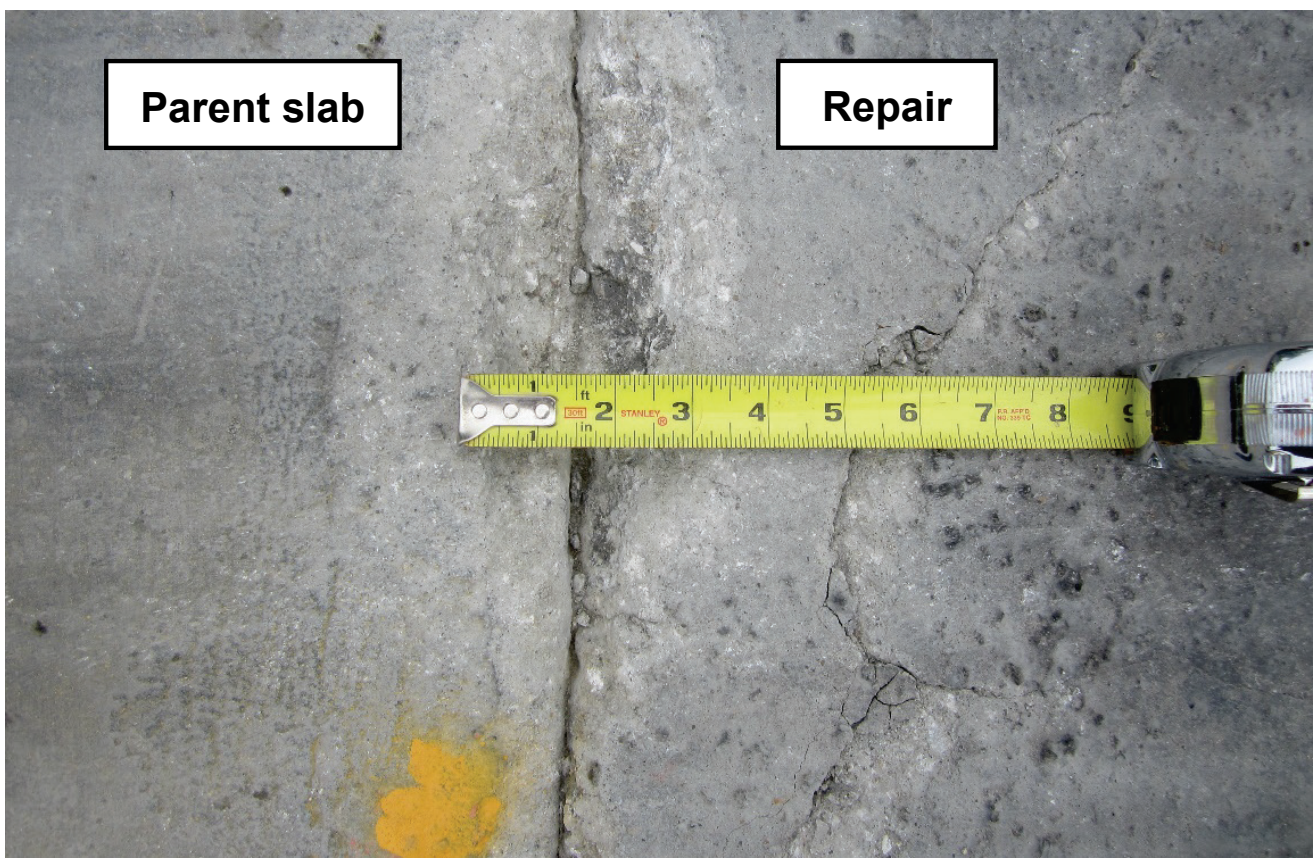

After 2,000 passes, all repairs exhibited considerable distress in the form of high-severity joint spalling on both the front and rear edges. Table 9 provides the spall measurements for each repair. Figure 26 shows an overall photo of Repair 1 after 2,00o passes, and Figures 27 and 28 show the front and rear edge of the repair, respectively. High-severity spalling can be seen on both edges with some cracking extending into the repair on the front edge. Figure 29 shows Repair 2 overall with Figure 30 showing the high-severity joint spalling on the rear edge. Figure 31 contains an overall photo of Repair 3 after 2,000 passes, and the high-severity joint spalling observed on the rear edge is shown in Figure 32. At 2,000 passes, the spall measurements for all repairs capped with Fastrac 246 exceeded the high-severity spall criterion, so the repairs were considered failed.

Table 9. Repairs 1, 2, and 3 joint spall dimensions after 2,000 passes.

\begin{tabular}{|c|l|c|c|c|}
\hline Repair \# & Location & Spall Length (in.) & Spall Width (in.) & Spall Depth (in.) \\
\hline $\mathbf{1}$ & Front Edge & 74 & 4.75 & 2.50 \\
\hline & Rear Edge & 62 & 6.50 & 2.25 \\
\hline $\mathbf{2}$ & Front Edge & 65 & 6.00 & 2.00 \\
\hline & Rear Edge & 70 & 4.75 & 2.50 \\
\hline 3 & Front Edge & 108 & 3.00 & 1.75 \\
\hline & Rear Edge & 72 & 8.00 & 2.25 \\
\hline
\end{tabular}


Figure 26. Repair 1, overall, 2,000 passes.

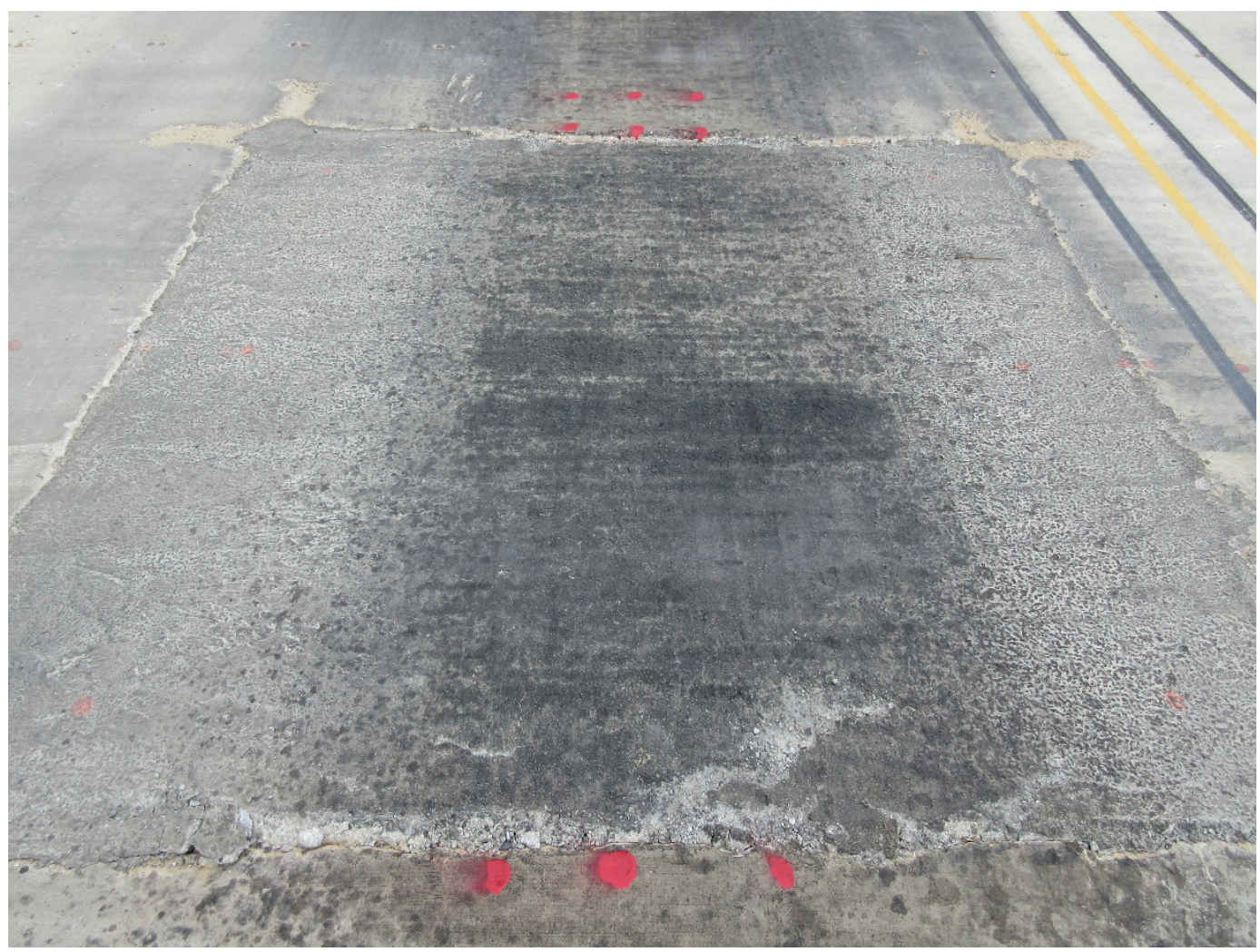

Figure 27. Repair 1, front edge, 2,000 passes.

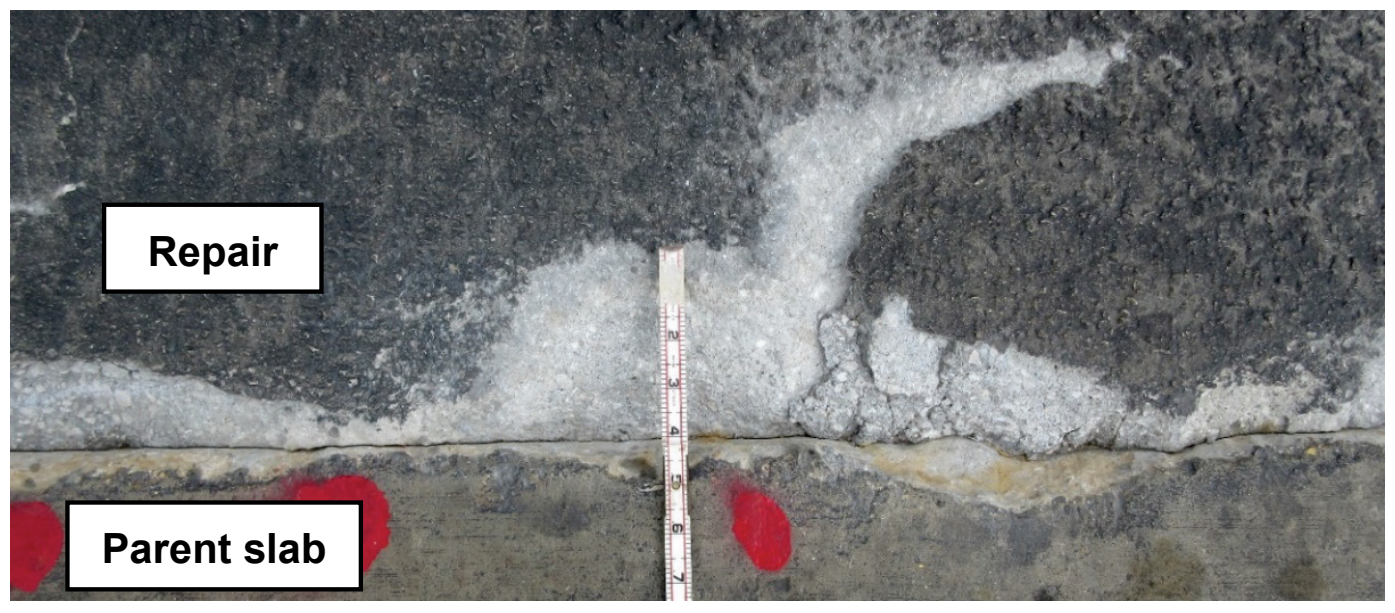


Figure 28. Repair 1, rear edge, 2,000 passes.

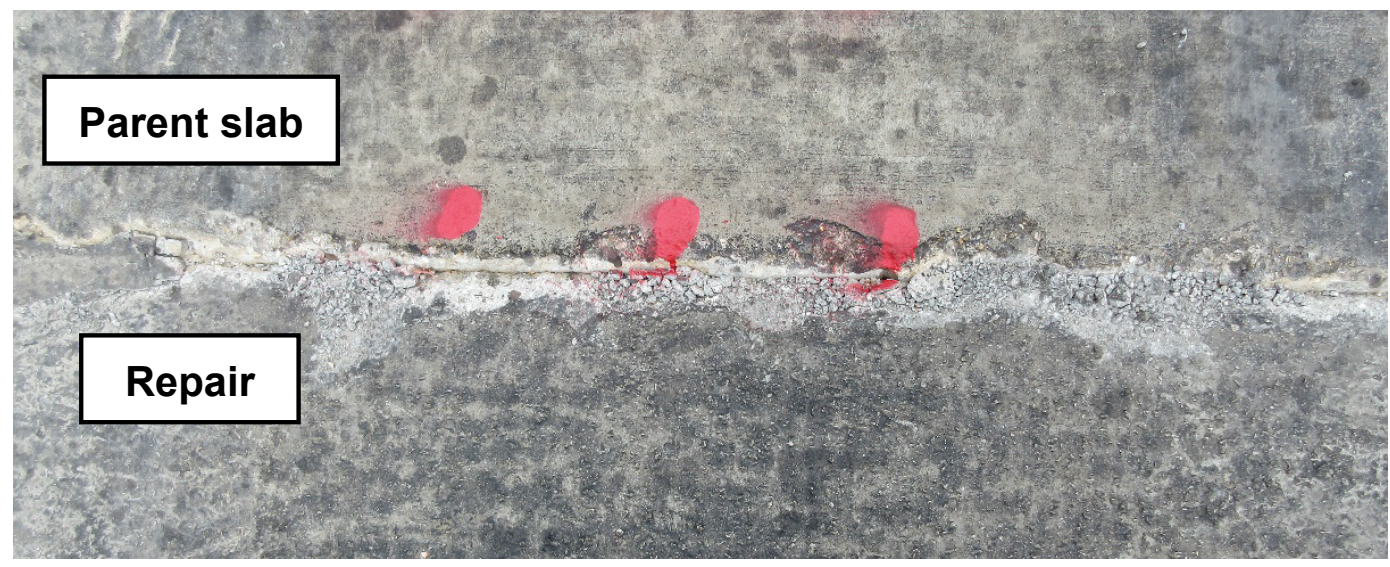

Figure 29. Repair 2, overall, 2,000 passes.

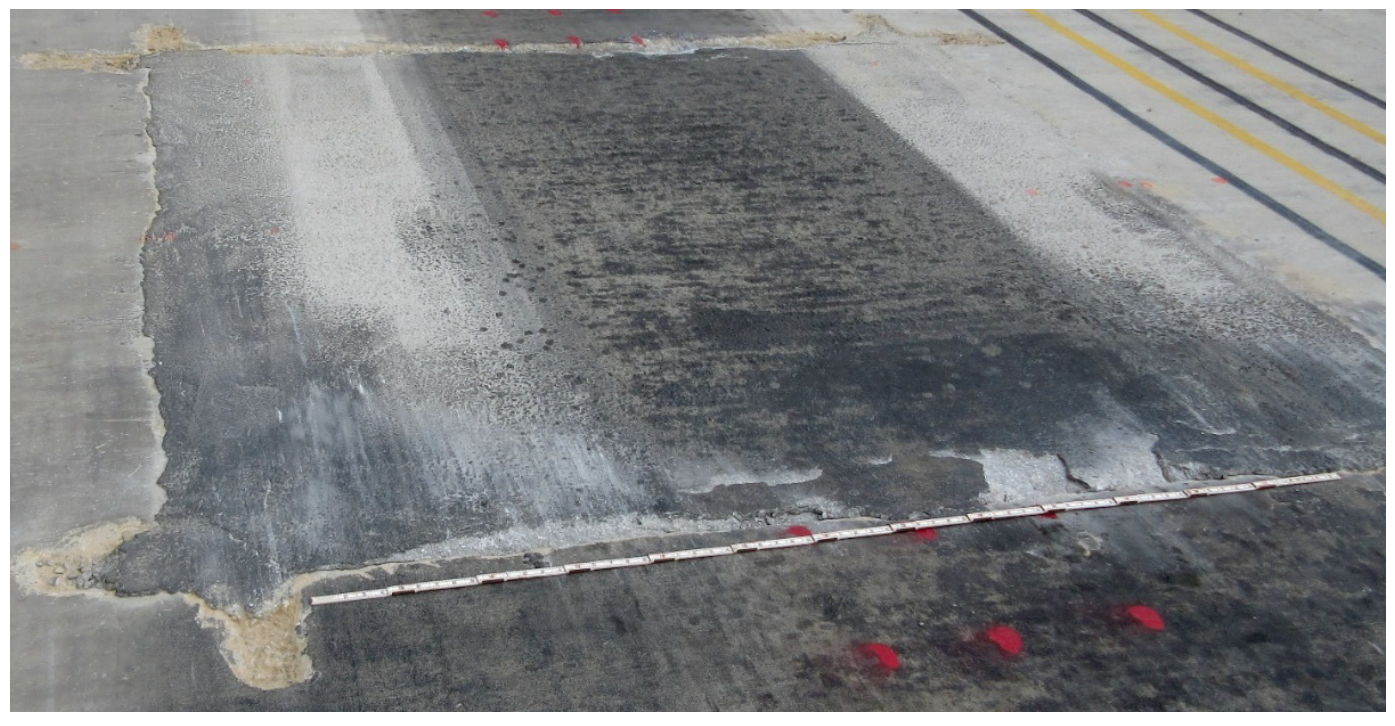

Figure 30. Repair 2, rear edge, 2,000 passes.

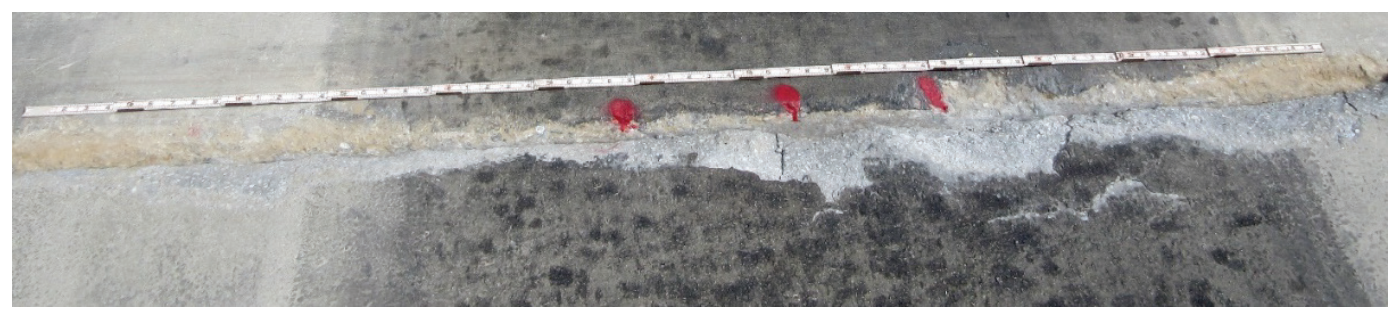


Figure 31. Repair 3, overall, 2,000 passes.

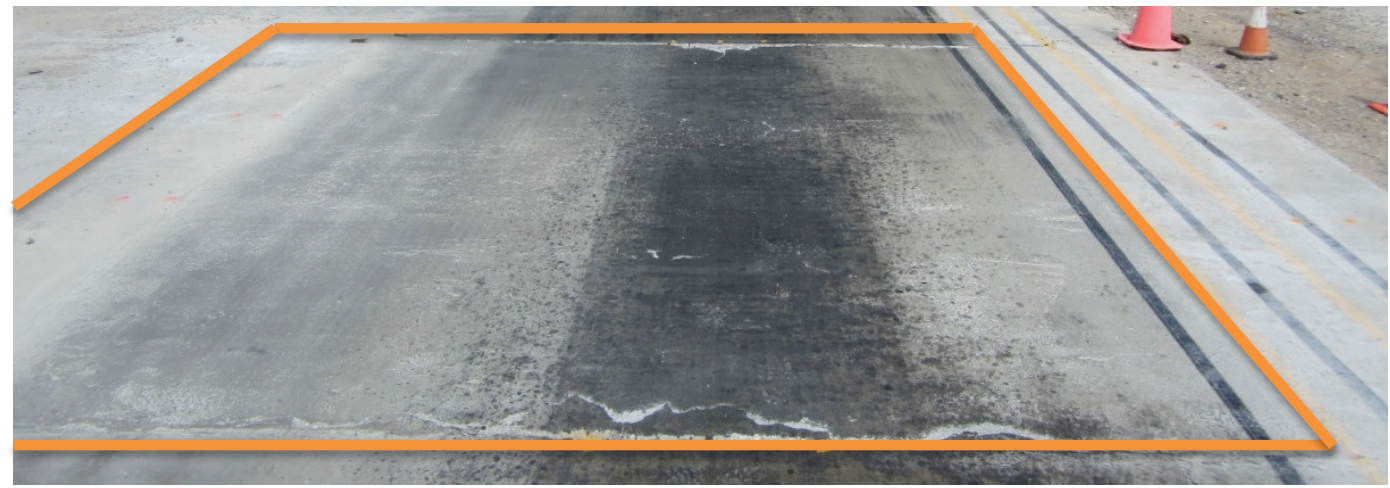

Figure 32. Repair 3, high-severity joint spalling on rear edge, 2,000 passes.

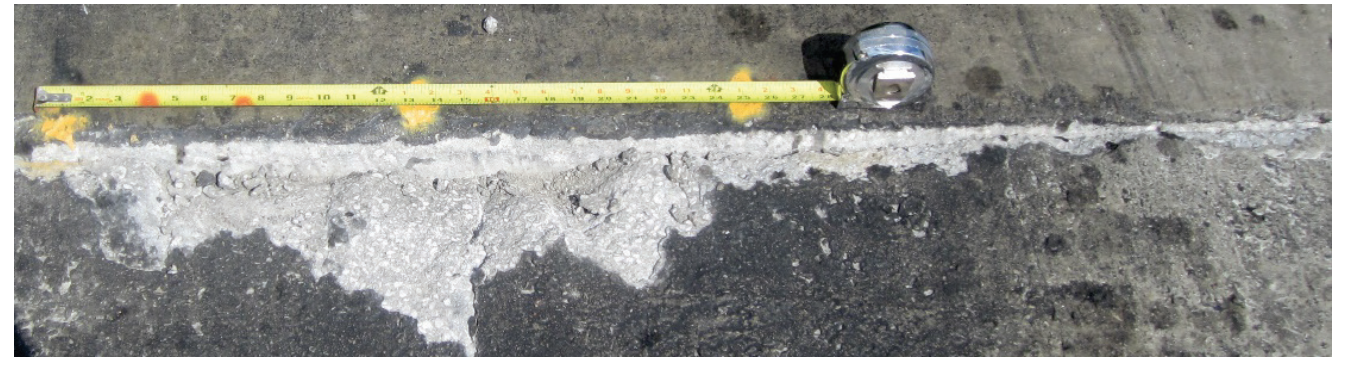

\subsubsection{Ulti-Pave ${ }^{\circledR}$ repairs}

Visual observations were first obtained after 112 passes for Repairs 4, 5, and 6. Repairs 4 and 5 were conducted and trafficked together, while Repair 6 was performed separately. Figures 33 and 34 show Repairs 4 and 5 , respectively, after 112 aircraft passes. No notable distresses were observed for Repairs 4, 5, and 6 at this pass level.

Figure 33. Repair 4, overall, 112 passes.

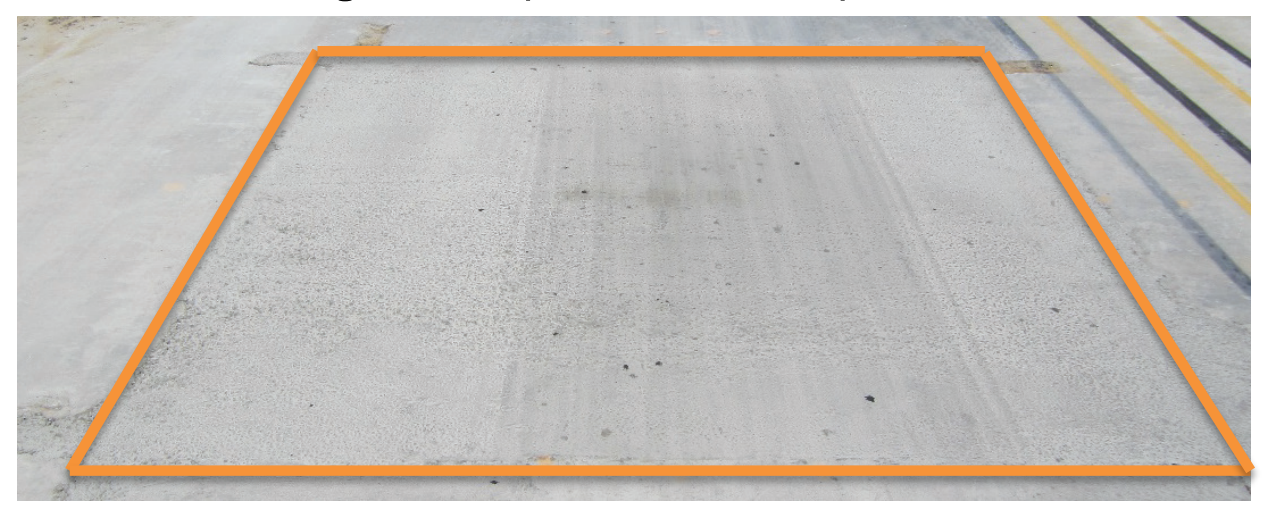


Figure 34. Repair 5, overall, 112 passes.

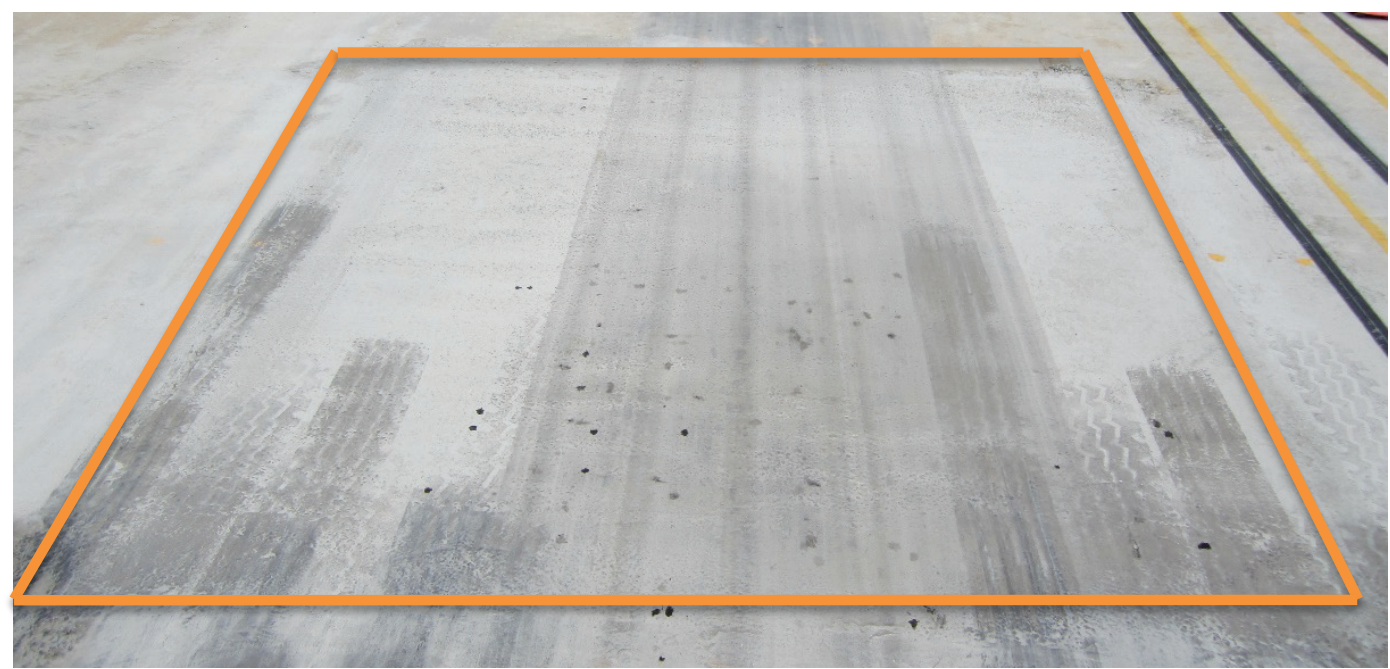

After 2,000 passes, Repairs 4 and 5 showed much less deterioration than Repairs 1 and 2. Figure 35 shows the rear edge of Repair 4 at 2,000 passes, and Repair 5 edges appeared visually similar. Repair 6 did exhibit more distress than Repairs 4 and 5 as evidenced by the spalling shown in Figure 36.

Figure 35. Repair 4, rear edge, 2,000 passes.

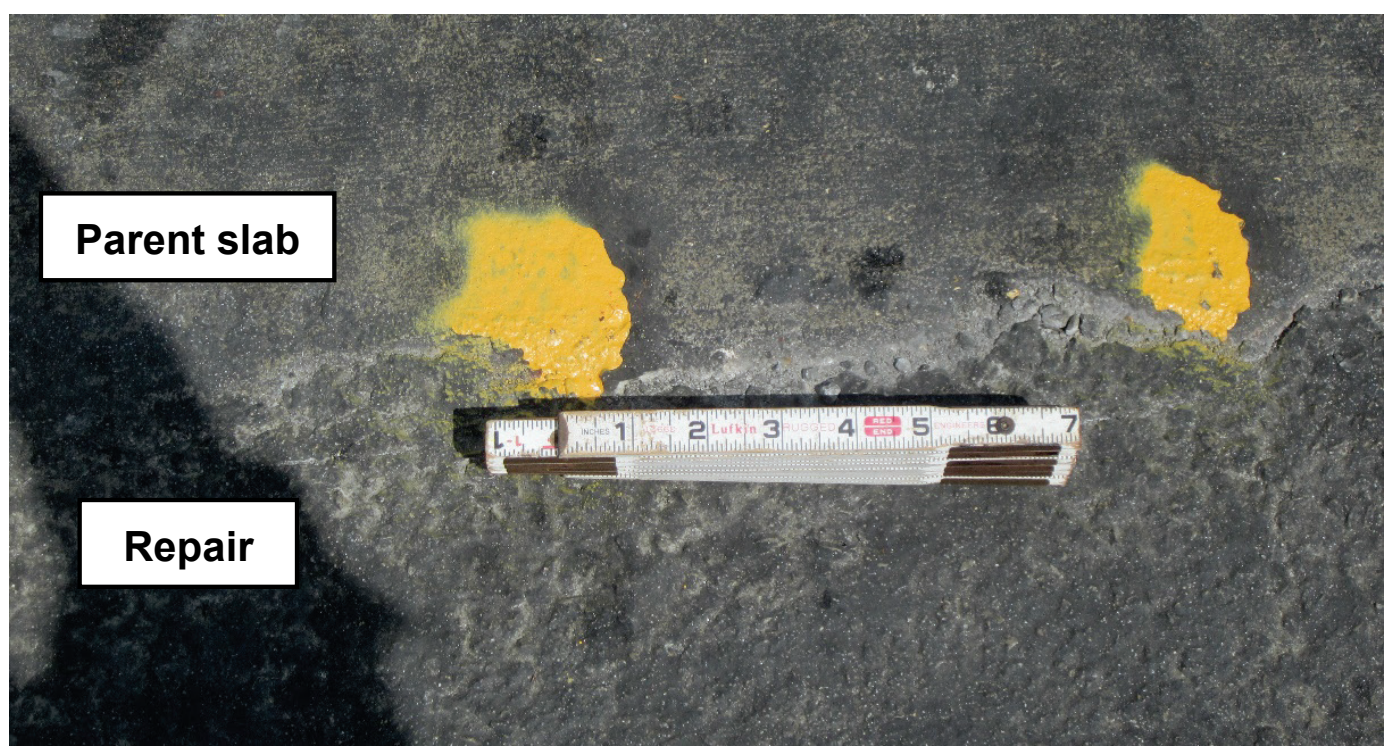


Figure 36. Repair 6, front edge, 2,000 passes.

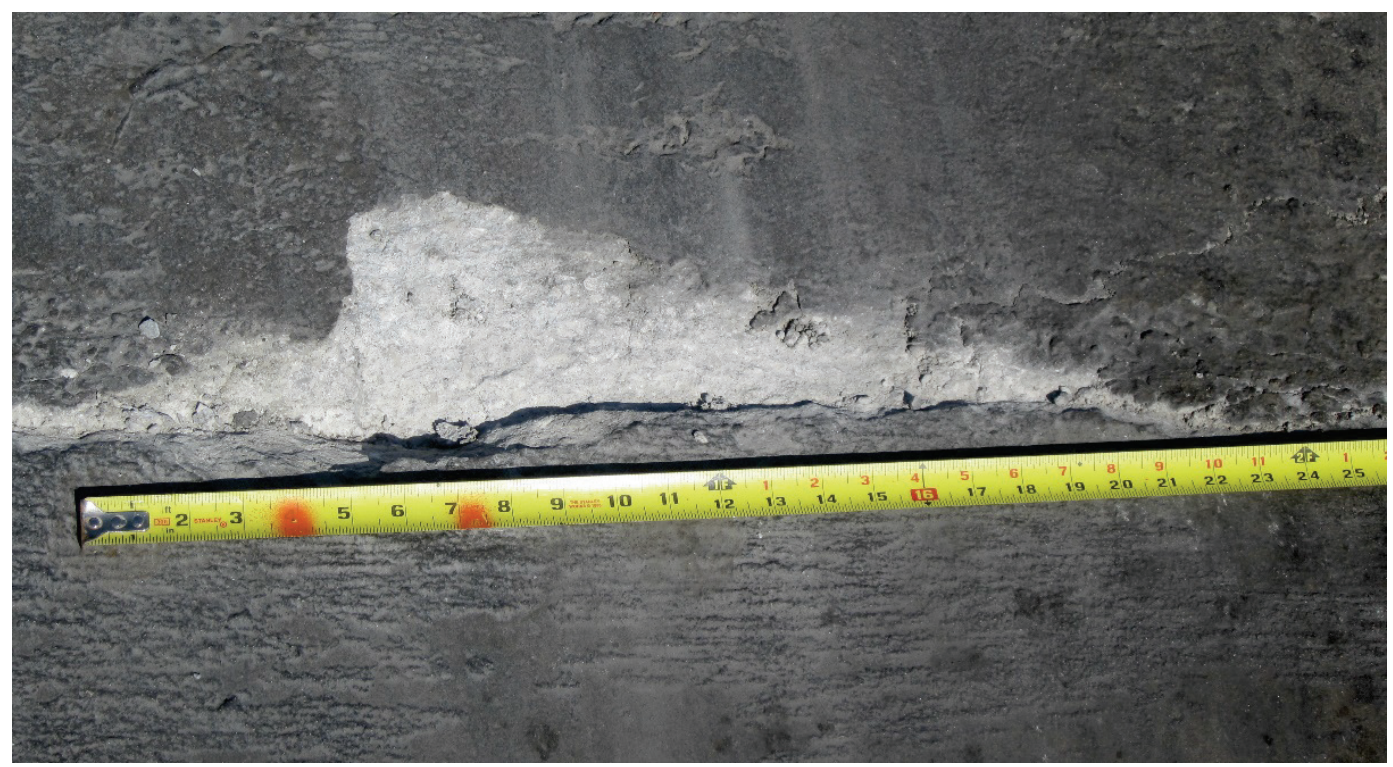

Trafficking and data collection continued periodically for Repairs 4, 5, and 6 . After the target number of passes $(3,500)$ was reached, trafficking was discontinued. After 3,500 passes, Figures 37 and 38 show some minor spalling on Repairs 4 and 5, respectively. Repair 6 again showed the most distress of the Ulti-Pave $3{ }^{\circledR}$ repairs with a high-severity spall that was 33 in. long, 3.25 in. wide, and 1.5 in. deep (Figure 39). These results were within the high-severity spall criteria, so Repair 6 was not considered failed at this pass level.

Figure 37 . Repair 4, medium-severity spalling, 3,500 passes.

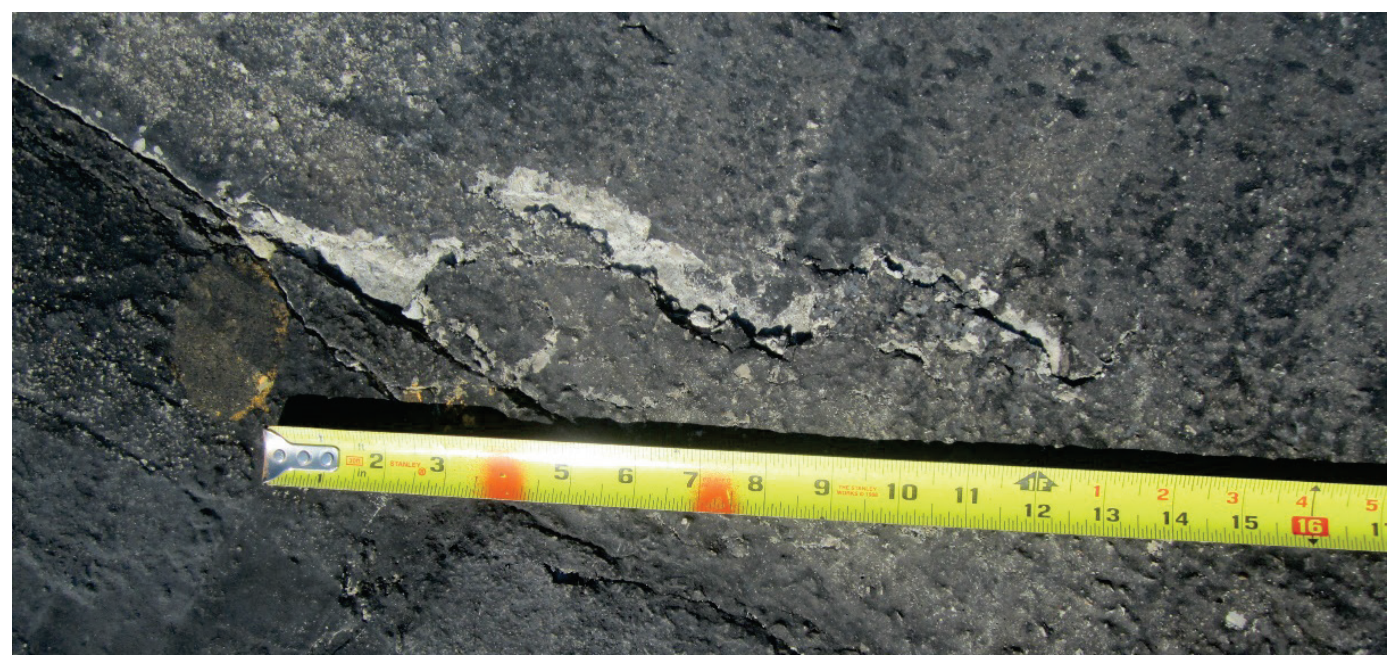


Figure 38. Repair 5, low-severity spalling, 3,500 passes.

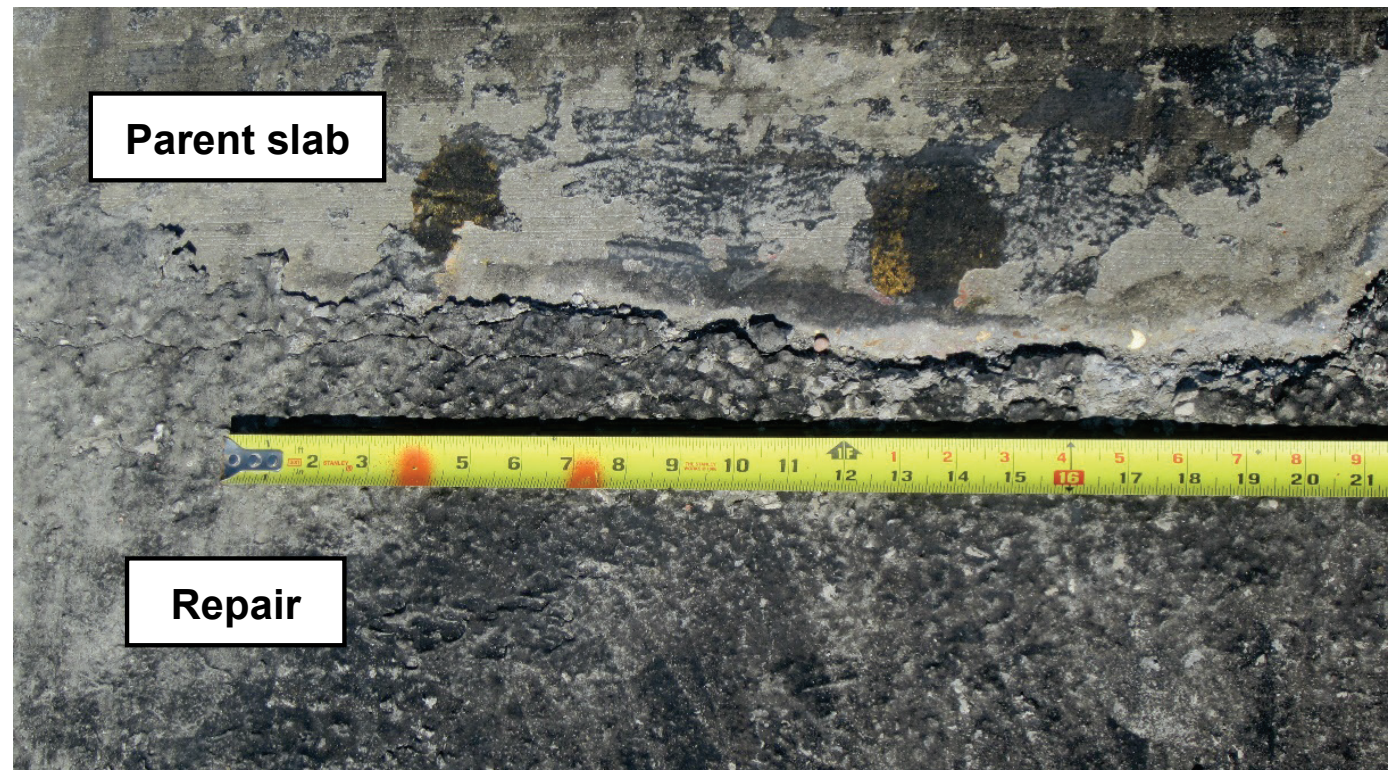

Figure 39. Repair 6, high- severity spalling, 3,500 passes

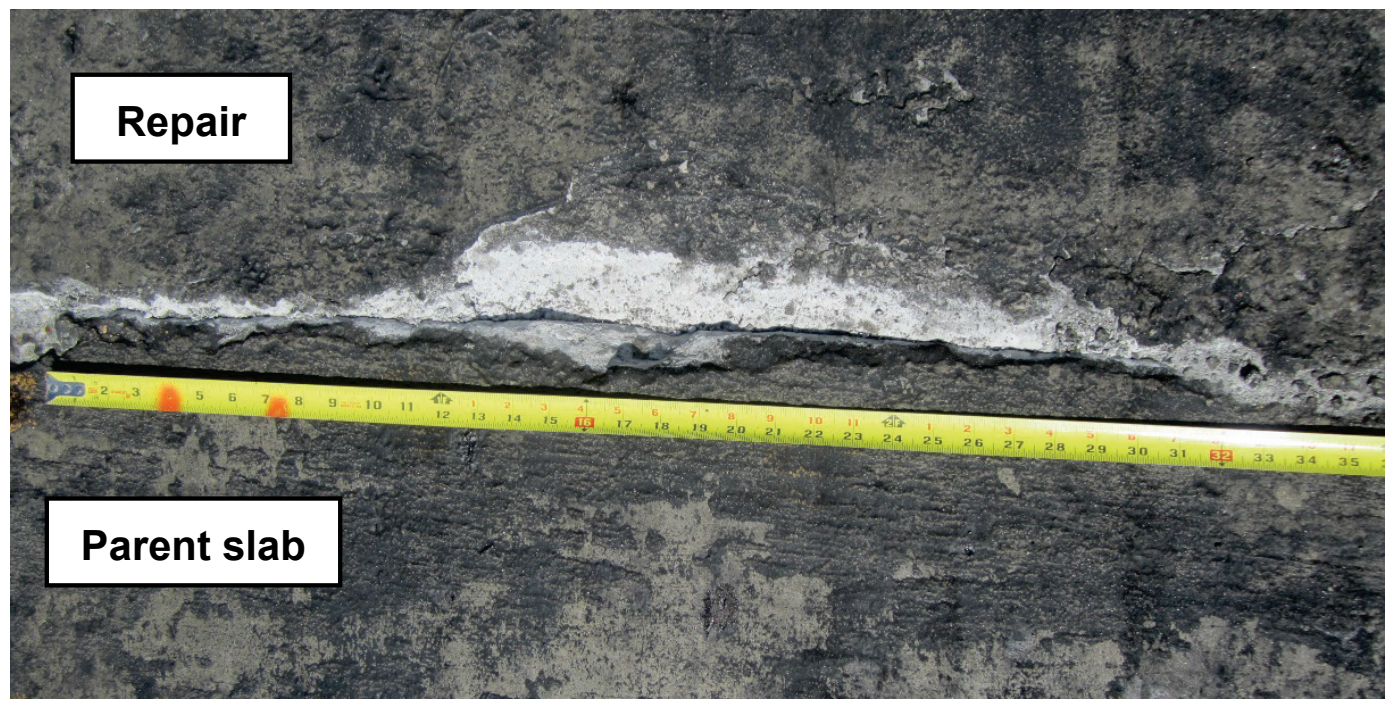

\subsubsection{Survey data}

Rod and level surveys of the repair surfaces were conducted periodically during trafficking to monitor any deformations that would cause the repair to fall outside of the +/- 0.75 in. criterion used for this study. While measurements were obtained near the edges to detect any faulting, the high-severity spall criterion discussed in Section 3.4 was used as the primary method of defining failure in this location since the survey rod often bridged over smaller spalls or measured the bottom of larger spalls. Table 10 shows the deformations measured after 2,000 passes for Repairs 1 and 2. While no deflections measured exceeded the +/- 0.75 in. criteria, 
both repairs were considered failed after 2,00o passes since the highseverity spall criterion was exceeded (see section 4.1.5).

Table 10. Repair 1 and 2 deformations, 2000 passes.

\begin{tabular}{|c|c|c|c|c|}
\hline \multicolumn{5}{|c|}{ Repair 1} \\
\hline Survey Point & $\mathrm{N}$ & C & $S$ & CS \\
\hline 1 & 0.24 & 0.12 & 0.12 & 0.12 \\
\hline 2 & 0.12 & 0.12 & 0.12 & 0.12 \\
\hline 3 & 0.12 & 0.00 & 0.00 & 0.00 \\
\hline 4 & 0.00 & 0.00 & 0.00 & 0.00 \\
\hline 5 & -0.12 & 0.00 & -0.12 & 0.00 \\
\hline 6 & 0.00 & -0.12 & 0.12 & -0.12 \\
\hline 7 & -0.12 & -0.12 & 0.00 & -0.12 \\
\hline 8 & 0.00 & -0.12 & -0.12 & -0.12 \\
\hline 9 & 0.00 & 0.00 & -0.24 & -0.12 \\
\hline 10 & 0.12 & 0.00 & 0.00 & 0.12 \\
\hline 11 & 0.00 & -0.12 & 0.00 & 0.00 \\
\hline 12 & 0.36 & 0.36 & 0.36 & 0.12 \\
\hline 13 & 0.24 & 0.24 & 0.36 & 0.36 \\
\hline \multicolumn{5}{|c|}{ Repair 2} \\
\hline Survey Point & $\mathrm{N}$ & $\mathrm{C}$ & $S$ & CS \\
\hline 1 & 0.12 & 0.12 & 0.24 & 0.24 \\
\hline 2 & 0.24 & 0.24 & 0.24 & 0.24 \\
\hline 3 & 0.00 & 0.24 & 0.00 & 0.24 \\
\hline 4 & 0.00 & 0.00 & 0.00 & 0.12 \\
\hline 5 & 0.12 & 0.00 & 0.00 & 0.12 \\
\hline 6 & 0.00 & -0.12 & 0.00 & 0.12 \\
\hline 7 & 0.00 & 0.00 & -0.12 & 0.00 \\
\hline 8 & 0.00 & -0.12 & -0.12 & -0.12 \\
\hline 9 & 0.00 & 0.00 & -0.24 & -0.12 \\
\hline 10 & -0.12 & 0.00 & 0.00 & 0.12 \\
\hline 11 & 0.00 & -0.12 & 0.12 & 0.12 \\
\hline 12 & 0.12 & 0.12 & 0.00 & 0.36 \\
\hline 13 & 0.24 & 0.12 & 0.00 & 0.12 \\
\hline
\end{tabular}

Repair 3 deformations are displayed in Table 11. Only one measurement exceeded the criteria, but the deflection was quite large (1.92 in.).

However, this measurement was obtained in a deep spall and the repair was considered failed after 2,000 passes due to failing the high-severity spall criterion as discussed in Section 4.1.5. 
Table 11. Repair 3 deformations, 2,000 passes.

\begin{tabular}{|c|c|c|c|c|c|}
\hline Survey Point & $\mathrm{N}$ & $\mathrm{C1}$ & $\mathrm{C} 2$ & $S$ & $\mathrm{CS}$ \\
\hline 1 & -0.12 & -0.12 & -0.12 & -0.12 & 0.00 \\
\hline 2 & 0.00 & -0.24 & -0.12 & 0.00 & -0.12 \\
\hline 3 & -0.72 & -0.60 & -0.48 & -0.12 & 0.00 \\
\hline 4 & -0.48 & -0.60 & -0.48 & -0.24 & -0.12 \\
\hline 5 & -0.48 & -0.48 & -0.48 & -0.24 & -0.24 \\
\hline 6 & -0.48 & -0.48 & -0.48 & -0.24 & -0.24 \\
\hline 7 & -0.48 & -0.48 & -0.48 & -0.48 & -0.36 \\
\hline 8 & -0.48 & -0.48 & -0.48 & -0.48 & -0.36 \\
\hline 9 & -0.36 & -0.48 & -0.48 & -0.60 & -0.48 \\
\hline 10 & -0.48 & -0.48 & -0.48 & -0.48 & -0.60 \\
\hline 11 & -0.48 & -0.48 & -0.48 & -0.48 & -0.48 \\
\hline 12 & -0.48 & -0.48 & -0.36 & -0.36 & -0.48 \\
\hline 13 & -0.48 & -0.48 & -0.60 & -0.36 & -0.48 \\
\hline 14 & -0.48 & -0.48 & -0.48 & -0.24 & -0.36 \\
\hline 15 & -0.48 & -0.60 & -0.48 & -0.36 & -0.36 \\
\hline 16 & -0.48 & -0.48 & -0.48 & -0.24 & -0.12 \\
\hline 17 & -0.60 & -0.60 & -0.48 & -0.24 & -0.12 \\
\hline 18 & -0.48 & -1.92 & -0.72 & 0.00 & -0.12 \\
\hline 19 & -0.12 & -0.12 & -0.12 & -0.12 & 0.00 \\
\hline 20 & -0.24 & -0.12 & -0.12 & -0.12 & 0.00 \\
\hline
\end{tabular}

- Survey layout corresponds to Figure 17.

Survey measurements for Repairs 4 and 5 can be found in Table 12. All measurements were within the criteria range. Trafficking was ceased for both repairs after 3,500 passes. Repair 6 deformation measurements are shown in Table 13. Three measurements were outside the failure criteria, i.e., Line $\mathrm{C} 1$ survey points 3 and 18 and Line $\mathrm{C} 2$ survey Point 3. All these measurements were obtained within a spall located just inside the repair near the joint between the repair and parent slab. Accordingly, highseverity spall criterion was used to determine if the repair had failed. All measurements within the interior of the repair were between -0.48 and 0.72 in., indicating that some overall settlement did occur, but within criteria limits. Trafficking was ceased after 3,500 passes. 
Table 12. Repair 4 and 5 deformations, 3,500 passes.

\begin{tabular}{|c|c|c|c|c|}
\hline \multicolumn{5}{|c|}{ Repair 4 } \\
\hline Survey Point & $\mathrm{N}$ & $\mathrm{C}$ & $\mathrm{S}$ & $\mathrm{CS}$ \\
\hline $\mathbf{1}$ & 0.00 & 0.00 & 0.12 & 0.12 \\
\hline $\mathbf{2}$ & 0.12 & 0.12 & 0.12 & 0.12 \\
\hline $\mathbf{3}$ & -0.12 & 0.12 & 0.00 & 0.00 \\
\hline $\mathbf{4}$ & -0.12 & 0.00 & 0.12 & 0.00 \\
\hline $\mathbf{5}$ & -0.12 & 0.12 & 0.12 & 0.12 \\
\hline $\mathbf{6}$ & 0.12 & 0.24 & 0.24 & 0.12 \\
\hline $\mathbf{7}$ & 0.12 & 0.24 & 0.12 & 0.12 \\
\hline $\mathbf{8}$ & 0.00 & 0.12 & 0.12 & 0.00 \\
\hline $\mathbf{9}$ & -0.24 & 0.00 & 0.00 & -0.12 \\
\hline 10 & 0.00 & -0.12 & 0.00 & -0.12 \\
\hline 11 & 0.00 & 0.12 & 0.00 & -0.12 \\
\hline 12 & -0.12 & -0.12 & 0.12 & -0.24 \\
\hline 13 & -0.12 & -0.12 & -0.12 & -0.24 \\
\hline \multicolumn{5}{|c|}{ Repair 5 } \\
\hline Survey Point & $\mathrm{N}$ & $\mathrm{C}$ & $\mathrm{S}$ & $\mathbf{C S}$ \\
\hline $\mathbf{1}$ & 0.00 & -0.12 & 0.00 & 0.24 \\
\hline $\mathbf{2}$ & -0.12 & 0.12 & 0.12 & 0.24 \\
\hline $\mathbf{3}$ & -0.12 & 0.12 & 0.12 & 0.12 \\
\hline $\mathbf{4}$ & 0.00 & 0.00 & 0.12 & 0.00 \\
\hline $\mathbf{5}$ & -0.12 & 0.00 & 0.36 & 0.12 \\
\hline 6 & 0.12 & 0.12 & 0.36 & 0.24 \\
\hline $\mathbf{7}$ & 0.12 & 0.12 & 0.12 & 0.24 \\
\hline $\mathbf{8}$ & 0.00 & 0.12 & 0.24 & 0.12 \\
\hline $\mathbf{9}$ & -0.12 & 0.00 & 0.00 & 0.12 \\
\hline 10 & -0.12 & -0.12 & -0.12 & 0.00 \\
\hline 11 & 0.12 & 0.12 & 0.12 & -0.12 \\
\hline 12 & -0.12 & 0.00 & 0.12 & -0.36 \\
\hline 13 & 0.00 & 0.00 & 0.00 & -0.24 \\
\hline
\end{tabular}

-- All measurements in inches.

- Survey layout corresponds to Figure 16. 
Table 13. Repair 6 deformations, 3,500 passes.

\begin{tabular}{|c|c|c|c|c|c|}
\hline Survey Point & $\mathbf{N}$ & $\mathbf{C 1}$ & $\mathbf{C 2}$ & $\mathbf{S}$ & $\mathbf{C S}$ \\
\hline $\mathbf{1}$ & -0.48 & -0.36 & -0.48 & -0.36 & -0.24 \\
\hline $\mathbf{2}$ & -0.48 & -0.48 & -0.36 & -0.36 & -0.48 \\
\hline $\mathbf{3}$ & -0.72 & -0.96 & -0.96 & -0.36 & -0.60 \\
\hline $\mathbf{4}$ & -0.60 & -0.60 & -0.48 & -0.48 & -0.36 \\
\hline $\mathbf{5}$ & -0.60 & -0.60 & -0.48 & -0.48 & -0.60 \\
\hline $\mathbf{6}$ & -0.48 & -0.60 & -0.48 & -0.60 & -0.48 \\
\hline $\mathbf{7}$ & -0.60 & -0.60 & -0.60 & -0.48 & -0.48 \\
\hline $\mathbf{8}$ & -0.72 & -0.60 & -0.60 & -0.48 & -0.48 \\
\hline $\mathbf{9}$ & -0.60 & -0.60 & -0.60 & -0.60 & -0.60 \\
\hline 10 & -0.60 & -0.60 & -0.60 & -0.60 & -0.60 \\
\hline 11 & -0.60 & -0.60 & -0.48 & -0.72 & -0.60 \\
\hline $\mathbf{1 2}$ & -0.60 & -0.48 & -0.60 & -0.72 & -0.48 \\
\hline 13 & -0.48 & -0.60 & -0.60 & -0.72 & -0.48 \\
\hline 14 & -0.72 & -0.60 & -0.60 & -0.72 & -0.60 \\
\hline 15 & -0.60 & -0.60 & -0.48 & -0.60 & -0.48 \\
\hline 16 & -0.60 & -0.48 & -0.60 & -0.60 & -0.48 \\
\hline 17 & -0.60 & -0.72 & -0.72 & -0.60 & -0.60 \\
\hline 18 & -0.72 & -0.84 & -0.72 & -0.48 & -0.60 \\
\hline 19 & -0.48 & -0.48 & -0.48 & -0.48 & -0.60 \\
\hline $\mathbf{2 0}$ & -0.36 & -0.36 & -0.36 & -0.48 & -0.48 \\
\hline- All measurements in inches. & & \\
\hline- Survey layout corresponds to Figure 17. & & \\
\hline
\end{tabular}

\subsection{Rapid-setting flowable fill results and discussion}

\subsubsection{Previous wet method testing}

CTS RSFF placed using the wet method was previously evaluated and documented by Cox and Carr (2018) and Cox and Hoffman (2019). Cylindrical samples were cast during placement and tested for compressive strength after $2 \mathrm{hr}, 1$ day, and 28 days of curing time for both studies. Current specifications for wet method placement require a 28-day compressive strength of 750 psi at 28 days (MIL-DTL-32527). Cox and Carr (2018) reported the first formulation produced excessive compressive strengths ranging from 2,00o to 2,750 psi at 28 days. A second formulation was tested by Cox and Hoffman (2019) and these results are shown in Table 14. Results indicated that the $2^{\text {nd }}$ formulation exhibited 28-day compressive strengths that were not excessive, but still met the requirements. 
Table 14. Compressive strength results from Cox and Hoffman (2019).

\begin{tabular}{|c|c|c|c|c|}
\hline Cure Time & $\begin{array}{c}\text { Specimen \#1 } \\
(\mathbf{p s i})\end{array}$ & $\begin{array}{c}\text { Specimen \#1 } \\
(\mathbf{p s i})\end{array}$ & $\begin{array}{c}\text { Specimen \#1 } \\
(\mathbf{p s i})\end{array}$ & Avg (psi) \\
\hline $2 \mathrm{hr}$ & 580 & 600 & 586 & 589 \\
\hline 1 day & 904 & 805 & 935 & 881 \\
\hline 28 days & 659 & 928 & 1,065 & 884 \\
\hline
\end{tabular}

\subsubsection{Current dry method testing}

The second formulation of CTS RSFF discussed in Section 4.2.1 was used to conduct repairs using the dry method for this study. As described in Section 3.2.2, three DCP tests were conducted for each repair after 0.5, 1 , 2 , and $24 \mathrm{hr}$ of cure time for all three repairs. All CBR results are shown in Table 15 and the raw DCP penetration measurements and blow counts can be found for each individual test in Figures B19-B54 in Appendix B. CBR estimates were developed for three zones: o to 5 in., 5 to 10 in., and 10 to 14 in. depths. These three estimates were then averaged to arrive at a composite value for each test. As shown in Table 15, there was considerable variability between test results, which is consistent with the results discussed in Edwards et al. (2018). However, the results can be used to discuss some general trends.

CBR data from all three repairs were averaged for each cure time and are shown in Table 16. The data indicate that the material gained strength relatively slowly over the first two hours before eventually reaching an average estimated CBR of 50 after $24 \mathrm{hr}$ of cure time. These results are considerably lower than those produced by the currently preferred proprietary material, which can reach a CBR of $80 \%$ or higher after only 18 hr of cure time (Priddy et al. 2016). The lower estimated CBRs could have been caused by the change in formulation discussed in the previous section.

Another possible cause could have been the slow percolation of water through the material. Even with the reduced water used on the final lift of material, 0.5 to 1.0 in. of standing water was present over most of the repair until 30 min of cure time had been reached (Figure 40). The majority of standing water is typically absorbed within the first 15 min of cure time, which enables the timely placement of a RSC cap. Any standing water could adversely impact the material properties of the RSC by introducing excess water. 
Table 15. CTS rapid-setting flowable fill dry method CBR results.

\begin{tabular}{|c|c|c|c|c|c|c|}
\hline \multirow[b]{2}{*}{ Repair } & \multirow[b]{2}{*}{$\begin{array}{l}\text { Cure Time } \\
\text { (hr) }\end{array}$} & & \multicolumn{4}{|c|}{ CBR } \\
\hline & & Test \# & $\begin{array}{l}\text { 0- to 5- } \\
\text { in. Depth }\end{array}$ & $\begin{array}{l}\text { 5- to 10- } \\
\text { in. Depth }\end{array}$ & $\begin{array}{l}\text { 10- to 14- } \\
\text { in. Depth }\end{array}$ & $\begin{array}{l}\text { Composite } \\
\text { Value }\end{array}$ \\
\hline \multirow[t]{12}{*}{ FF-1 } & \multirow[t]{3}{*}{0.5} & 1 & 12 & 35 & 12 & 20 \\
\hline & & 2 & 15 & 16 & 7 & 13 \\
\hline & & 3 & 8 & 6 & 12 & 9 \\
\hline & \multirow[t]{3}{*}{1} & 1 & 13 & 15 & 14 & 14 \\
\hline & & 2 & 33 & 45 & 11 & 30 \\
\hline & & 3 & 29 & 48 & 10 & 29 \\
\hline & \multirow[t]{3}{*}{2} & 1 & 14 & 12 & 32 & 19 \\
\hline & & 2 & 15 & 26 & 17 & 19 \\
\hline & & 3 & 15 & 35 & 16 & 22 \\
\hline & \multirow[t]{3}{*}{24} & 1 & 56 & 92 & 63 & 70 \\
\hline & & 2 & 37 & 100 & 100 & 79 \\
\hline & & 3 & 36 & 24 & 24 & 28 \\
\hline \multirow[t]{12}{*}{ FF-2 } & \multirow[t]{3}{*}{0.5} & 1 & 2 & 12 & 13 & 9 \\
\hline & & 2 & 25 & 14 & 13 & 17 \\
\hline & & 3 & 12 & 2 & 16 & 10 \\
\hline & \multirow[t]{3}{*}{1} & 1 & 16 & 7 & 5 & 9 \\
\hline & & 2 & 10 & 3 & 3 & 5 \\
\hline & & 3 & 4 & 5 & 8 & 6 \\
\hline & \multirow[t]{3}{*}{2} & 1 & 4 & 2 & 17 & 8 \\
\hline & & 2 & 23 & 13 & 8 & 15 \\
\hline & & 3 & 21 & 30 & 26 & 26 \\
\hline & \multirow[t]{3}{*}{24} & 1 & 24 & 21 & 28 & 24 \\
\hline & & 2 & 54 & 70 & 34 & 53 \\
\hline & & 3 & 24 & 26 & 22 & 24 \\
\hline \multirow[t]{12}{*}{ FF-3 } & \multirow[t]{3}{*}{0.5} & 1 & 19 & 15 & 6 & 13 \\
\hline & & 2 & 8 & 12 & 6 & 9 \\
\hline & & 3 & 22 & 35 & 9 & 22 \\
\hline & \multirow[t]{3}{*}{1} & 1 & 23 & 24 & 12 & 20 \\
\hline & & 2 & 40 & 8 & 6 & 18 \\
\hline & & 3 & 56 & 19 & 12 & 29 \\
\hline & \multirow[t]{3}{*}{2} & 1 & 45 & 35 & 7 & 29 \\
\hline & & 2 & 21 & 20 & 17 & 19 \\
\hline & & 3 & 26 & 17 & 19 & 21 \\
\hline & \multirow[t]{3}{*}{24} & 1 & 75 & 100 & 100 & 92 \\
\hline & & 2 & 38 & 71 & 14 & 41 \\
\hline & & 3 & 60 & 73 & 23 & 52 \\
\hline
\end{tabular}


Table 16. Summary of CBR results.

\begin{tabular}{|c|c|}
\hline Cure Time (hr) & Average CBR (\%) \\
\hline 0.5 & 13 \\
\hline 1 & 18 \\
\hline 2 & 20 \\
\hline 24 & 51 \\
\hline
\end{tabular}

Figure 40. CTS rapid-setting flowable fill after $\mathbf{3 0}$ min cure time.

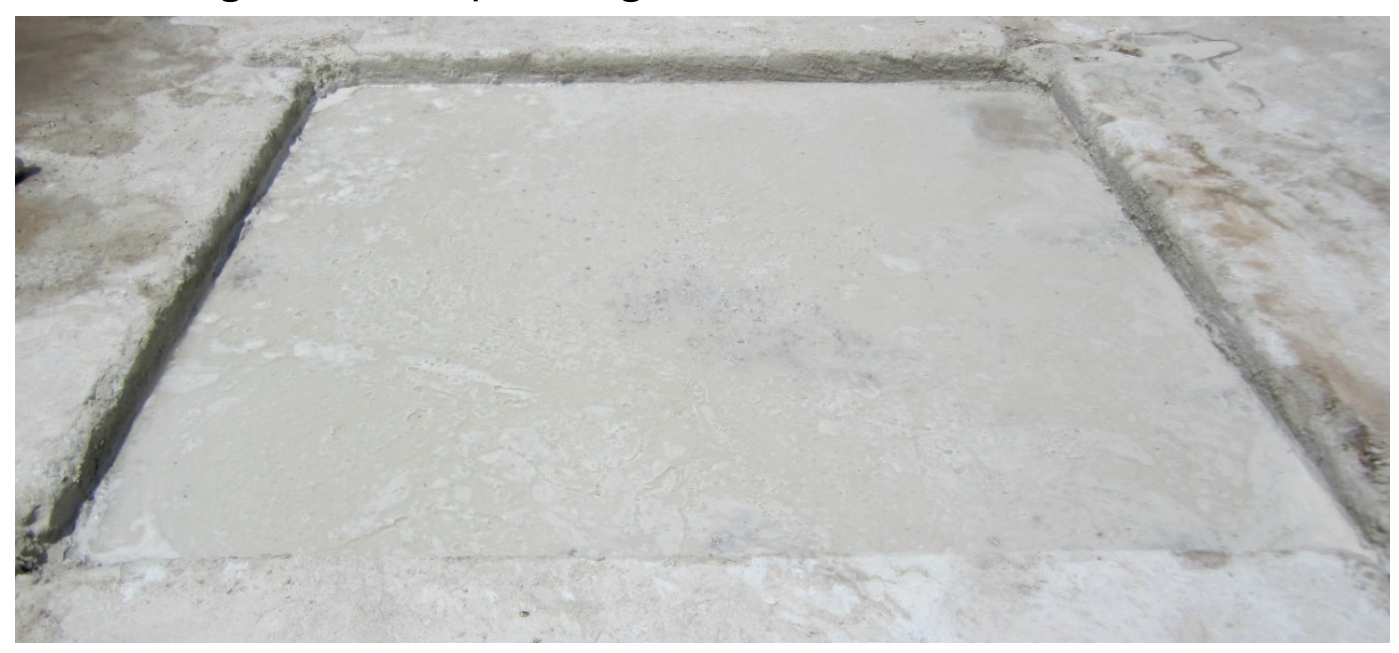




\section{Conclusions and Recommendations}

Proprietary RSC materials Fastrac 246 and Ulti-Pave ${ }^{\circledR}{ }^{\circledR}$ were successfully evaluated using full-scale simulated F-15 aircraft traffic after results from previous testing indicated that both products performed well during laboratory testing. Specific conclusions and recommendations developed are discussed in the following sections.

\subsection{Conclusions}

- Fastrac 246 repairs sustained 2,000 passes before failure, and UltiPave $3^{\circledR}$ repairs withstood 3,500 passes before trafficking was discontinued.

- Fastrac 246 was easily placed and finished and exhibited approximately 20 min longer working time than the currently approved rapid-setting concrete capping material (CTS Rapid-Set Concrete Mix ${ }^{\circledR}$ ) and Ulti-Pave $3^{\circledR}$.

- Fastrac 246 repairs all failed due to high severity spalling along the repair joints that were perpendicular to the traffic direction. These results are consistent with the failure modes observed previously for repairs capped with rapid-setting concrete. No classic structural distresses (i.e. shattered slabs or faulting) were observed.

- The higher compressive strength of Ulti-Pave ${ }^{\circledR}$ is a likely cause of its higher performance relative to Fastrac 246.

- Ulti-Pave $3^{\circledR}$ was placed and finished without any issues except for the necessity of engaging the vibrators on the SVM often to ensure the fibers in the dry material did not impede material from reaching the conveyor belt to be delivered to the mix auger. Typically, the vibrators can be set to automatic mode and do not require manual engagement for any length of time.

- CTS RSFF produced estimated CBRs that were considerably lower than the currently preferred rapid-setting flowable fill backfill material (Buzzi Unicem Utility Fill One-Step 750). The cause is expected by the researchers to be the reformulation of the product or the slow water percolation.

- Repairs backfilled with CTS RSFF exhibited standing water on the backfill surface up to 30 min after placement was completed, which is undesirable for RADR operations. 


\subsection{Recommendations}

- Fastrac 246 is not recommended for use as an RSC material for RADR operations. The material can be used for training, if desired, since it behaves relatively similar to the currently preferred RSC capping material during placement with the exception of a longer set time.

- A new formulation of Fastrac 246 with a higher compressive strength could potentially result in a material that is capable of meeting RADR performance requirements.

- Ulti-Pave $3^{\circledR}$ is recommended for use as a rapid-setting capping material for RADR operations. The recommended gate setting for the Cementech version of the SVM is 5.5 .

- Ulti-Pave $3{ }^{\circledR}$ was provided in 2,00o lb supersacks. Future procurements should require the vendor to provide $3,000 \mathrm{lb}$ supersacks to reduce the overall number of supersacks needed and to remain consistent with supersack quantities used in the interim RADR TTPs.

- An Ulti-Pave $3^{\circledR}$ formulation without fibers should be investigated to see if it can meet RADR performance requirements. Without the fibers, performance could be reduced slightly, but the need to engage SVM bin vibrators often would be eliminated.

- CTS RSFF in its present form is not recommended for use as a RSFF backfill for RADR operations due to the standing water present after dry method placement and low CBR results. The material can be used for training, if desired, since it is placed similarly to the preferred RADR RSFF backfill material. 


\section{References}

American Society for Testing and Materials (ASTM). 2018. Standard test method for compressive strength of cylindrical concrete specimens. Designation C39/C39M18. West Conshohocken, PA: American Society for Testing and Materials.

. 2017. Standard test method for flow consistency of controlled low strength material (CLSM). Designation D6103-17. West Conshohocken, PA: American Society for Testing and Materials.

. 2009. Standard test method for use of the dynamic cone penetrometer in shallow pavement applications. Designation D6951. In Annual book of ASTM standards. West Conshohocken, PA: American Society for Testing Materials.

Bell. H. P. 2017. Inclement weather crater repair tool kit. ERDC/GSL TR-17-26. Vicksburg, MS: U.S. Army Engineer Research and Development Center.

Bell. H. P., C. L. Dean, and C. A. Rutland. 2018. Wet weather crater repair methods for grooved and smooth pavements. ERDC/GSL TR-18-6. Vicksburg, MS: U.S. Army Engineer Research and Development Center.

Bell, H. P., L. Edwards, W. D. Carruth, J. S. Tingle, and J. R. Griffin. 2013. Wet weather crater repair testing at Silver Flag Exercise Site, Tyndall Air Force Base, Florida. ERDC/GSL TR-13-42. Vicksburg, MS: U.S. Army Engineer Research and Development Center.

Bell, H. P., L. P. Priddy, Q. S. Mason, and C. A. Rutland. 2015. Concrete cutting refinement for crater repair. ERDC/GSL TR-13-42. Vicksburg, MS: U.S. Army Engineer Research and Development Center.

Bell. H. P., and J. Rowland. 2017. Next generation airfield damage repair: Deployable saw technologies. ERDC/GSL TR-17-26. Vicksburg, MS: U.S. Army Engineer Research and Development Center.

Carruth, W. D., and I. L. Howard. 2016. Evaluation of flowable fill surface performance. ERDC/GSL TR-16-33 Vicksburg, MS: U.S. Army Engineer Research and Development Center.

Carruth, W. D., L. Edwards, H. P. Bell, J. S. Tingle, J. R. Griffin, and C. A. Rutland. 2015. Large crater repair at silver flag exercise site, Tyndall Air Force Base, Florida. ERDC/GSL TR-15-27. Vicksburg, MS: U.S. Army Engineer Research and Development Center.

Cox, B. C., and T. A. Carr. 2018. Camouflet repair alternatives. ERDC/GSL TR-18-20. Vicksburg, MS: U.S. Army Engineer Research and Development Center.

Cox, B. C., and N. R. Hoffman. 2019. Development of an Integrated Pavement Screed for Screeding Asphalt or Concrete Crater Repairs. ERDC/GSL TR-19-39. Vicksburg, MS: U.S. Army Engineer Research and Development Center. 
Edwards, L., H. P. Bell, W. D. Carruth, J. R. Griffin, and J. S. Tingle. 2013. Cold weather crater repair testing at Malmstrom Air Force Base, Montana. ERDC/GSL TR13-32. Vicksburg, MS: U.S. Army Engineer Research and Development Center.

Edwards, L., W. D. Carruth, J. S. Tingle, and I. L. Howard. 2018. Rapid-Setting flowable fill performance in cold weather for airfield damage repair. ERDC/GSL TR-1826. Vicksburg, MS: U.S. Army Engineer Research and Development Center.

Priddy, L. P., H. P. Bell, L. Edwards, W. D. Carruth, and J. F. Rowland. 2016. Evaluation of the structural performance of Rapid Set Concrete Mixß. ERDC/GSL TR-1620. Vicksburg, MS: U.S. Army Engineer Research and Development Center.

Priddy, L. P., J. R. Griffin, and J. S. Tingle. 2011. Live-flight certification testing of CRATR technologies, Avon Park Air Force Range, Florida. ERDC/GSL TR-11-7. Vicksburg, MS: US Army Engineer Research and Development Center.

Priddy, L. P., J. S. Tingle, M. C. Edwards, J. R. Griffin, and T. J. McCaffrey. 2013 a. Critical Runway Assessment and Repair (CRATR) technology demonstration: Limited Operational Utility Assessment 2 (LOUA2), Tyndall Air Force Base, Florida. ERDC/GSL TR-13-39. Vicksburg, MS: U.S. Army Engineer Research and Development Center.

Priddy, L. P., J. S. Tingle, J. R. Griffin, M. C. Edwards, and T. J. McCaffrey. 2013b. Critical Runway AssessmenT and Repair (CRATR) technology demonstration: Operational Utility Assessment (OUA), Avon Park Air Force Range, Florida. ERDC/GSL TR-13-33. Vicksburg, MS: U.S. Army Engineer Research and Development Center.

Tingle, J. S., L. P. Priddy, M. C. Edwards, C. A. Gartrell, and T. J. McCaffrey. 2009. Critical Runway Assessment and Repair (CRATR) technology demonstration: Limited Operational Utility Assessment 1 (LOUA1), Tyndall Air Force Base, Florida. ERDC/GSL TR-09-12. Vicksburg, MS: U.S. Army Engineer Research and Development Center.

United States Air Force (USAF). 1992. Crushed-stone cater repair and line-of-sight profile measurement for rapid runway repair. TO 35E2-5-1. Washington, DC: United States. 


\section{Appendix A: Repair Material Certification Results}


Table A1. Fastrac \#246 Laboratory repair material certification protocol results.

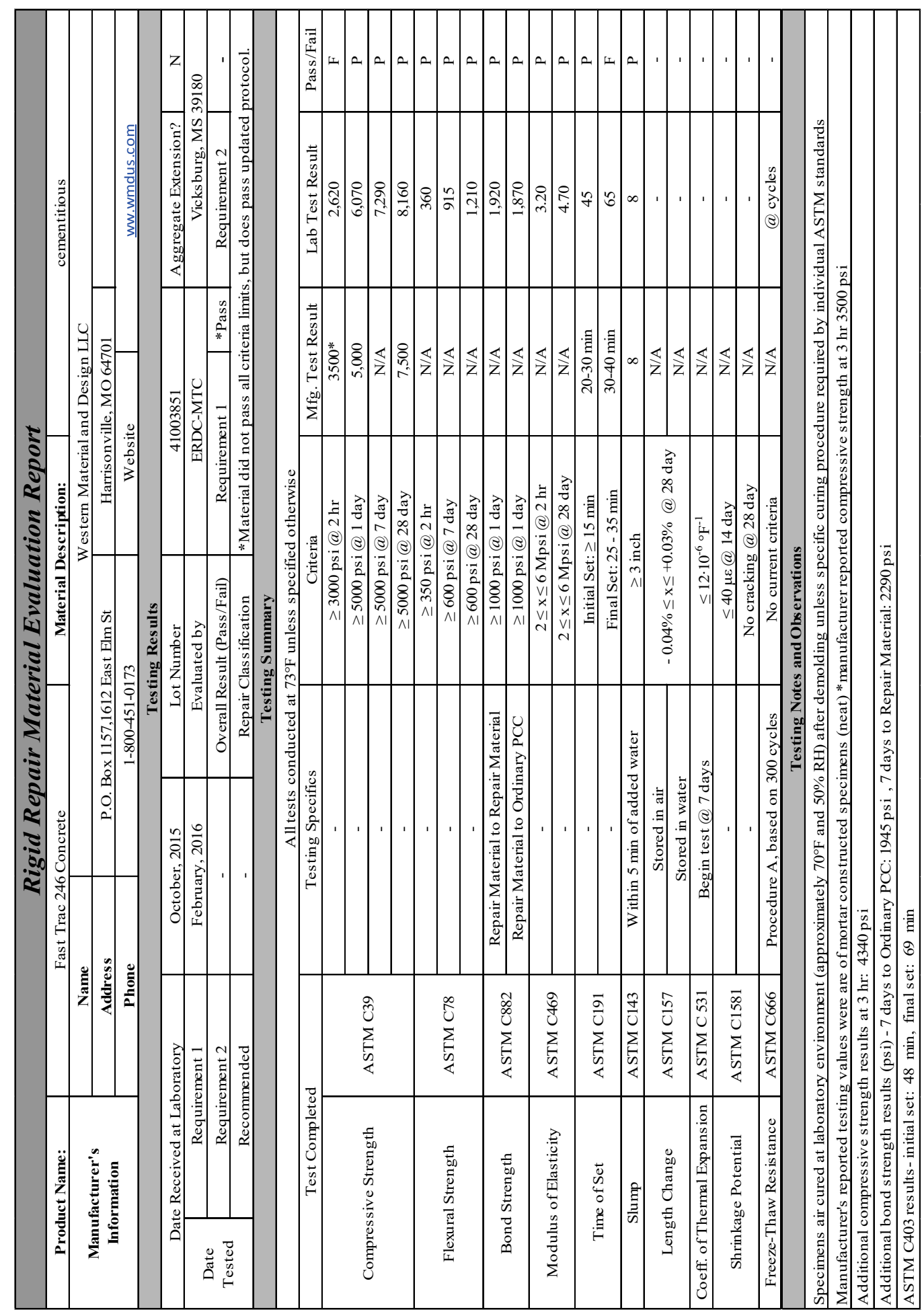


Table A2. Ulti-Pave3 Laboratory repair material certification protocol results.

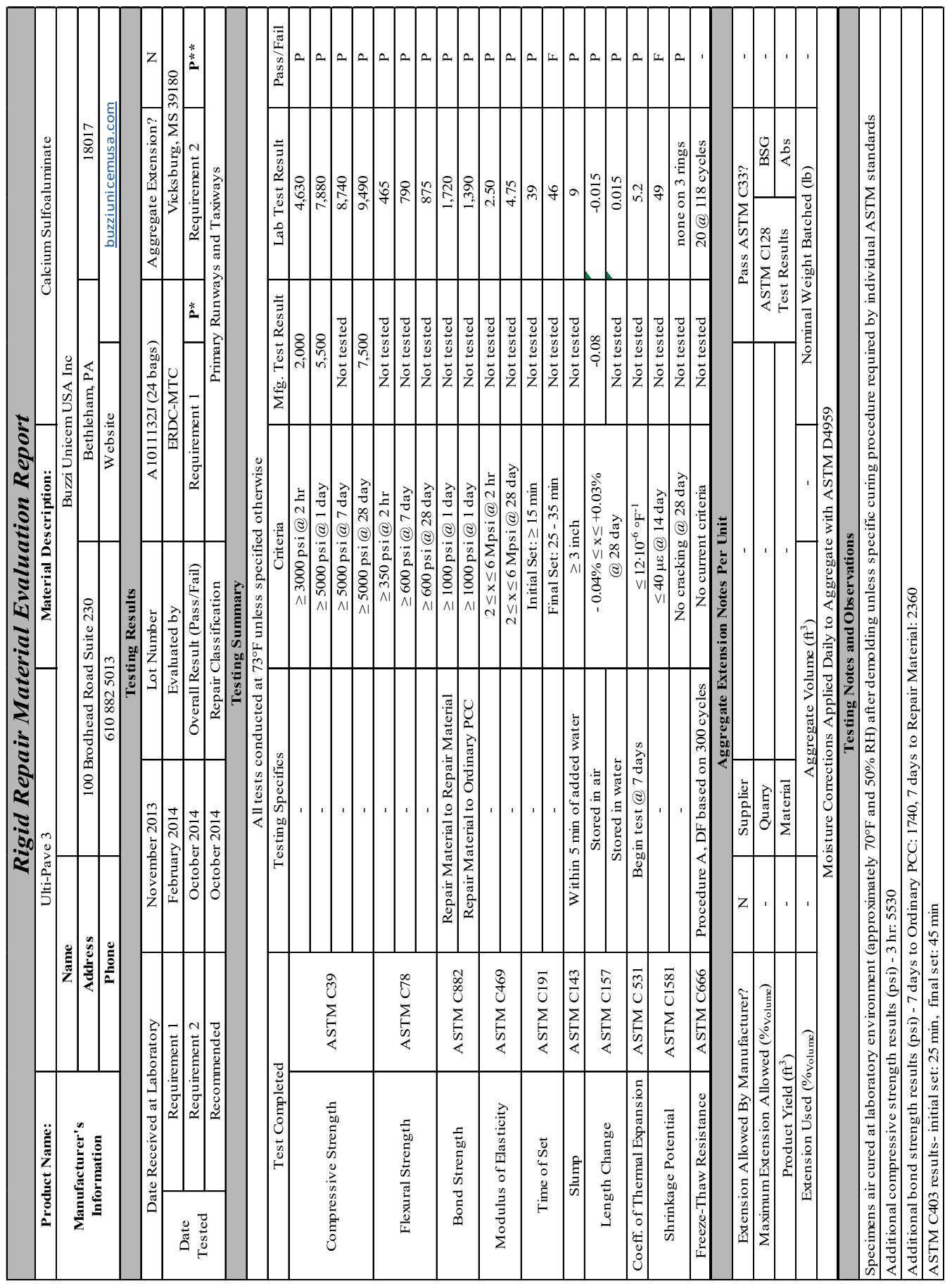




\section{Appendix B: Dynamic Cone Penetrometer (DCP) Data}


Figure B1. Repair 1, Test 1 DCP data.

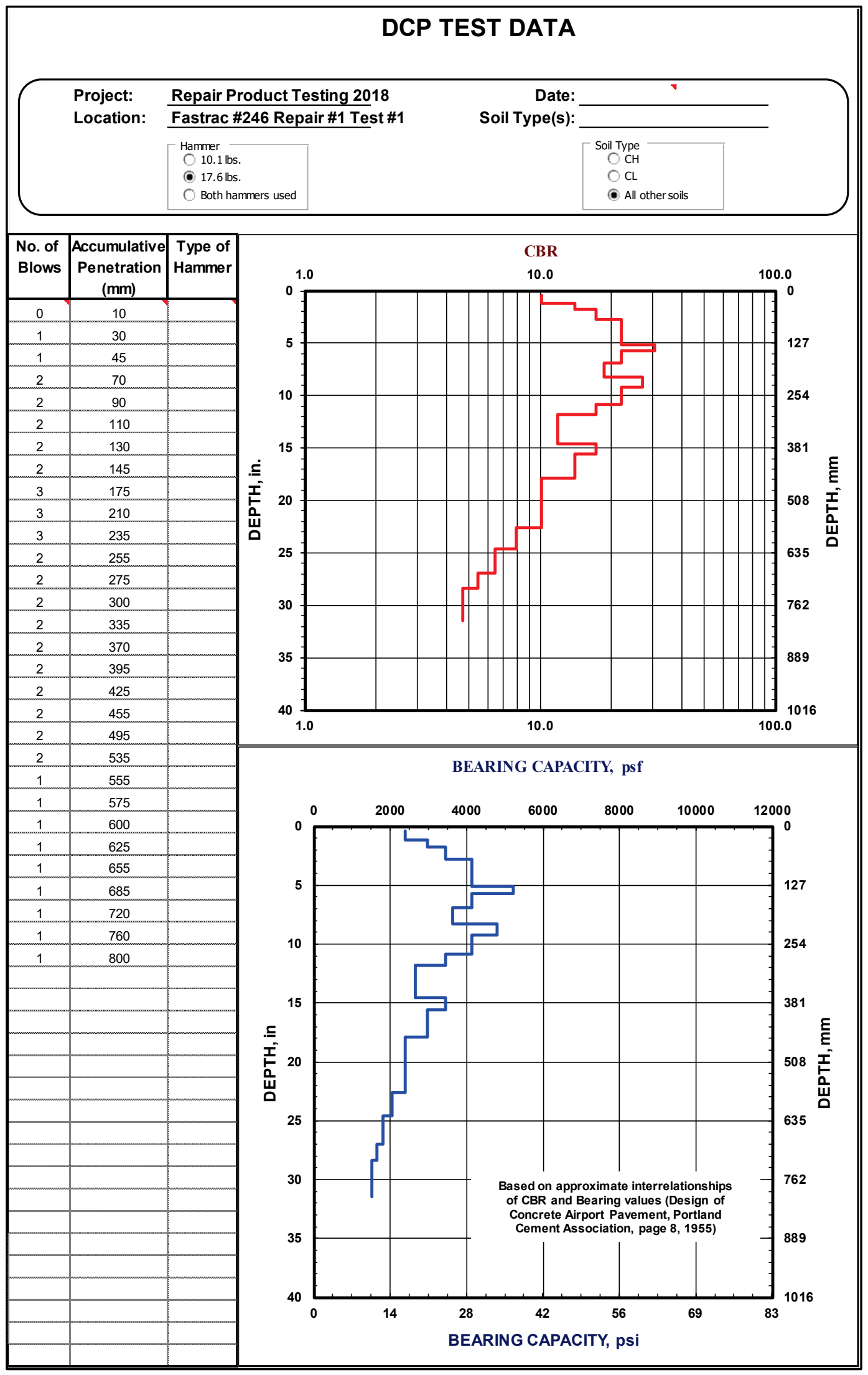


Figure B2. Repair 1. Test 2 DCP data.

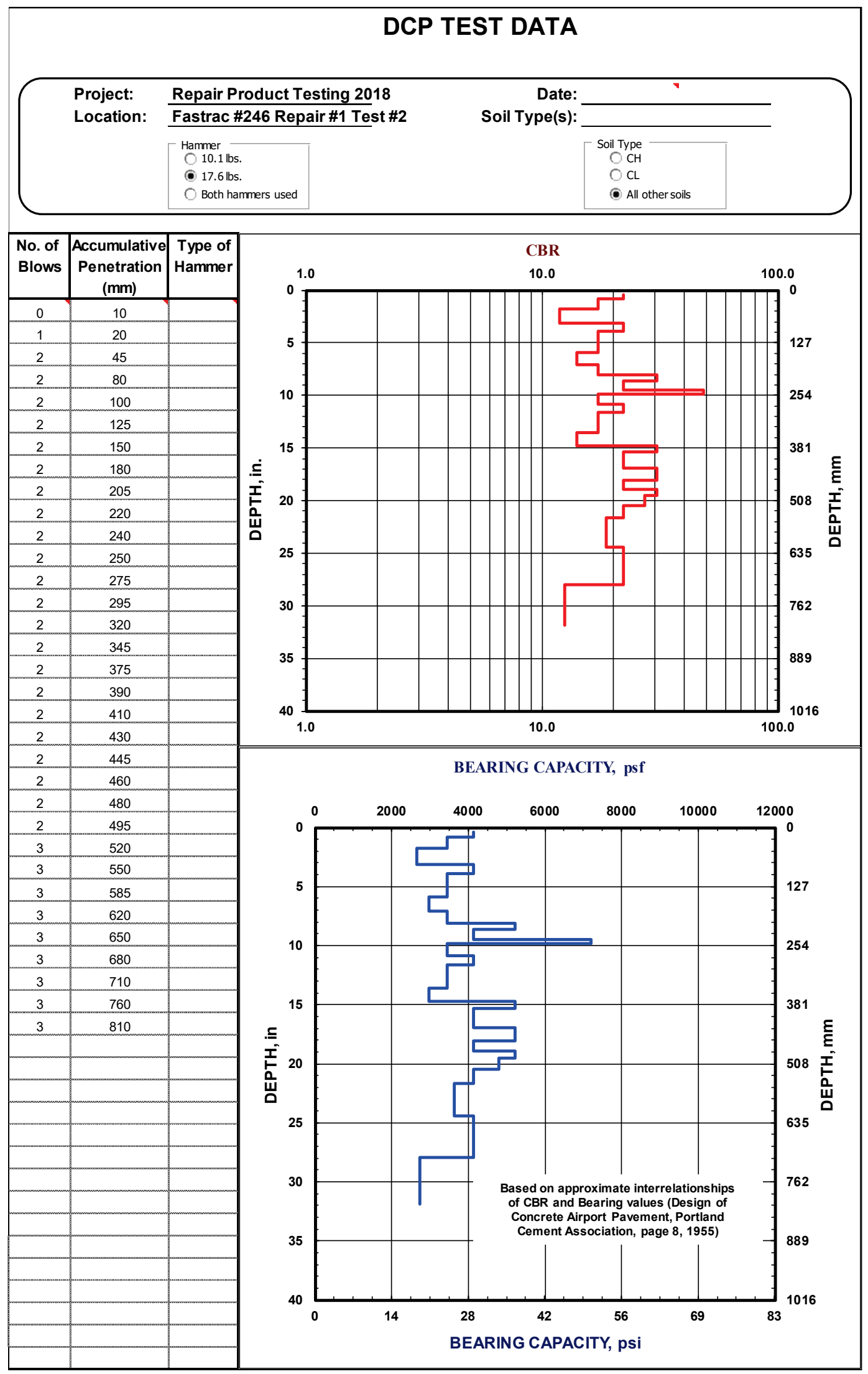


Figure B3. Repair 1. Test 3 DCP data.

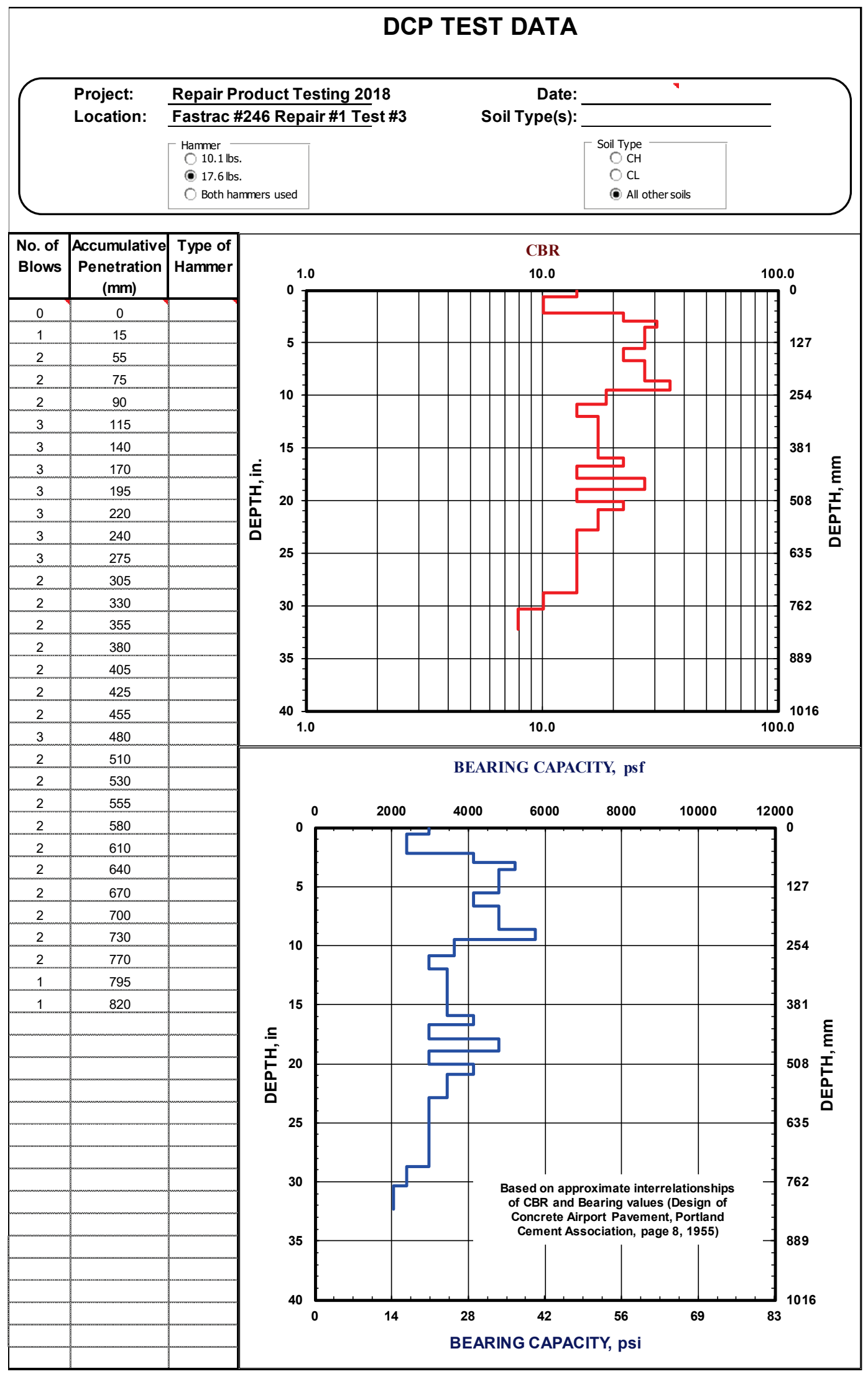


Figure B4. Repair 2, Test 1 DCP data.

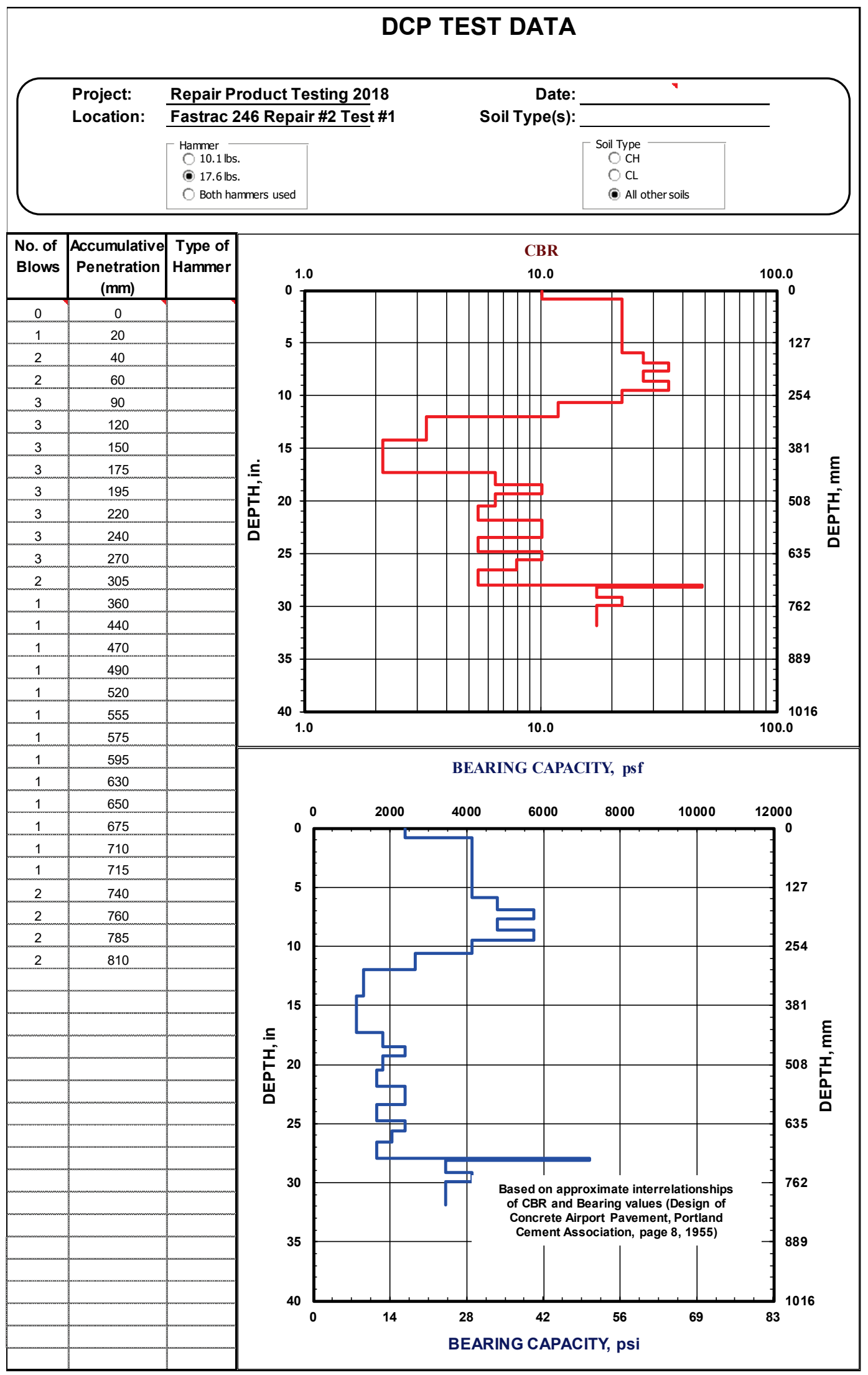


Figure B5. Repair 2, Test 2 DCP data.

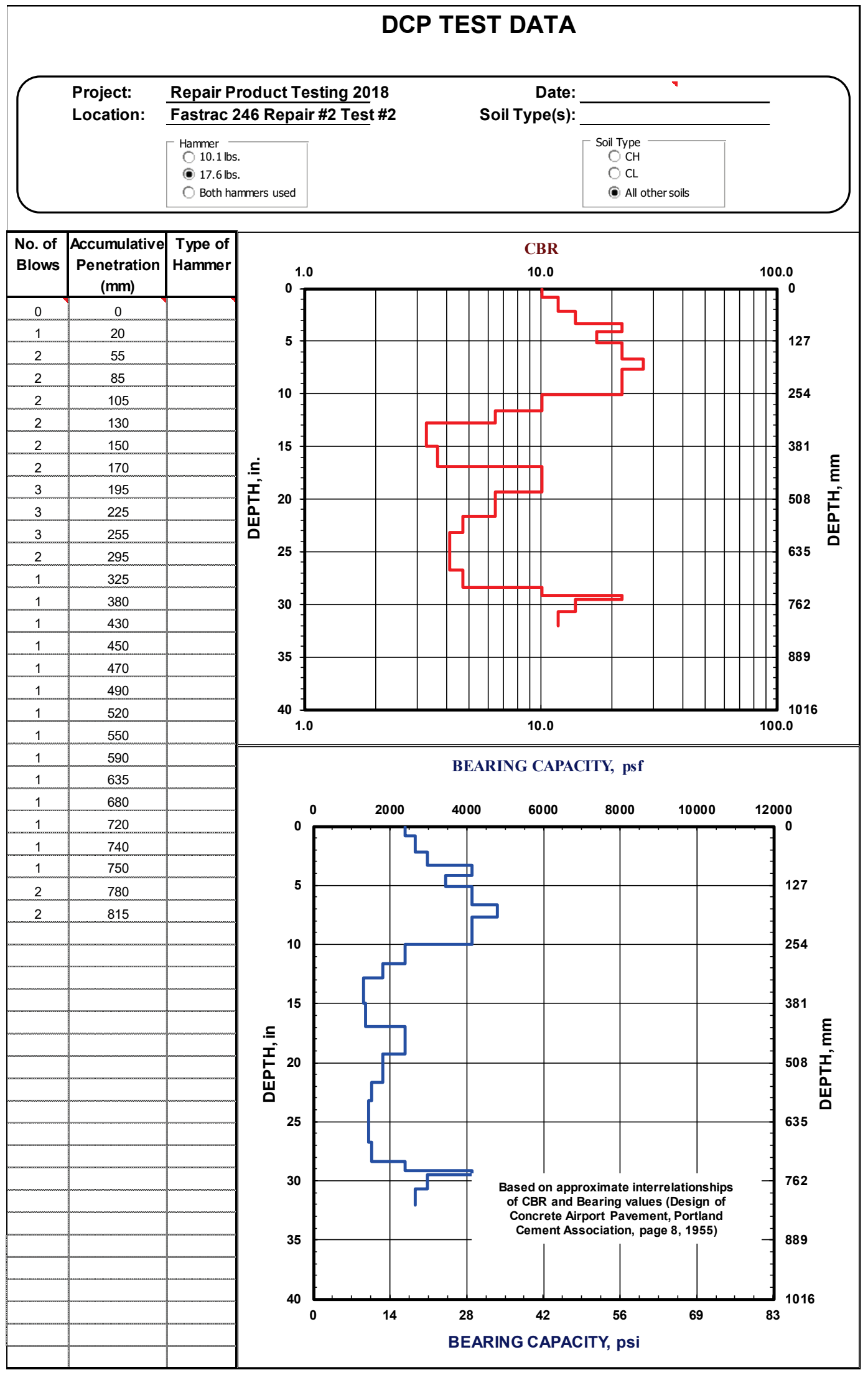


Figure B6. Repair 2, Test 3 DCP data.

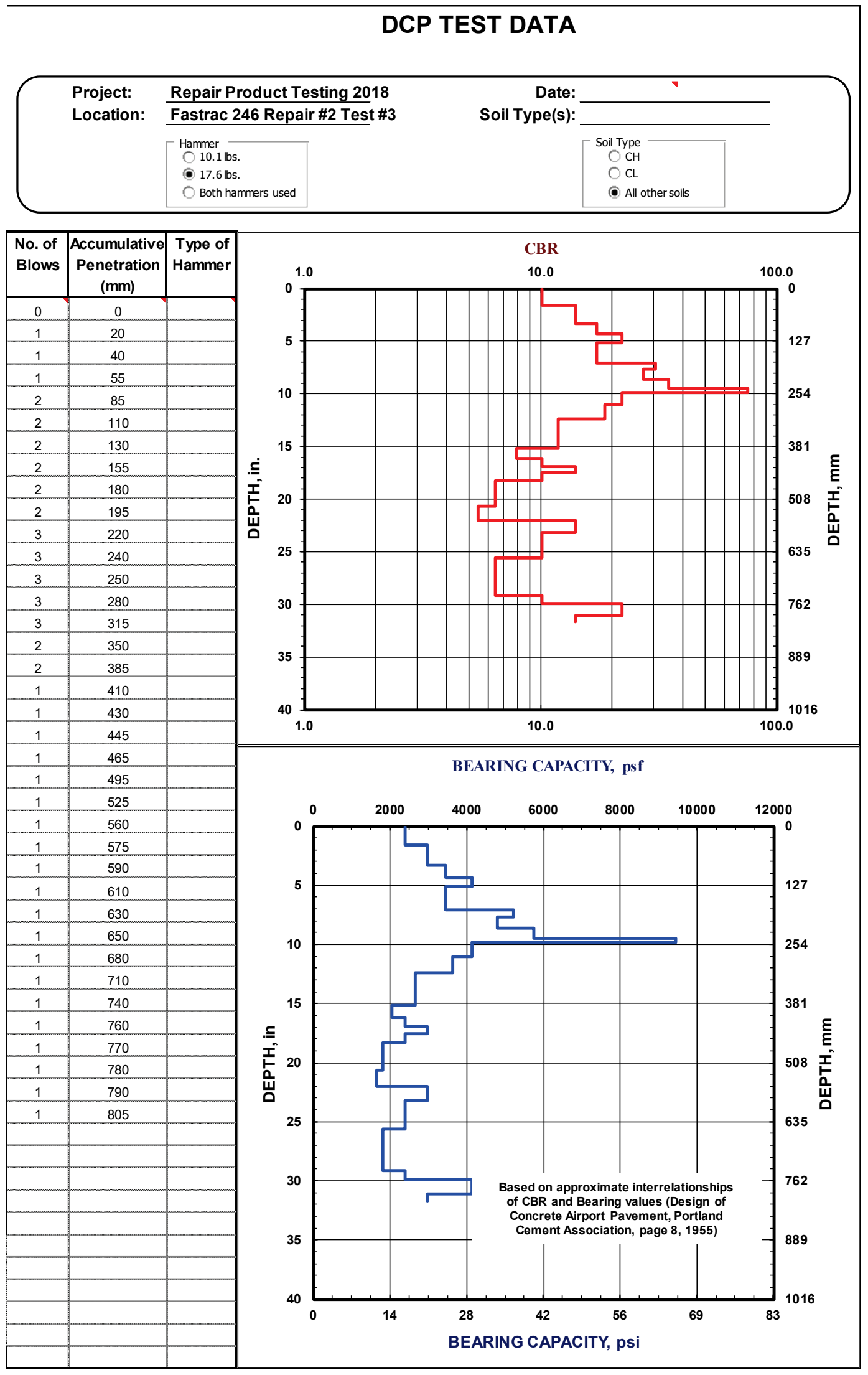


Figure B7. Repair 3, Test 1 DCP data.

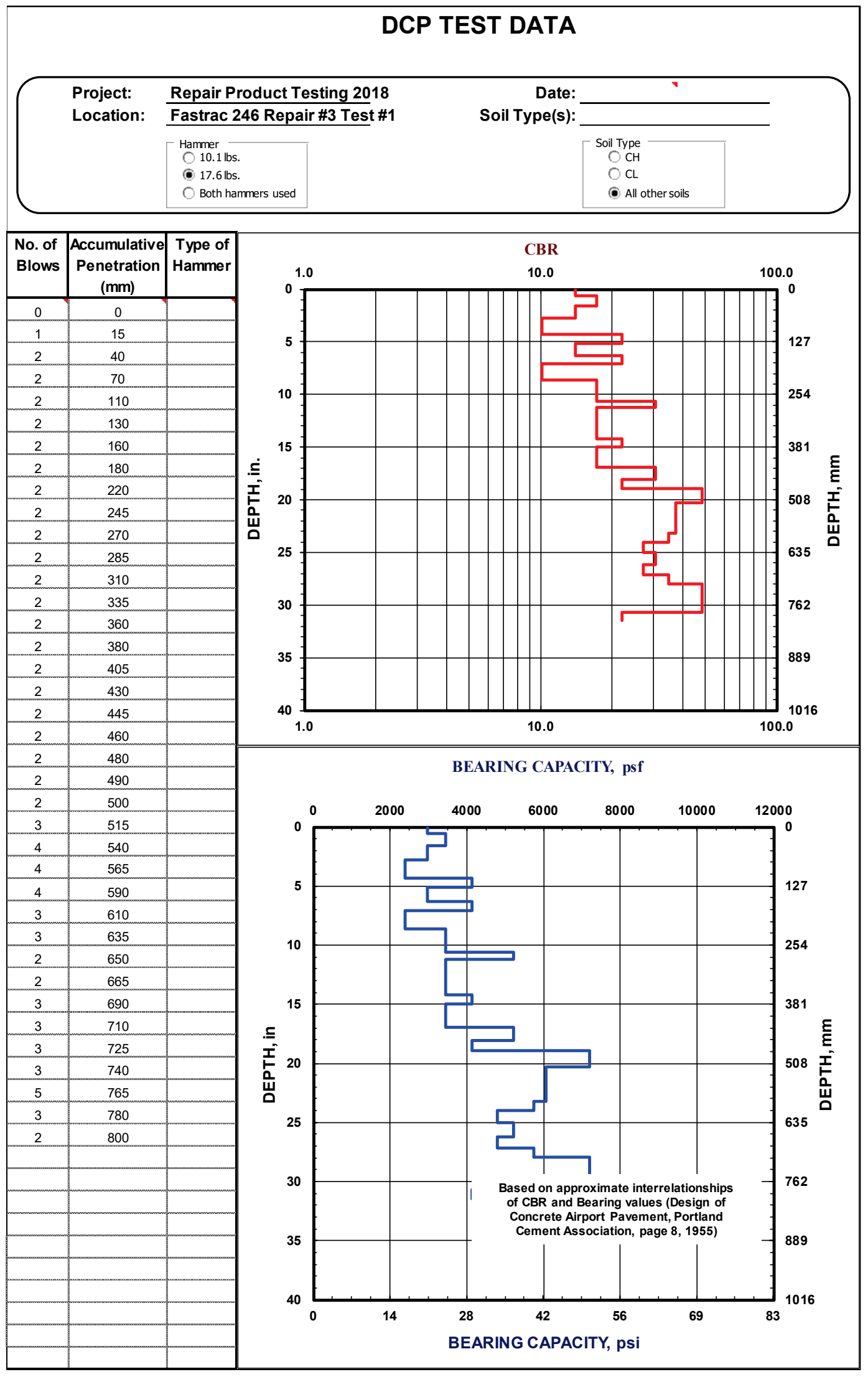


Figure B8. Repair 3, Test 2 DCP data.

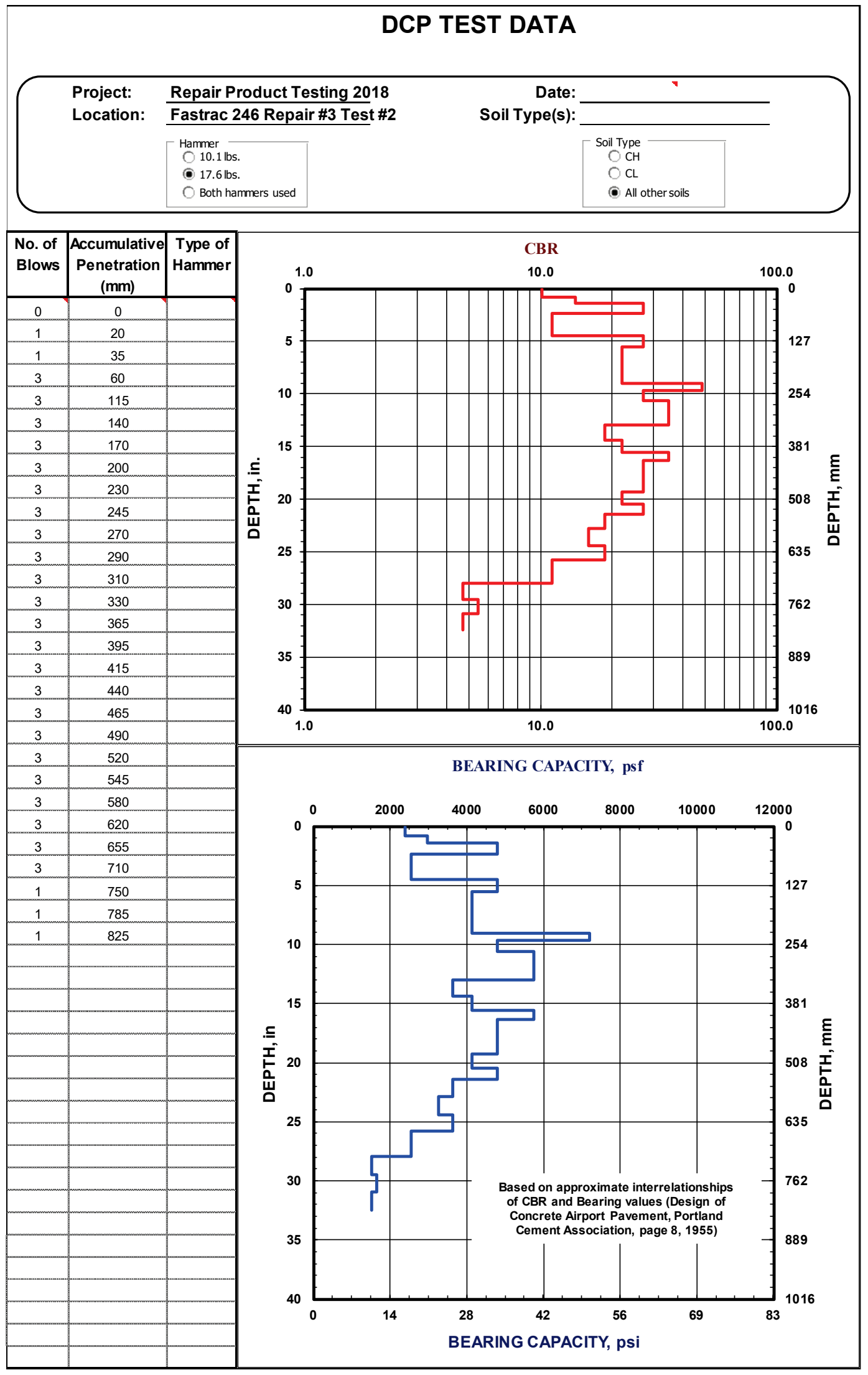


Figure B9. Repair 3, Test 3 DCP data.

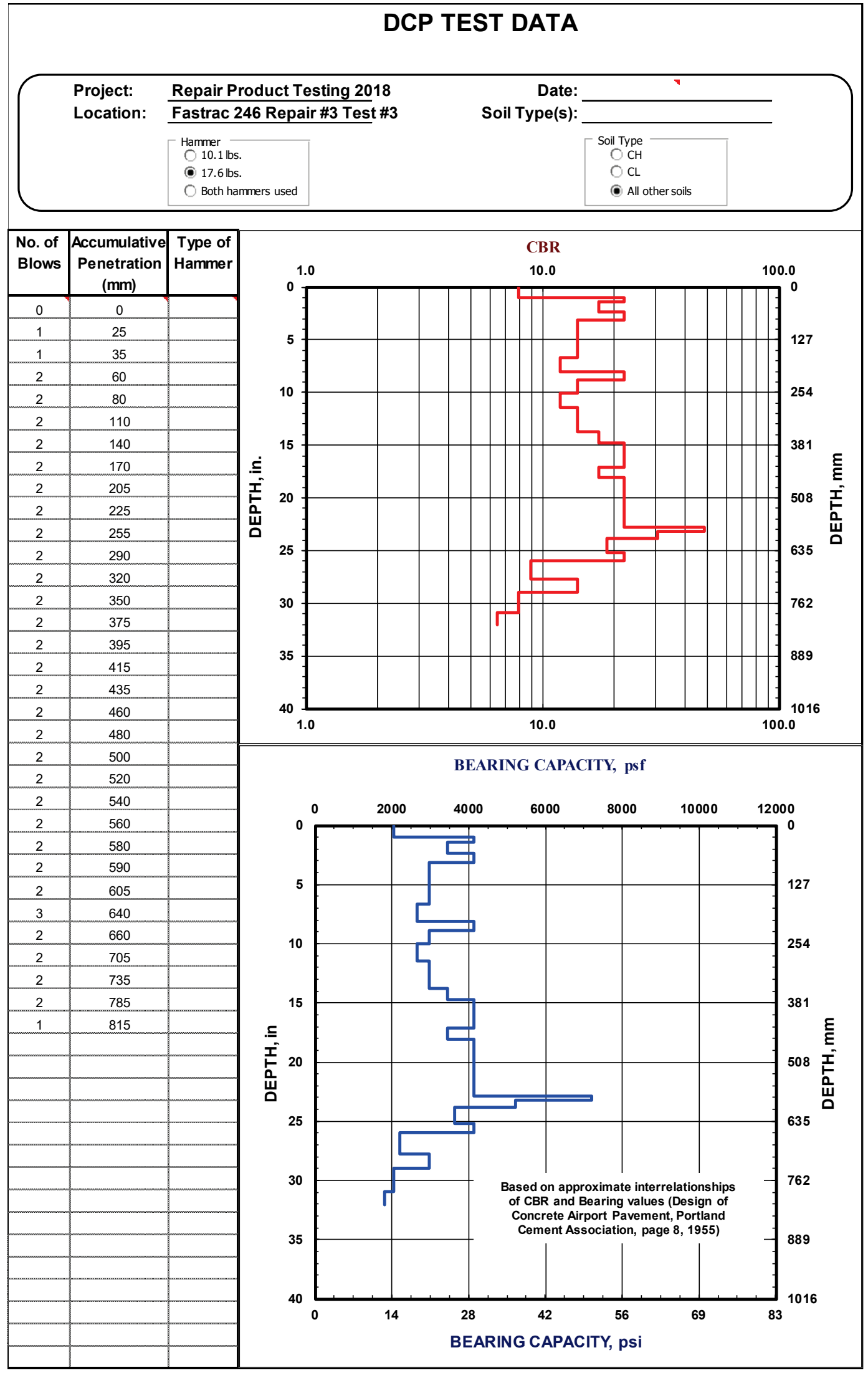


Figure B10. Repair 4, Test 1 DCP data.

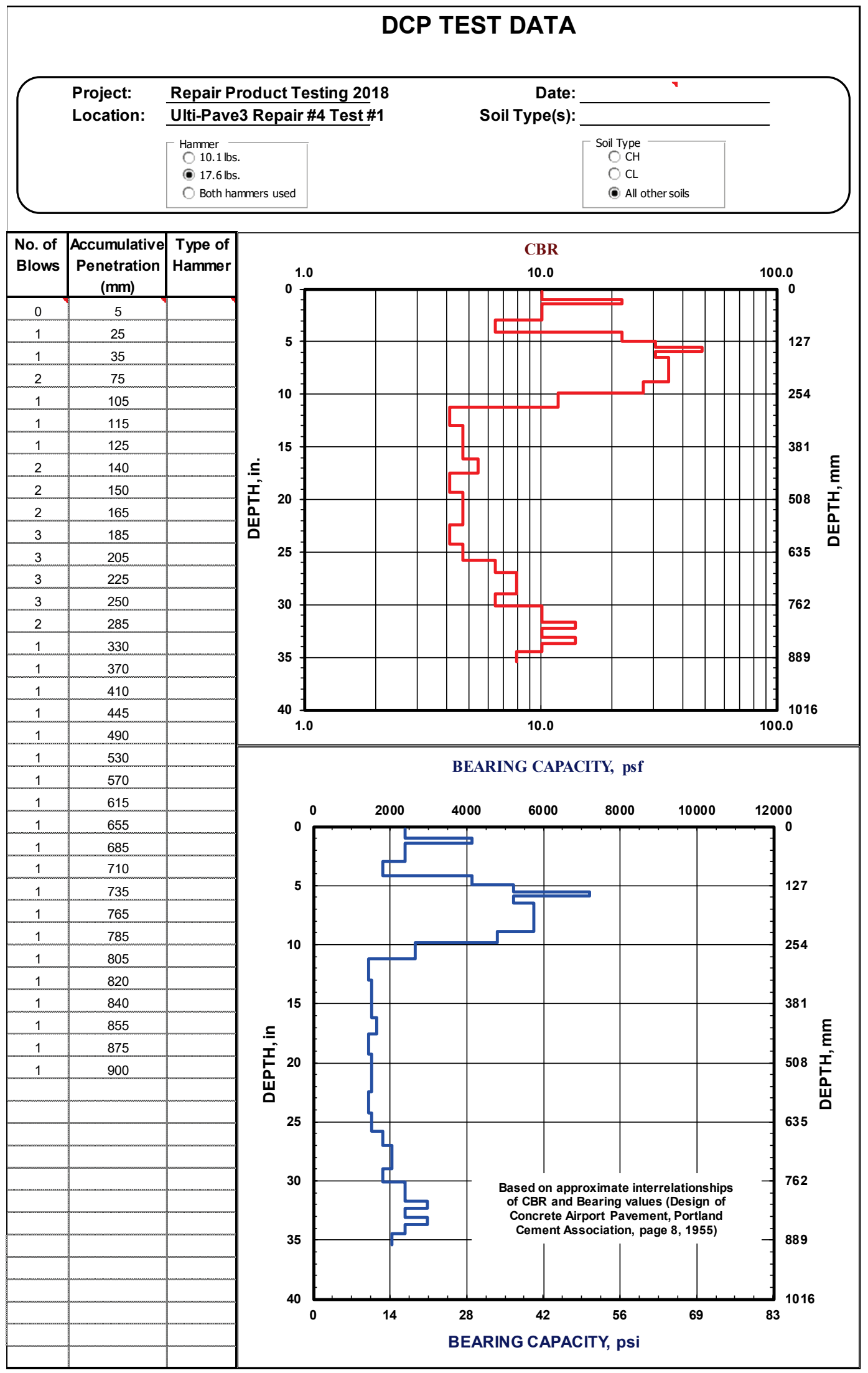


Figure B11. Repair 4, Test 2 DCP data.

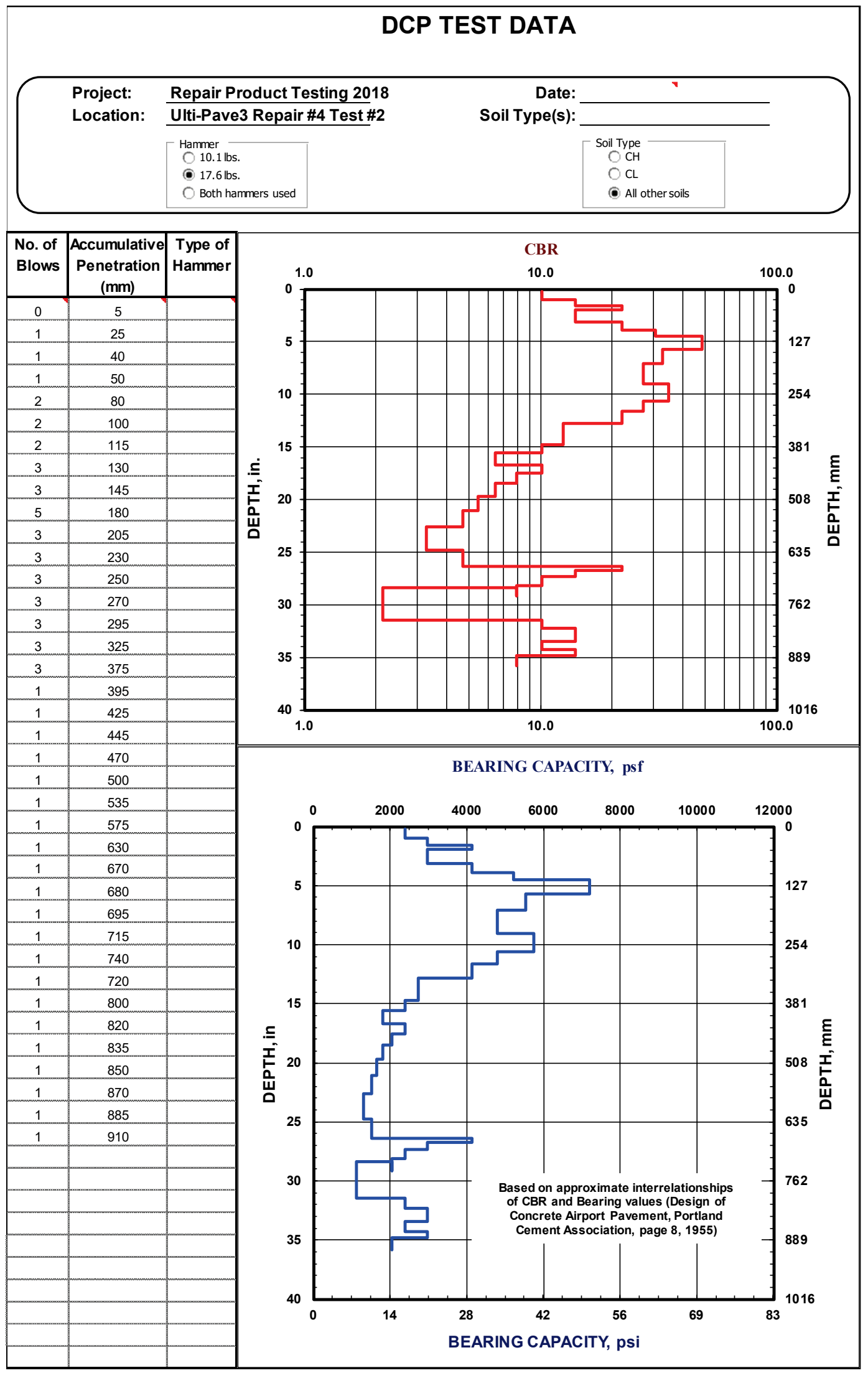


Figure B12. Repair 4, Test 3 DCP data.

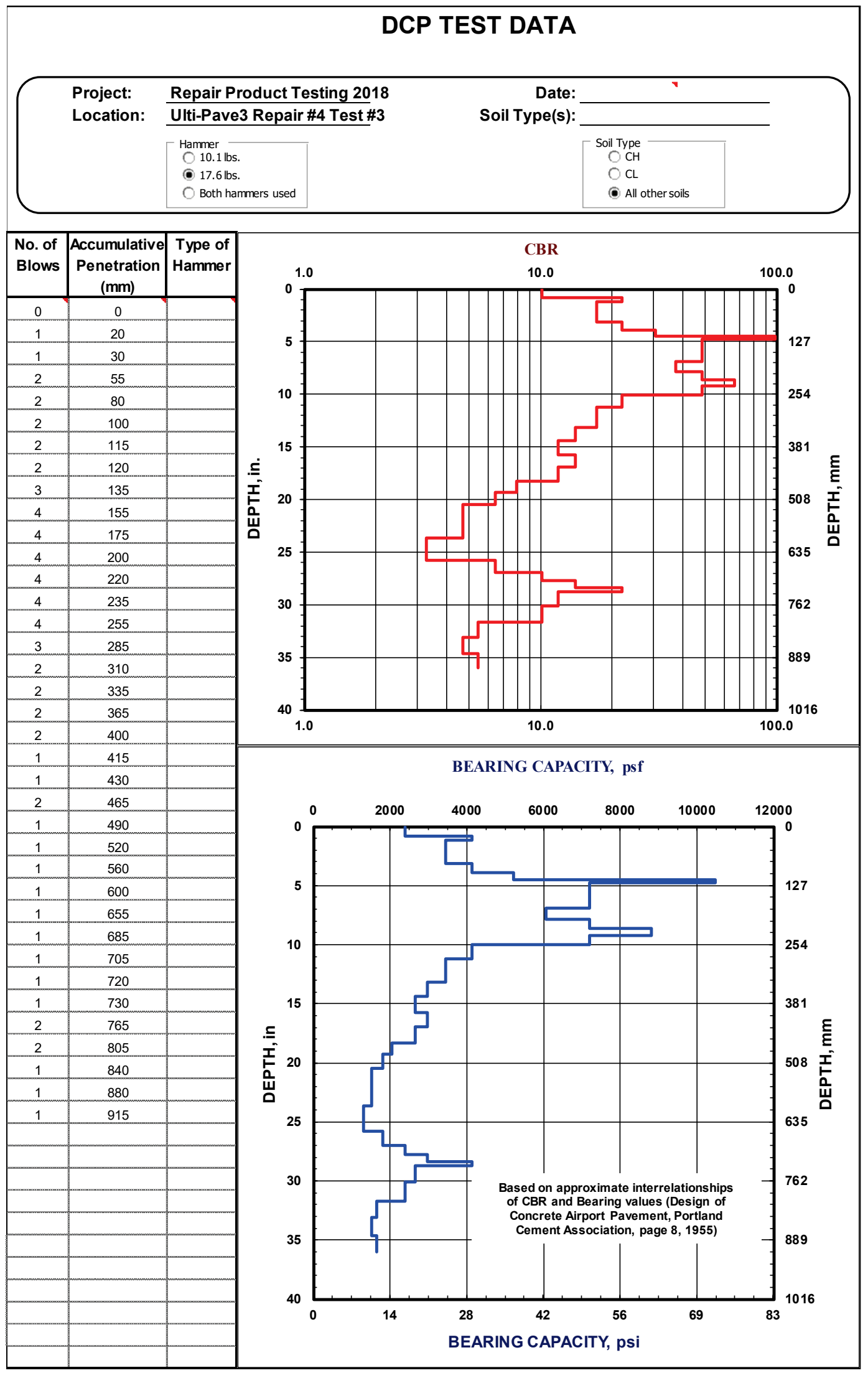


Figure B13. Repair 5, Test 1 DCP data.

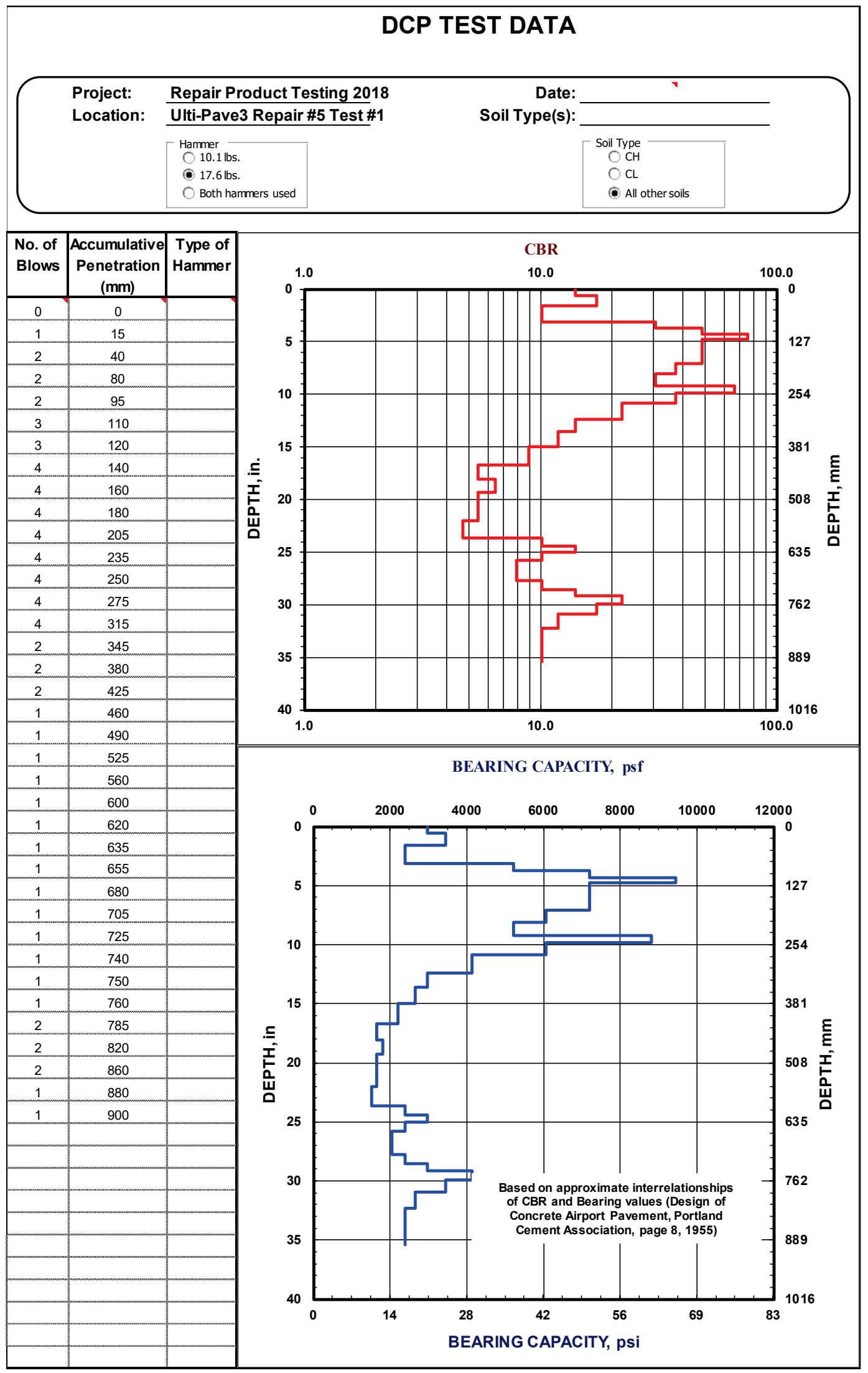


Figure B14. Repair 5, Test 2 DCP data.

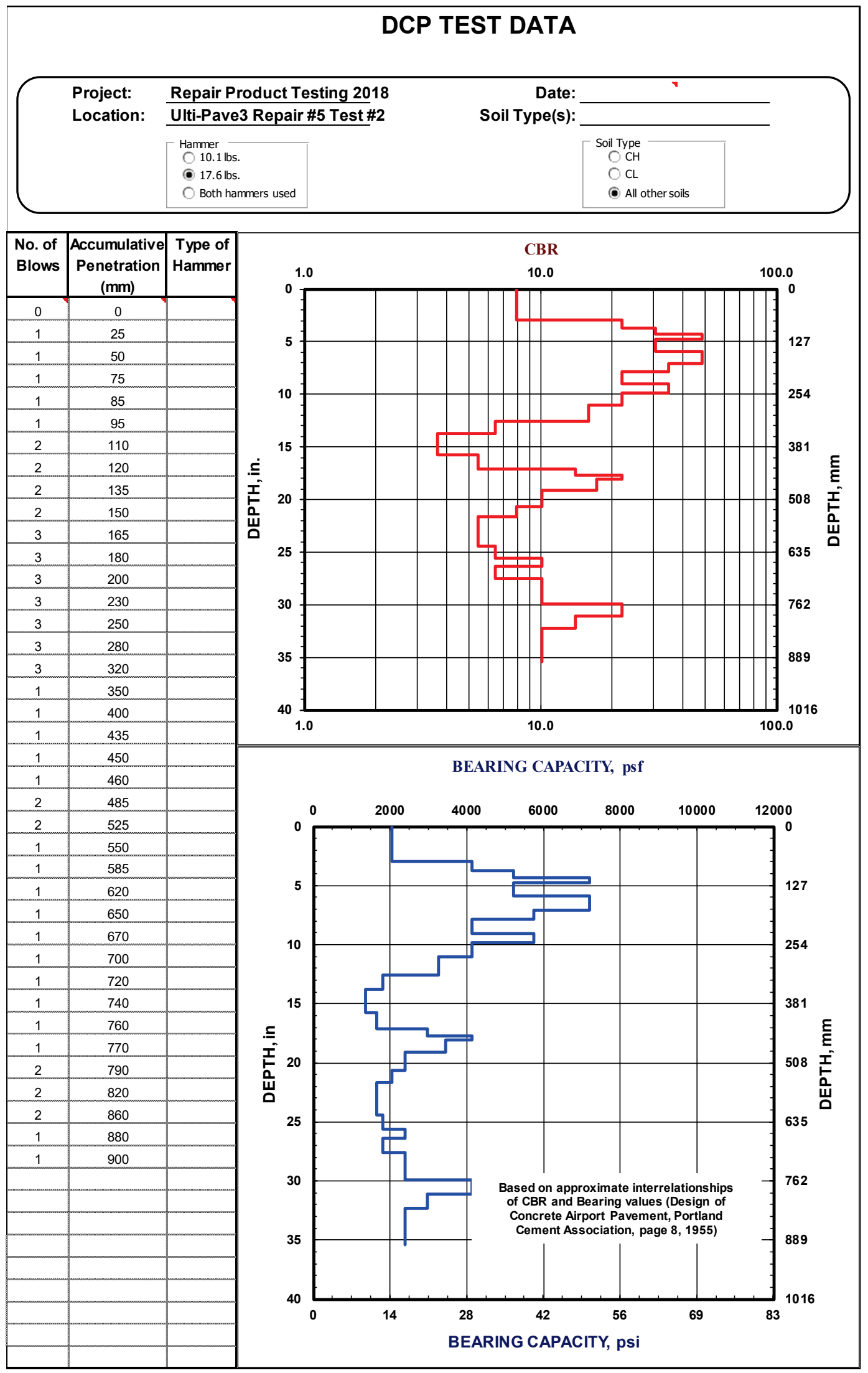


Figure B15. Repair 5, Test 3 DCP data.

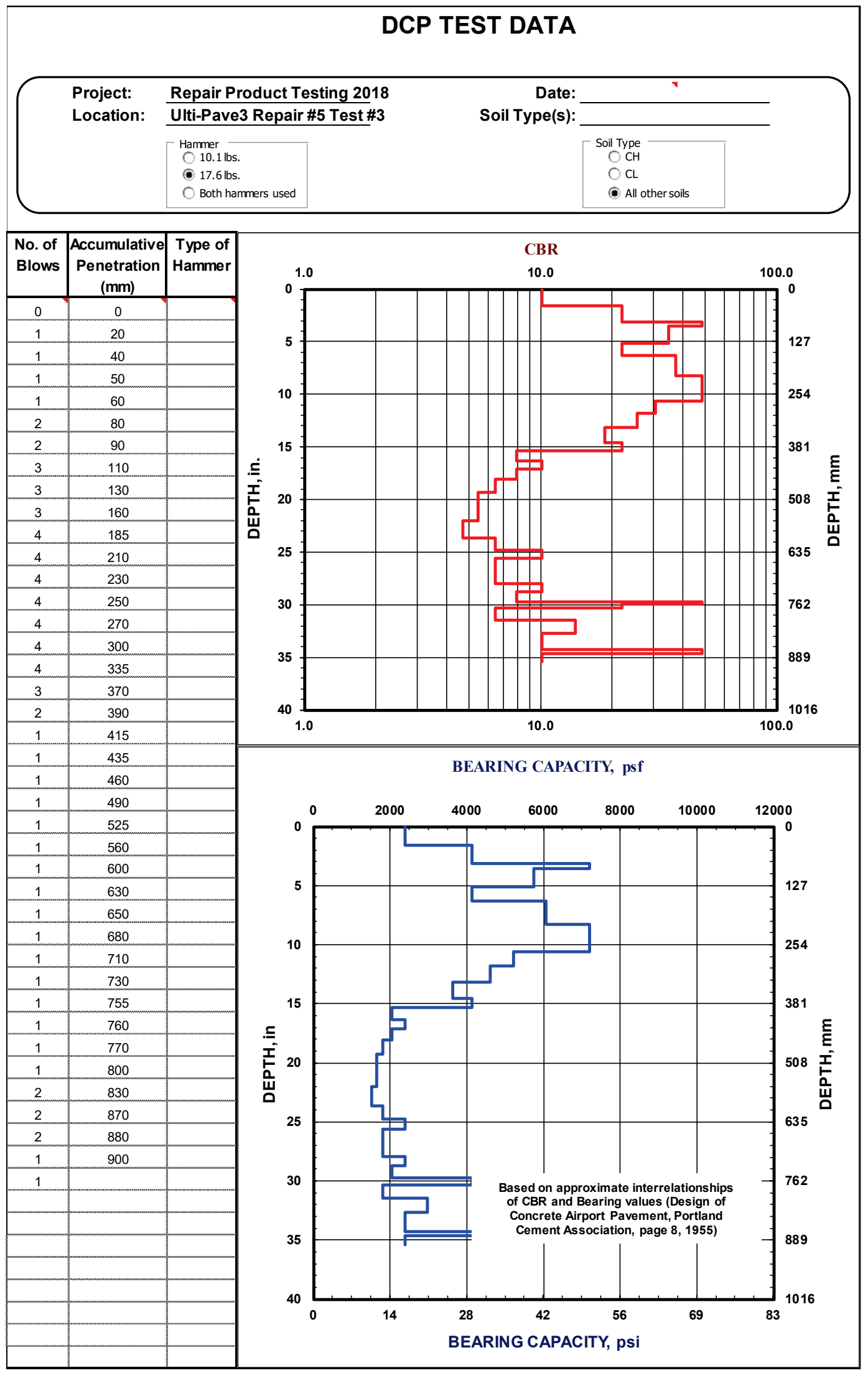


Figure B16. Repair 6, Test 1 DCP data.

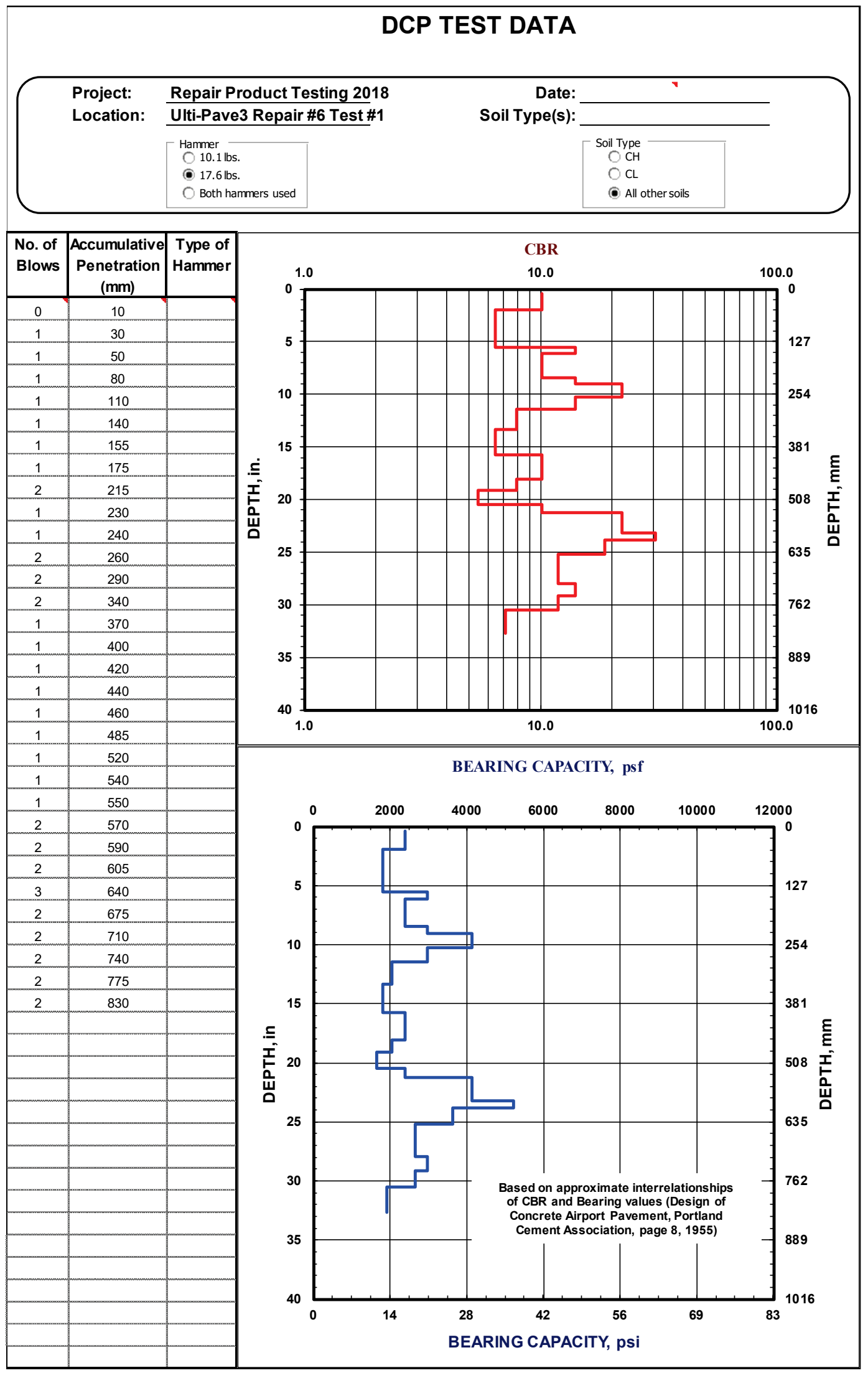


Figure B17. Repair 6, Test 2 DCP data.

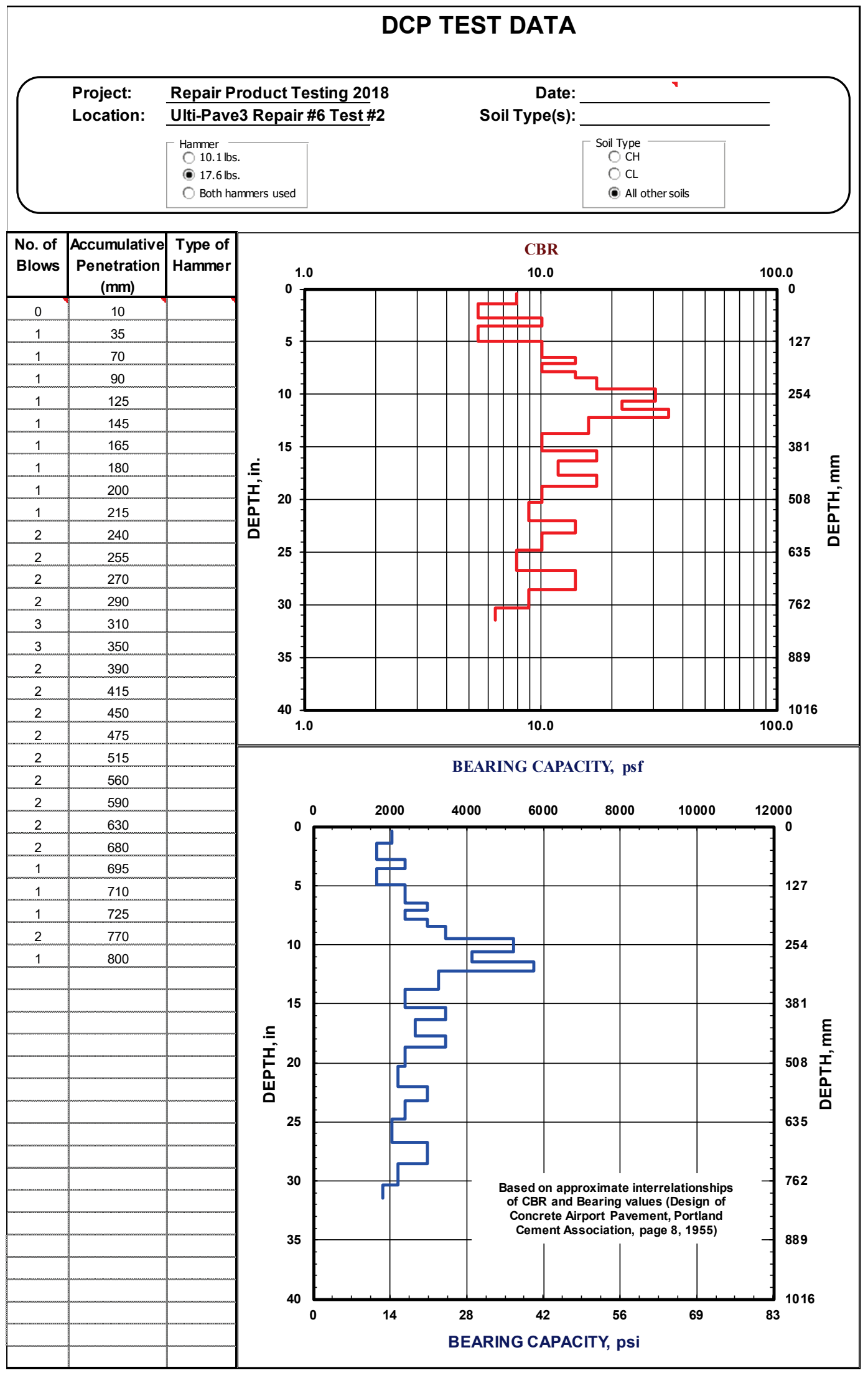


Figure B18. Repair 6, Test 3 DCP data.

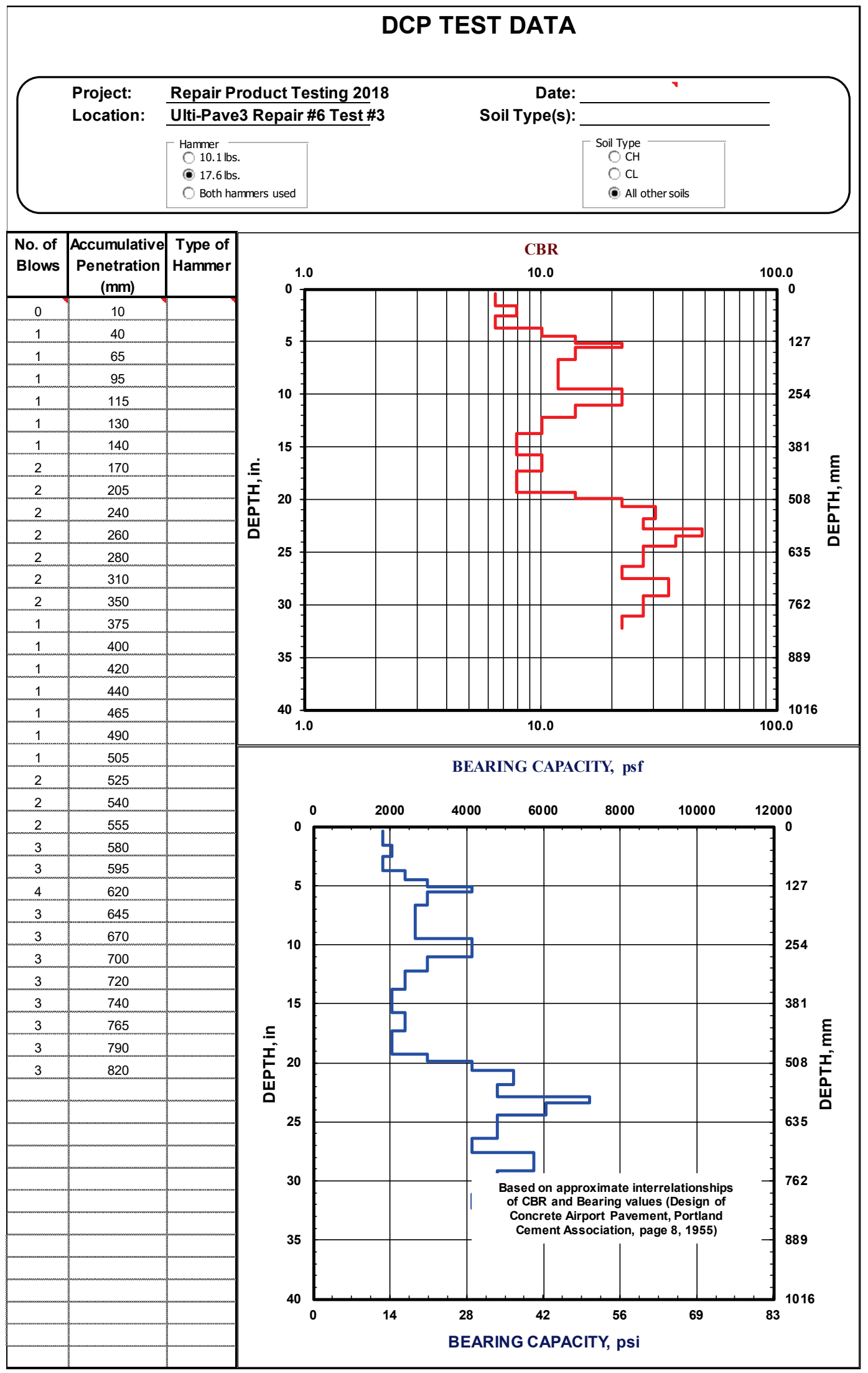


Figure B19. Repair FF-1, Test 1, DCP data at 30 min cure time.

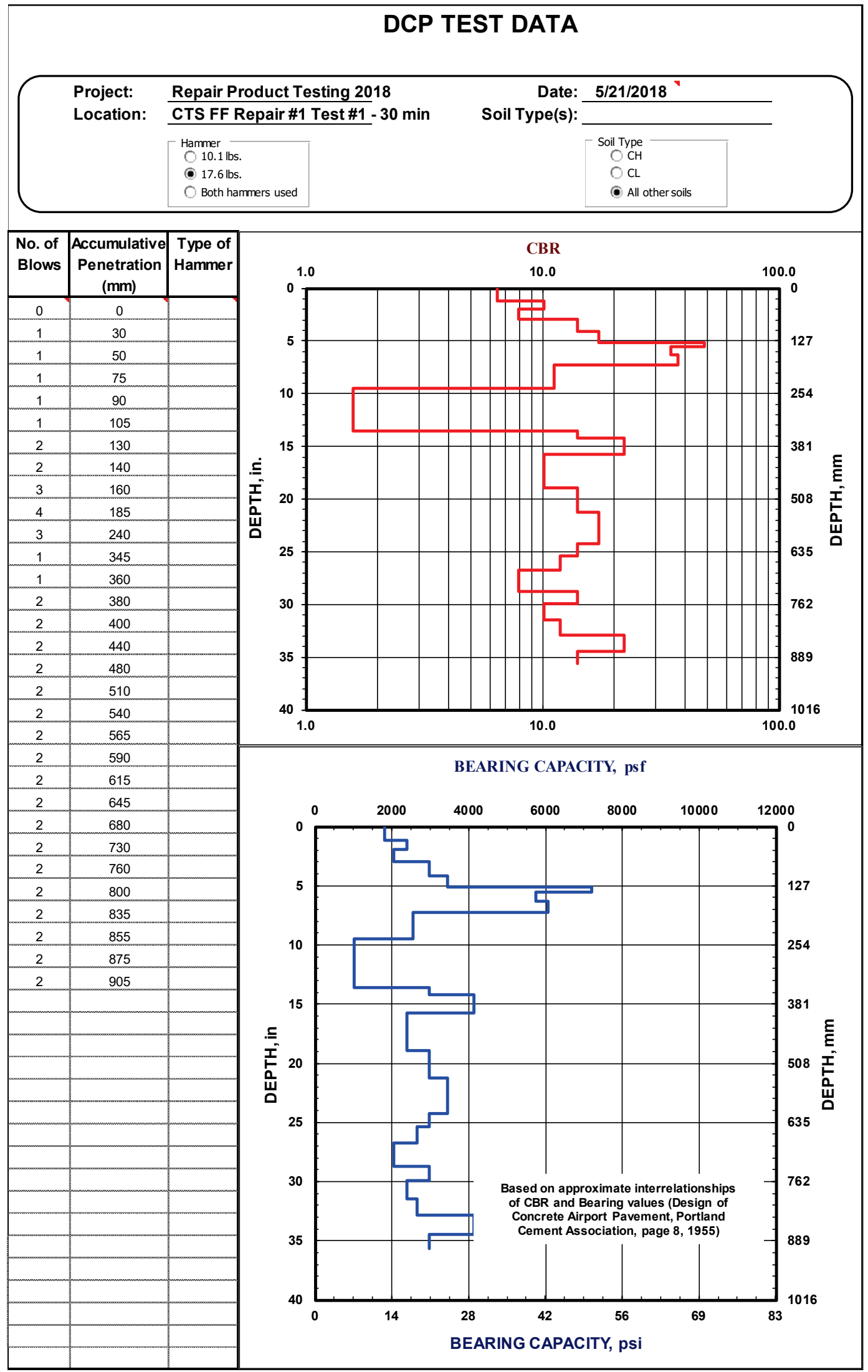


Figure B20. Repair FF-1, Test 2, DCP data at 30 min cure time.

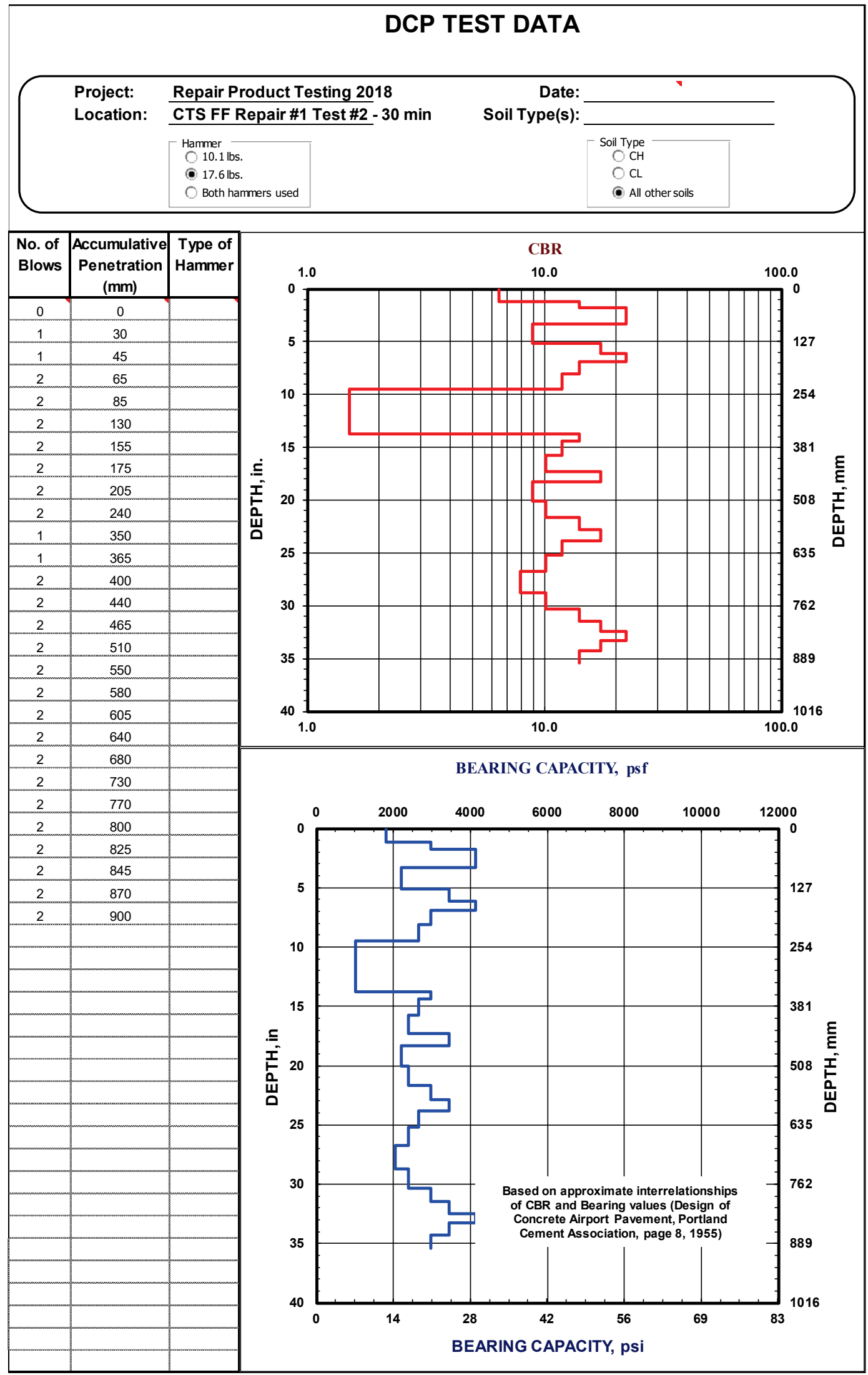


Figure B21. Repair FF-1, Test 1, DCP data at 30 min cure time.

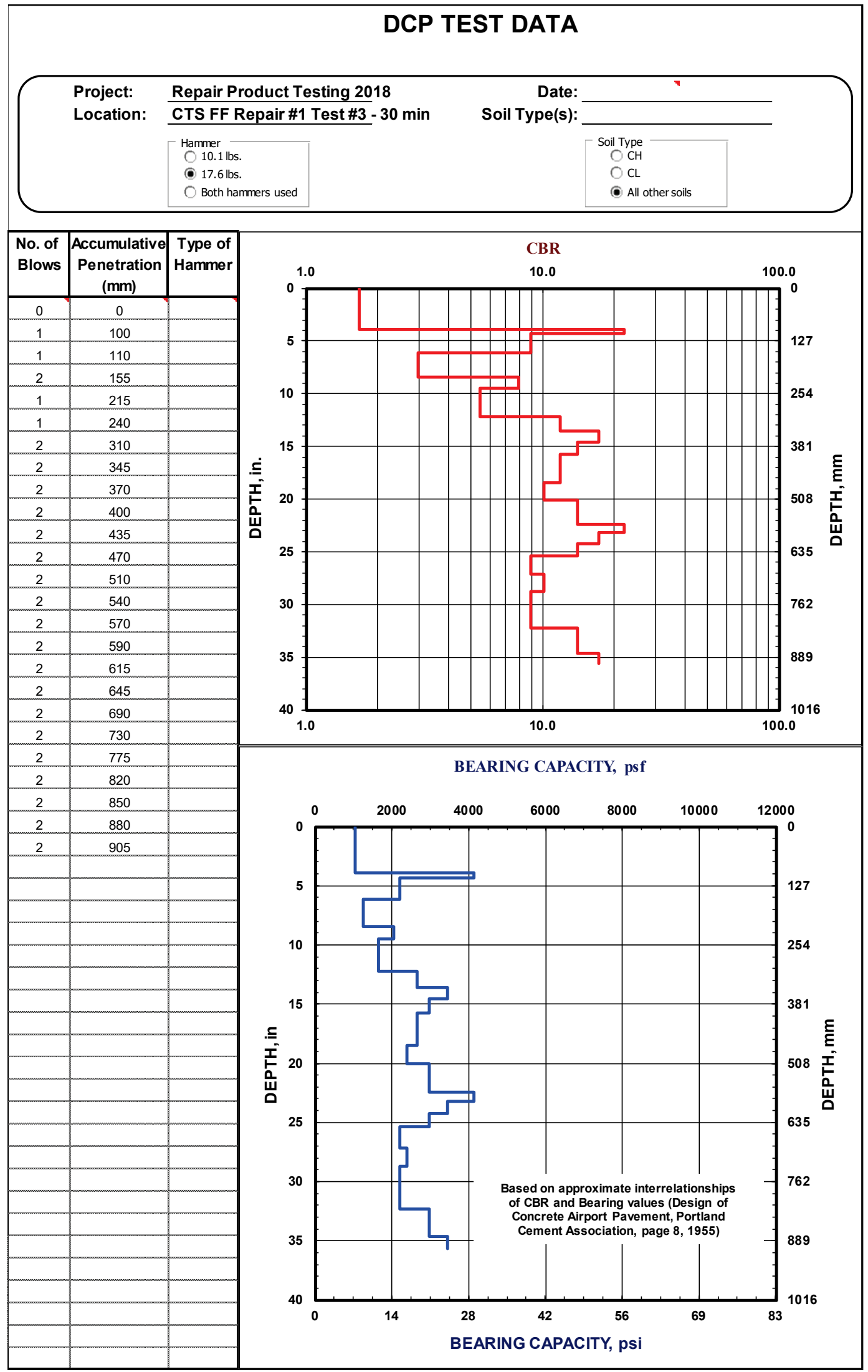


Figure B22. Repair FF-2, Test 1, DCP data at 30 min cure time.

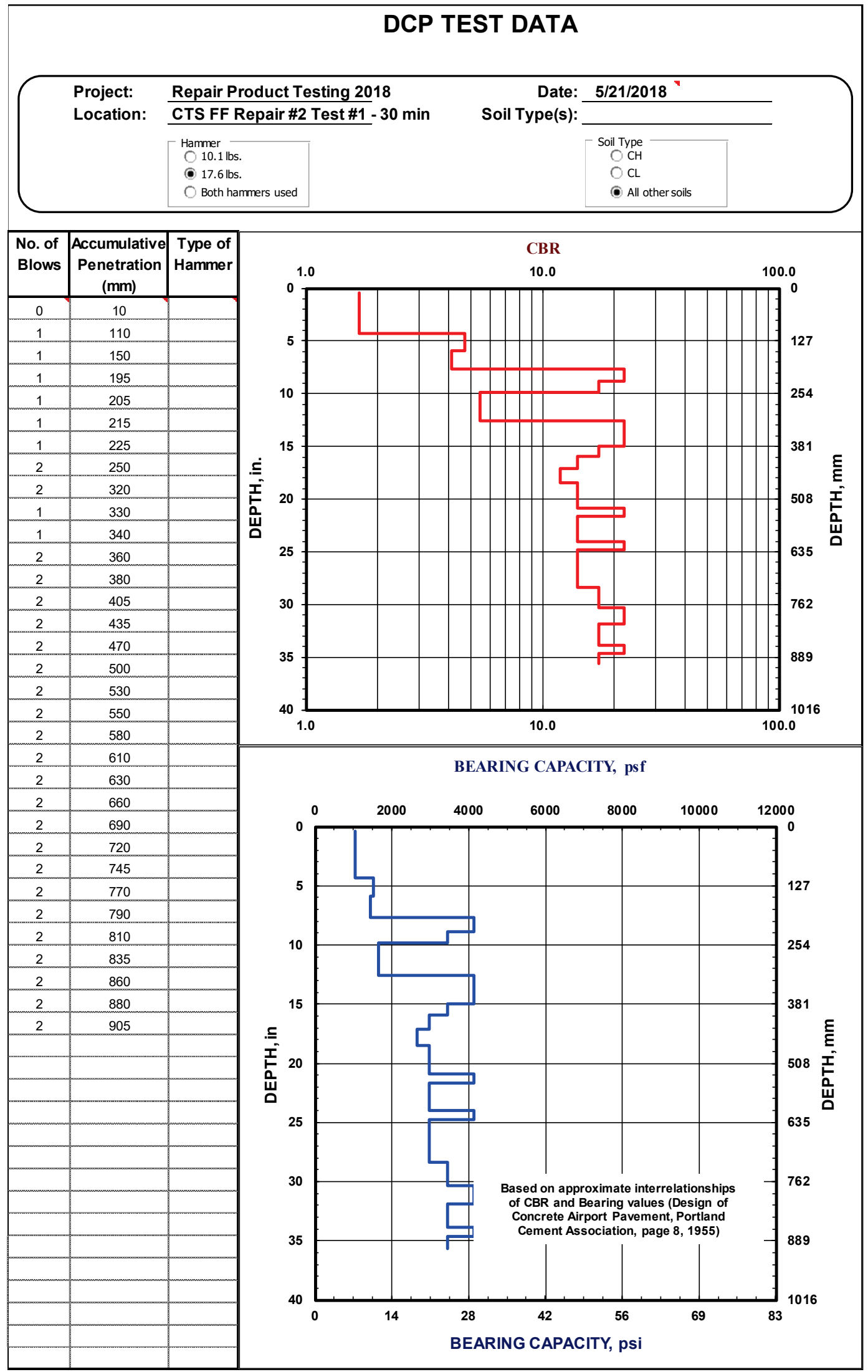


Figure B23. Repair FF-2, Test 2, DCP data at 30 min cure time.

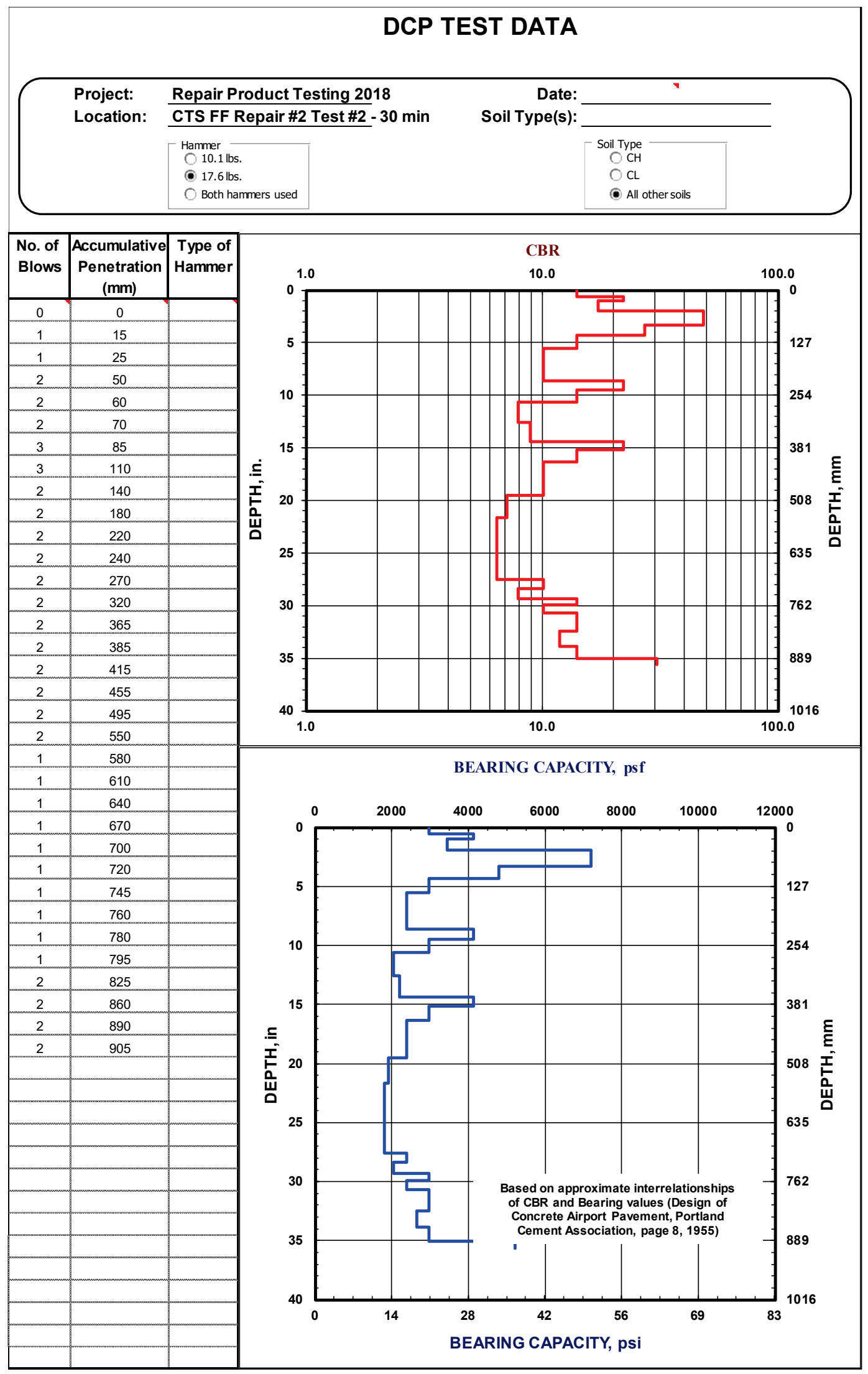


Figure B24. Repair FF-2, Test 3, DCP data at 30 min cure time.

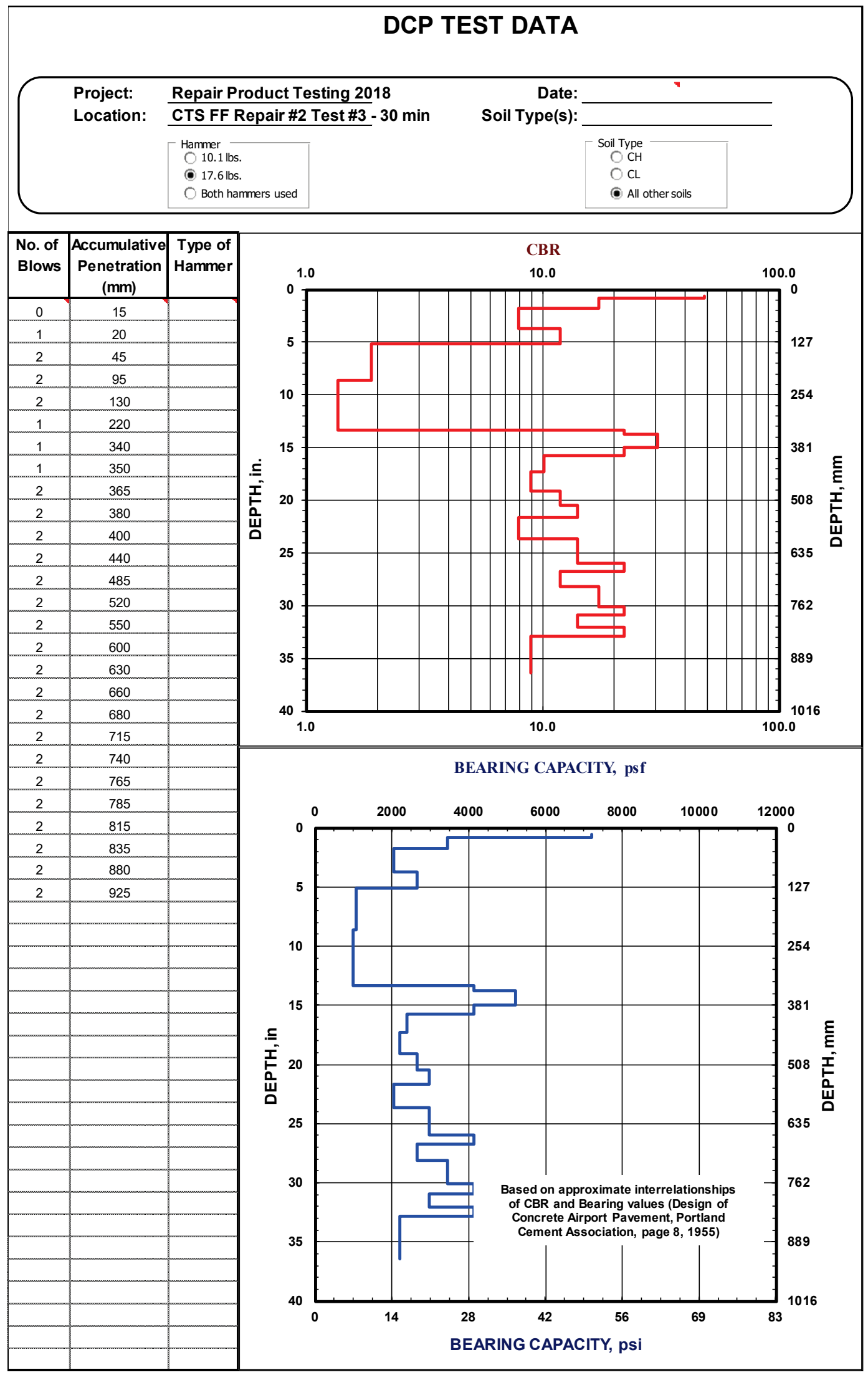


Figure B25. Repair FF-3, Test 1, DCP data at 30 min cure time.

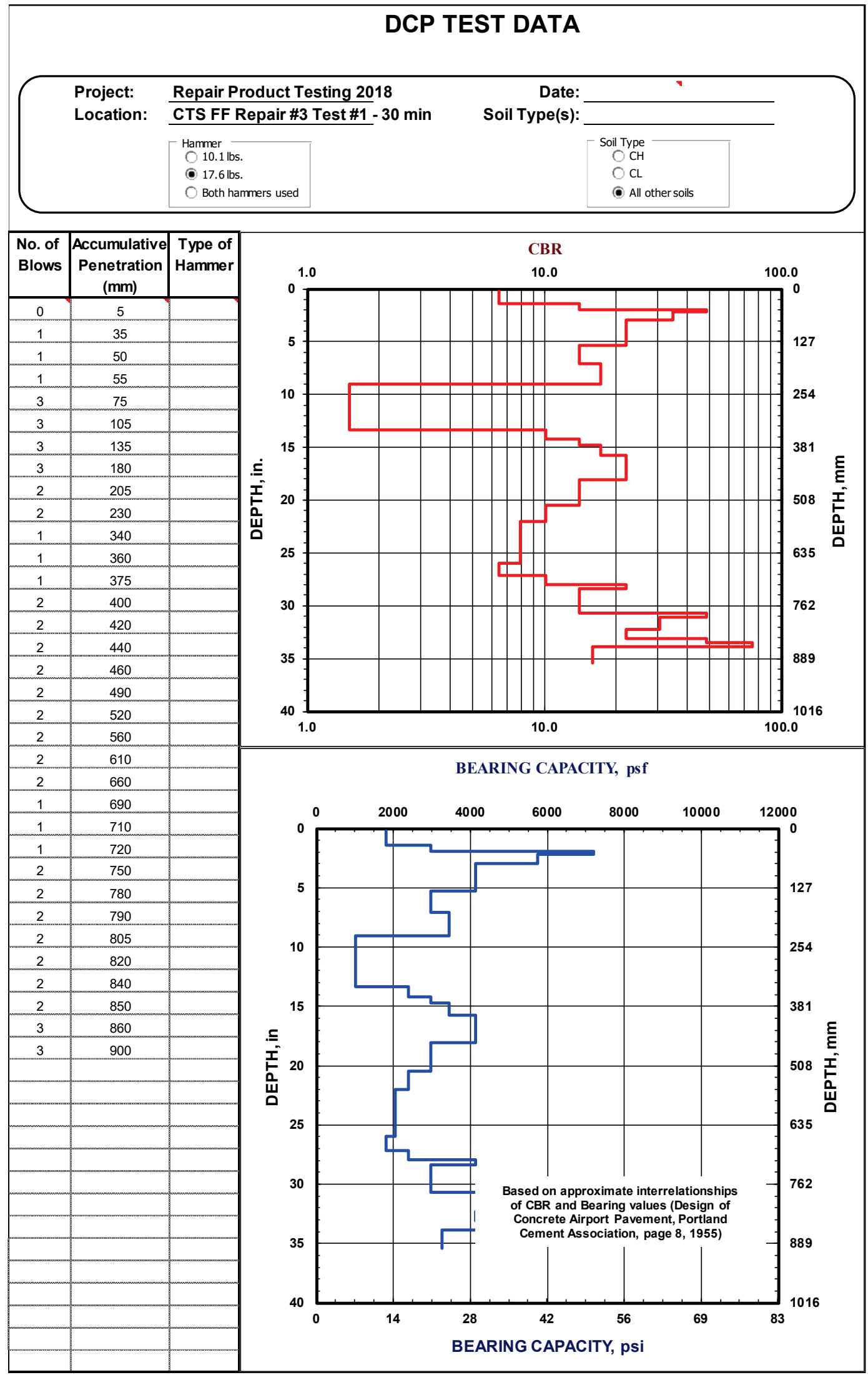


Figure B26. Repair FF-3, Test 2, DCP data at 30 min cure time.

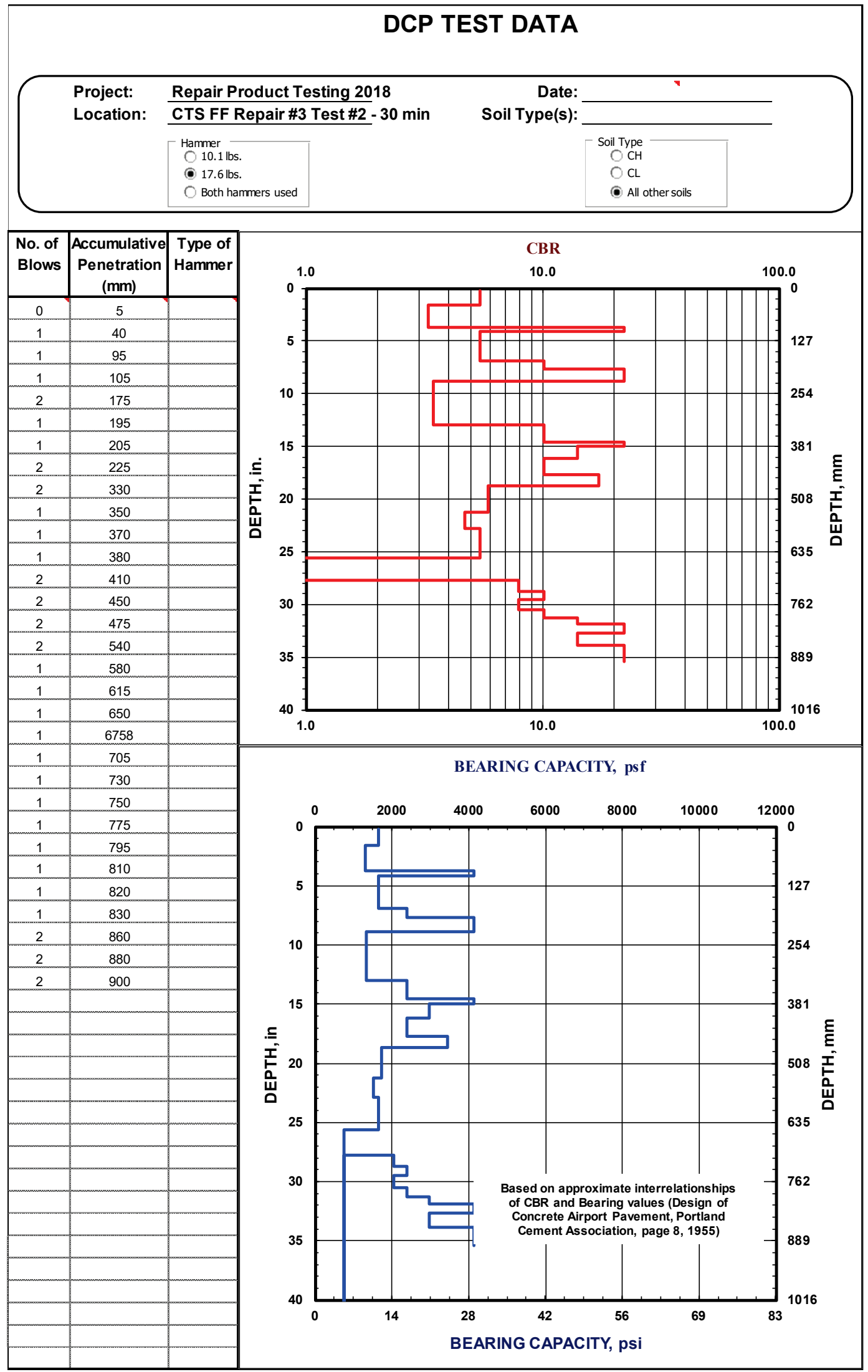


Figure B27. Repair FF-3, Test 3, DCP data at 30 min cure time.

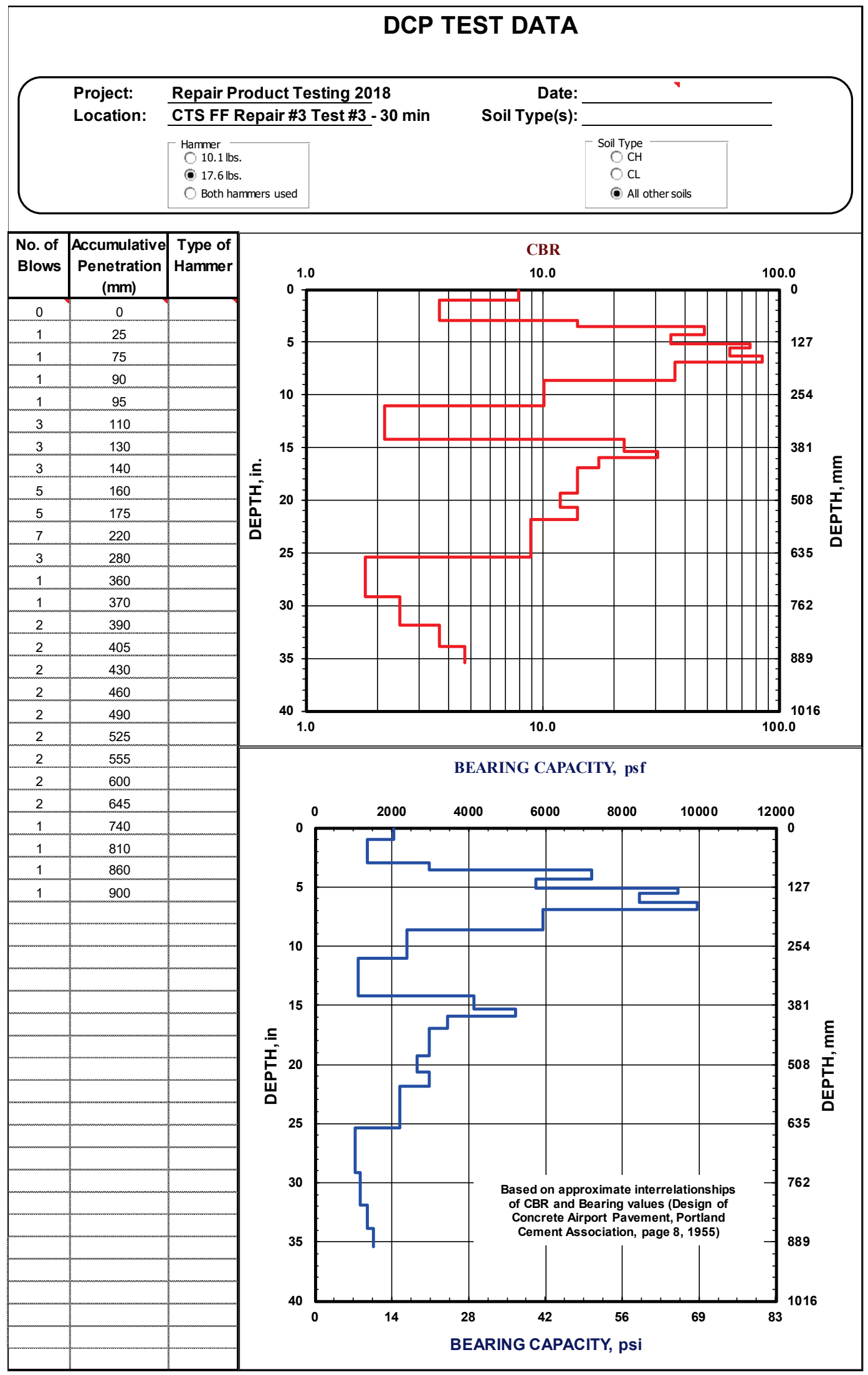


Figure B28. Repair FF-1, Test 1, DCP data at $1 \mathrm{hr}$ cure time.

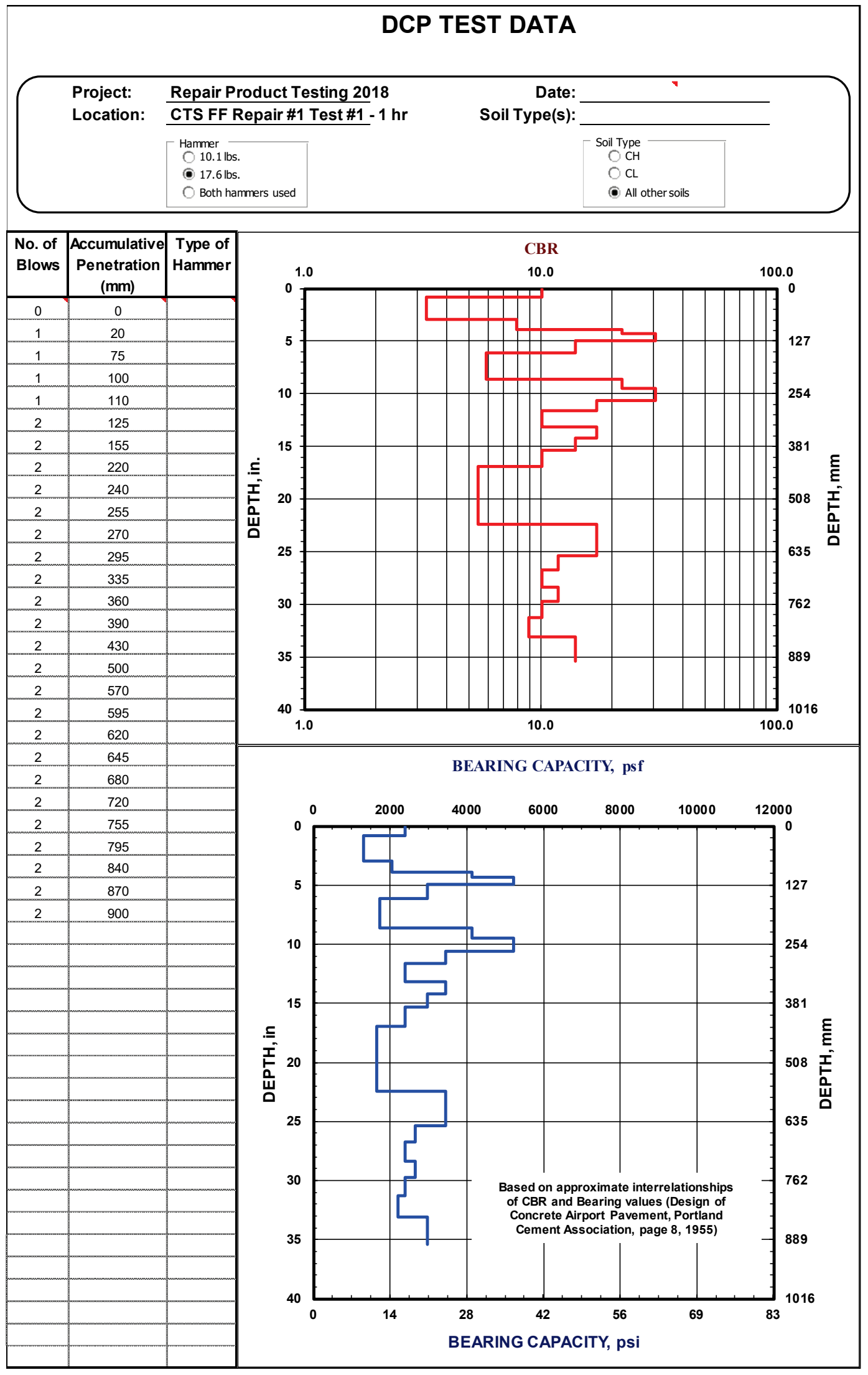


Figure B29. Repair FF-1, Test 2, DCP data at $1 \mathrm{hr}$ cure time.

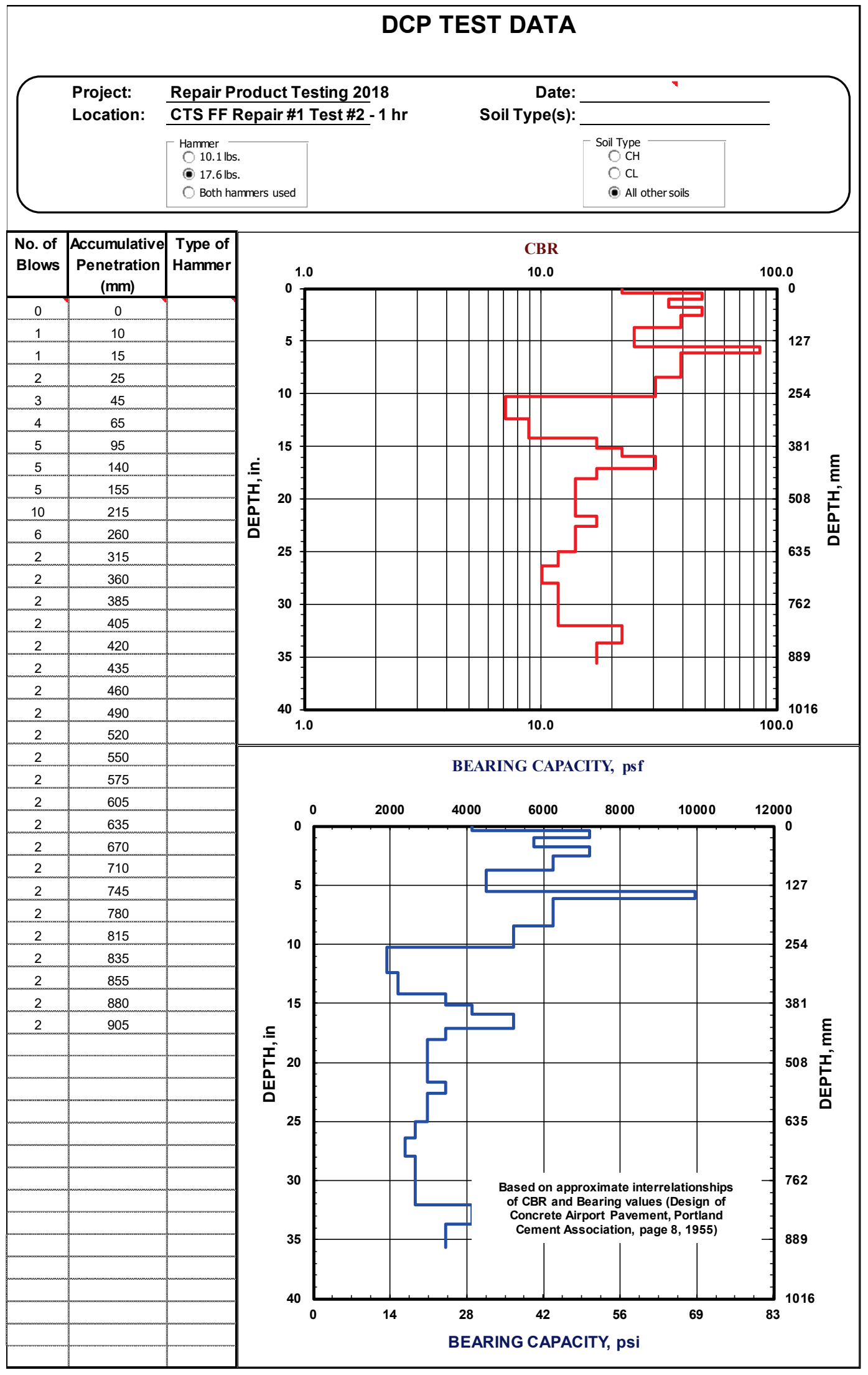


Figure B30. Repair FF-1, Test 3, DCP data at $1 \mathrm{hr}$ cure time.

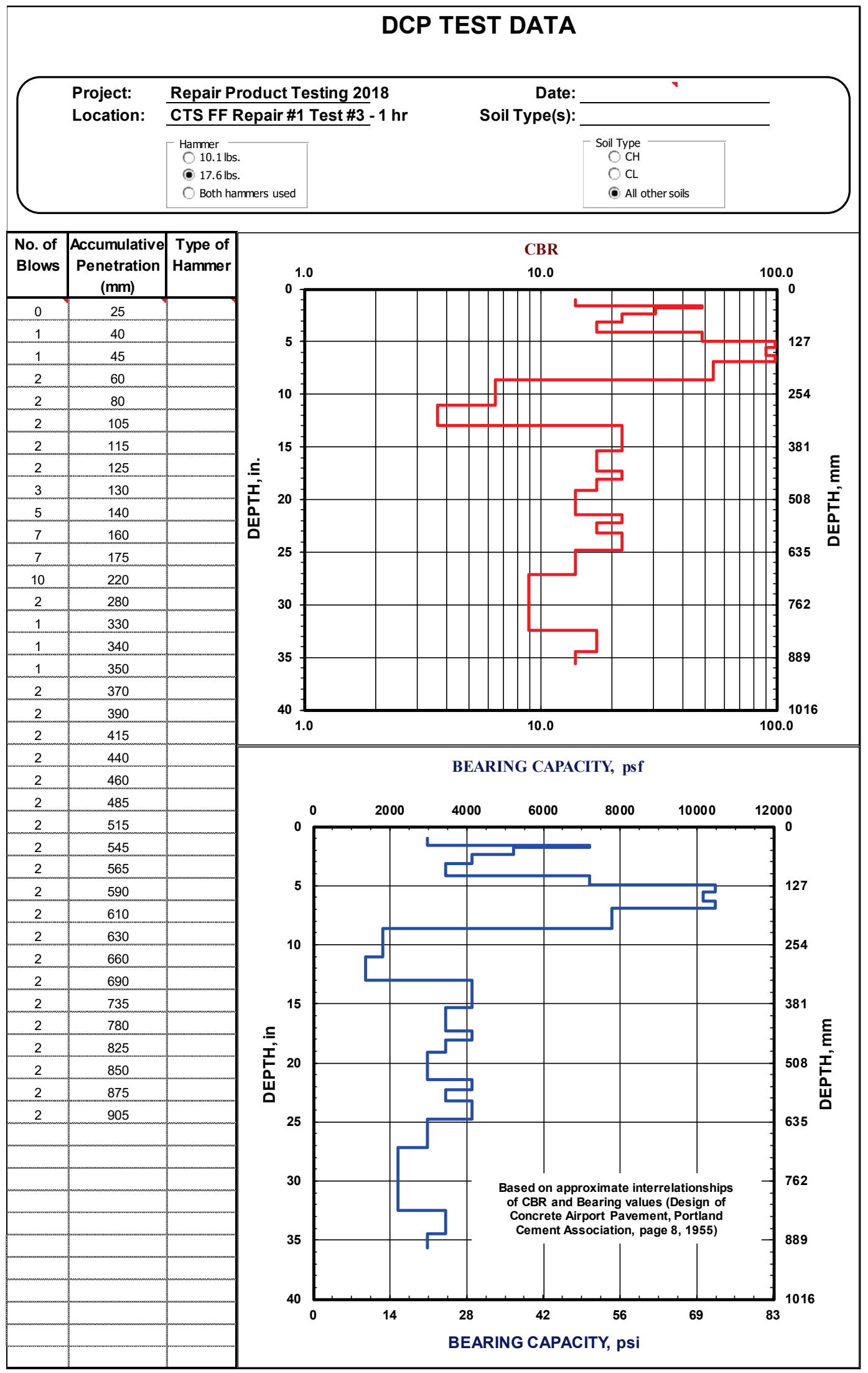


Figure B31. Repair FF-2, Test 1, DCP data at $1 \mathrm{hr}$ cure time.

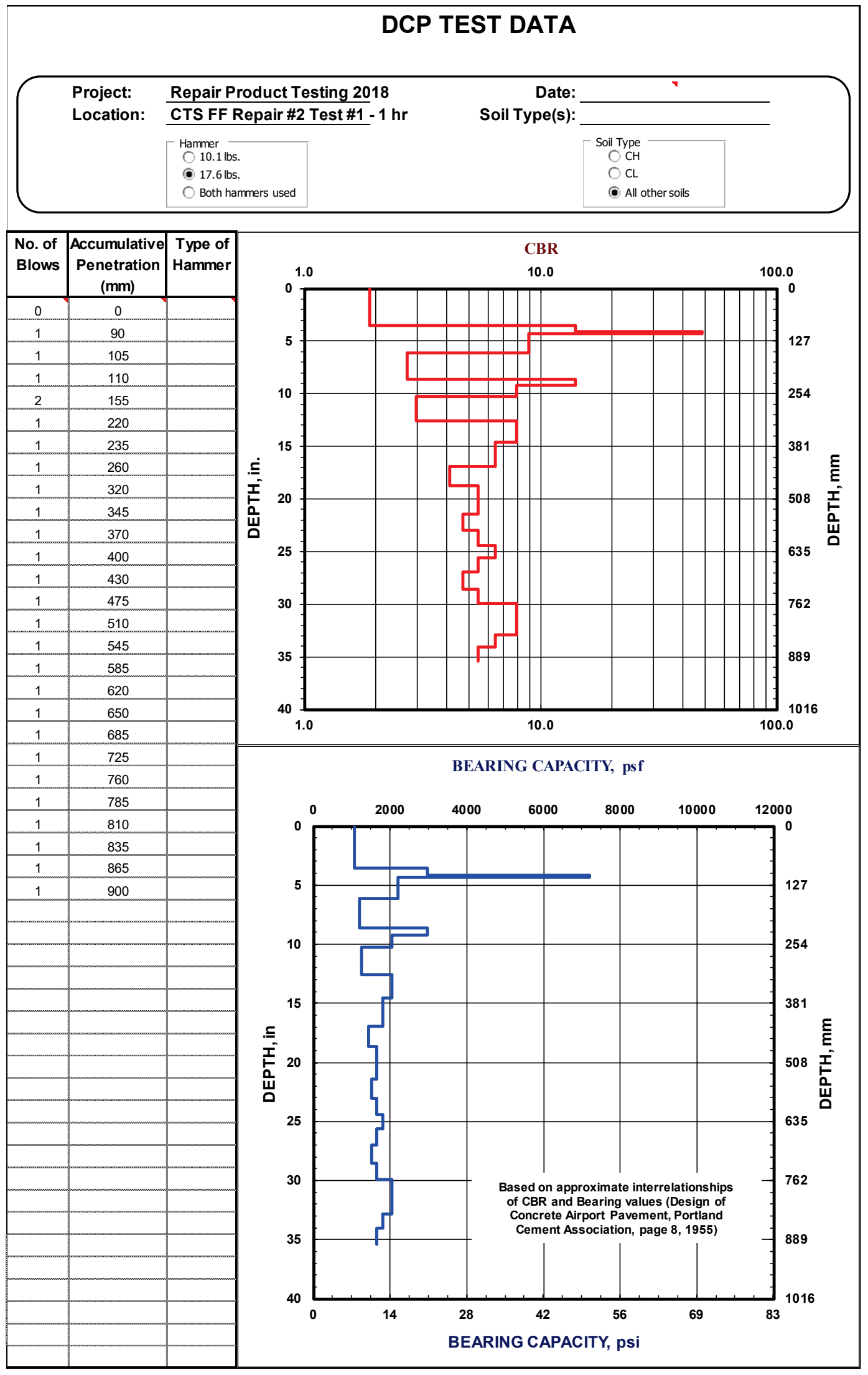


Figure B32. Repair FF-2, Test 2, DCP data at $1 \mathrm{hr}$ cure time.

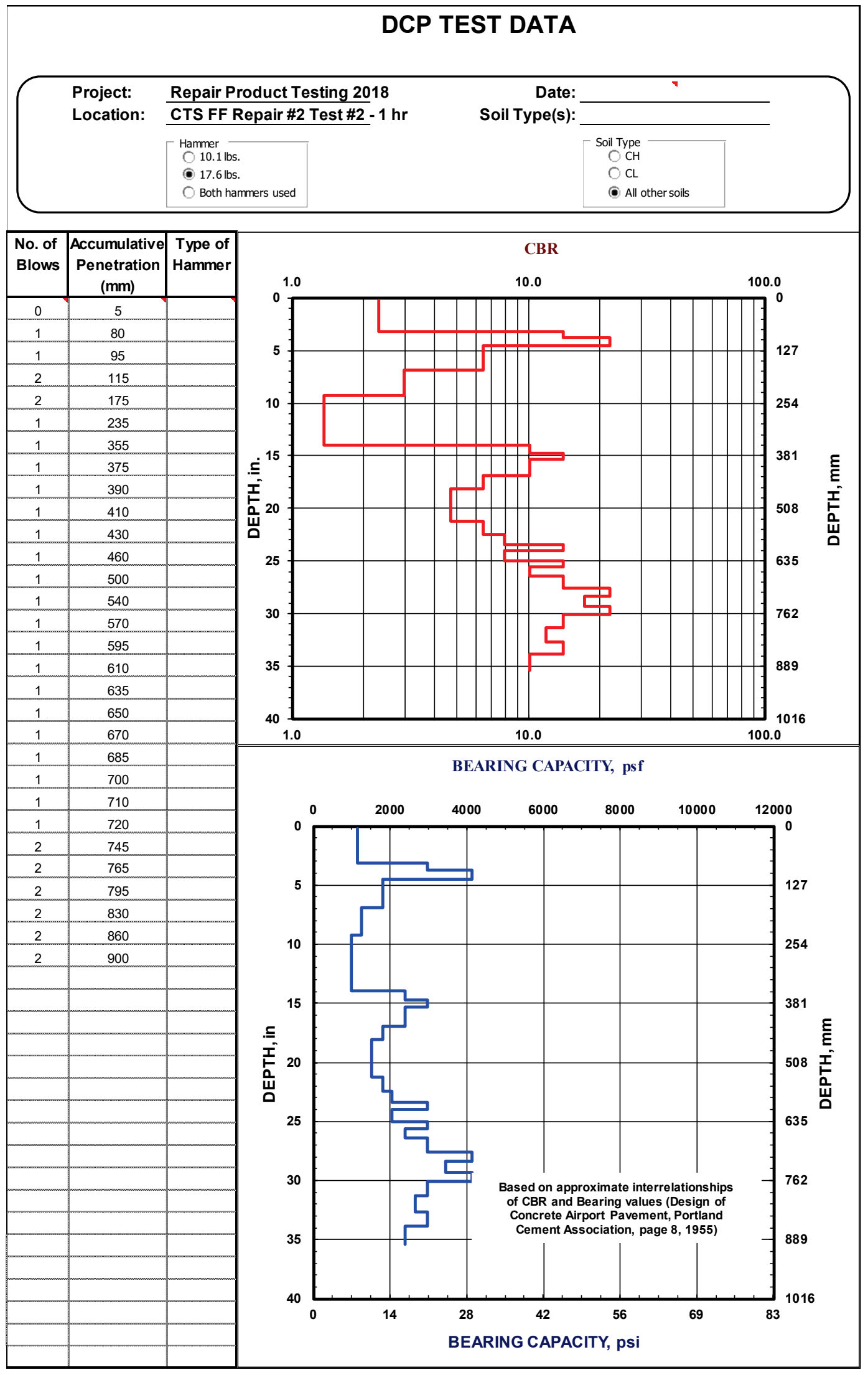


Figure B33. Repair FF-2, Test 3, DCP data at $1 \mathrm{hr}$ cure time.

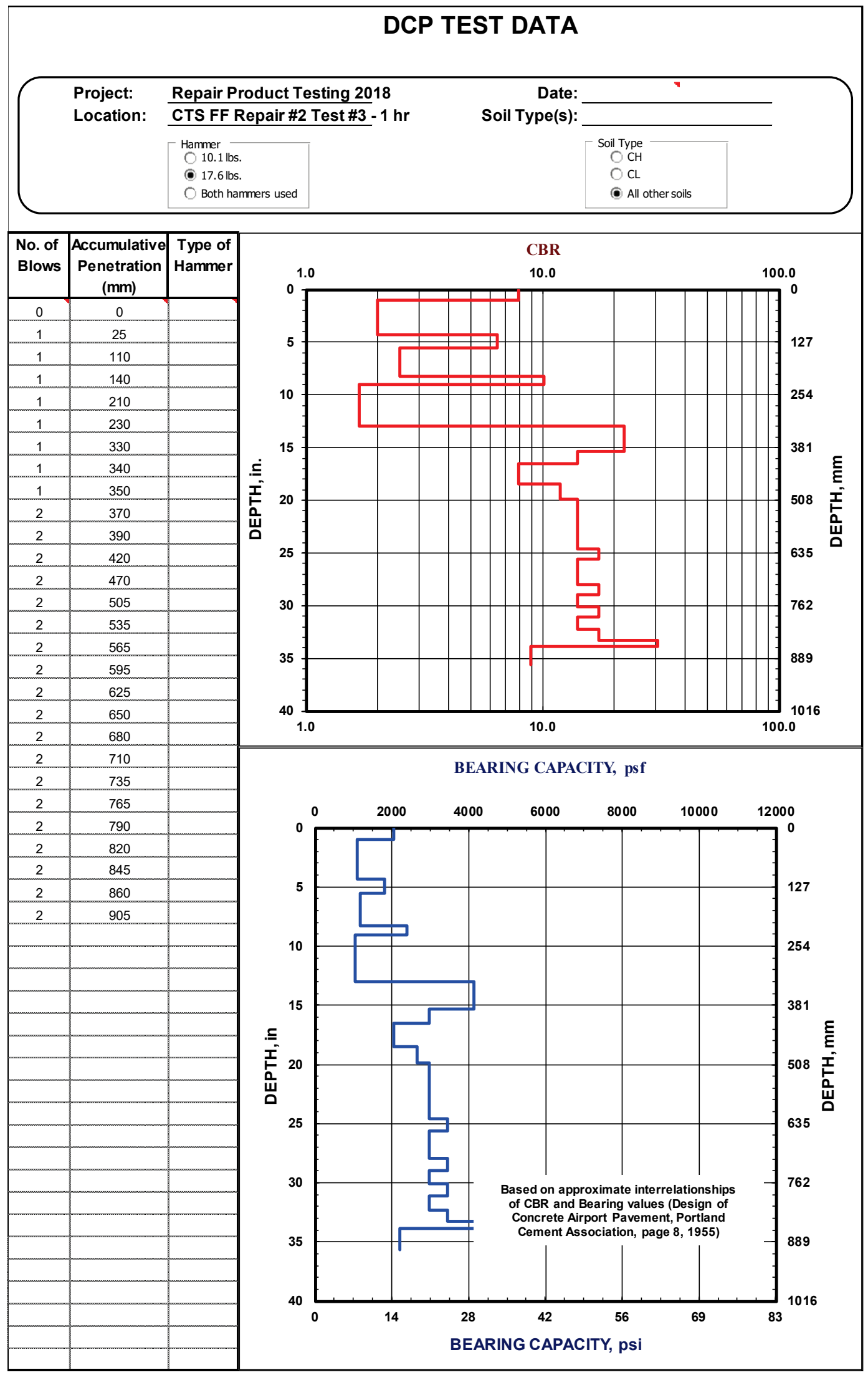


Figure B34. Repair FF-3, Test 1, DCP data at $1 \mathrm{hr}$ cure time.

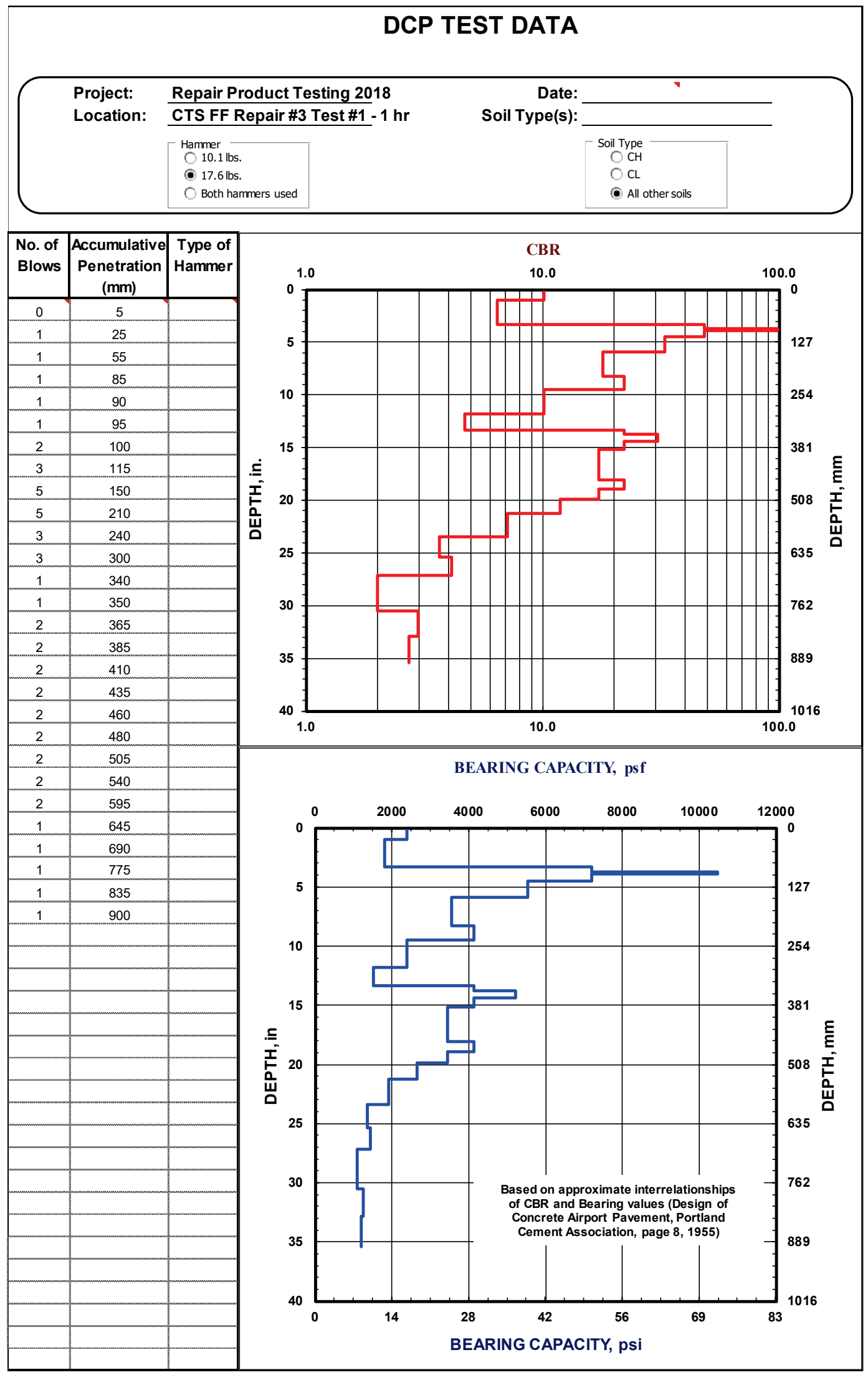


Figure B35. Repair FF-3, Test 2, DCP data at $1 \mathrm{hr}$ cure time.

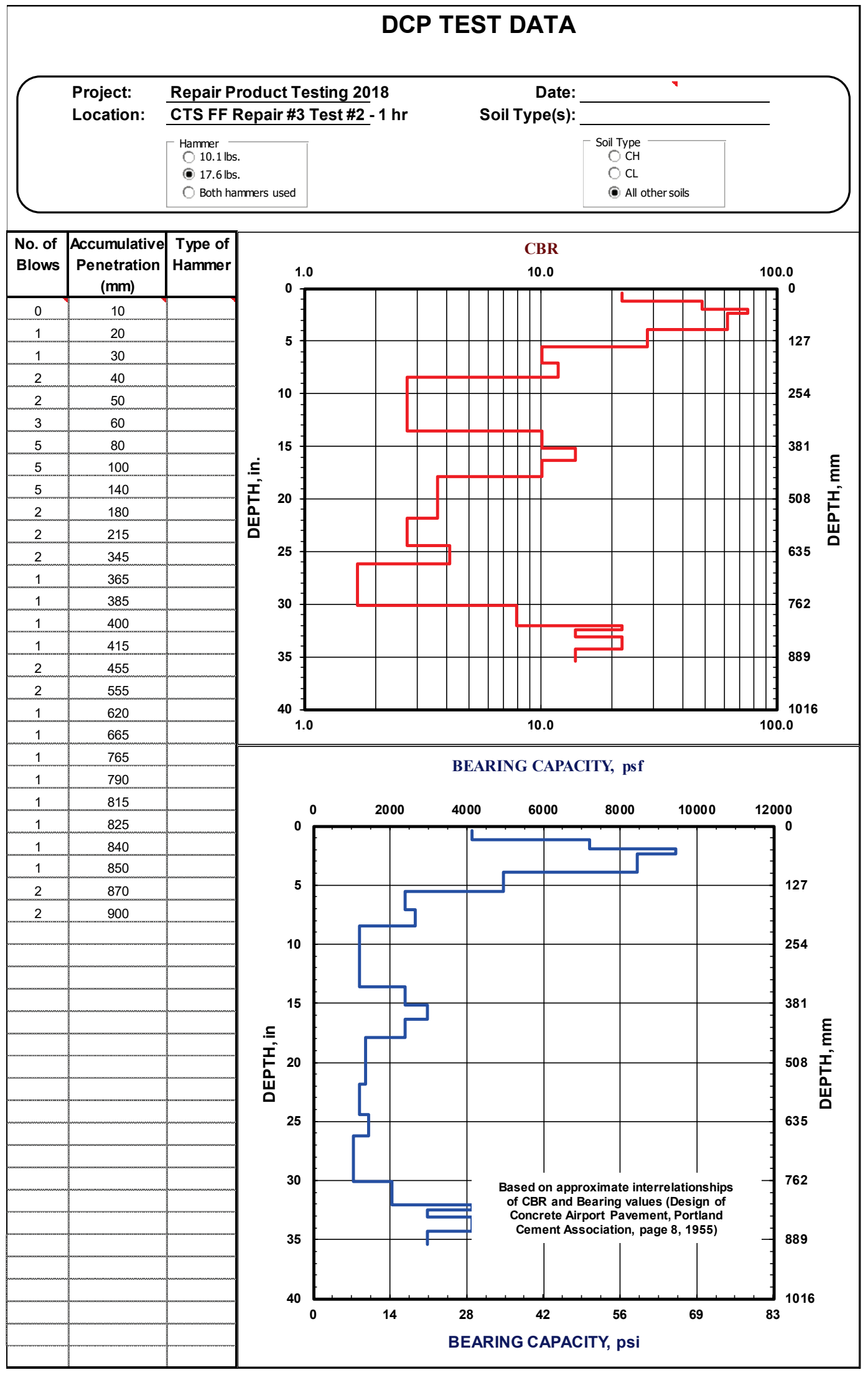


Figure B36. Repair FF-3, Test 3, DCP data at $1 \mathrm{hr}$ cure time.

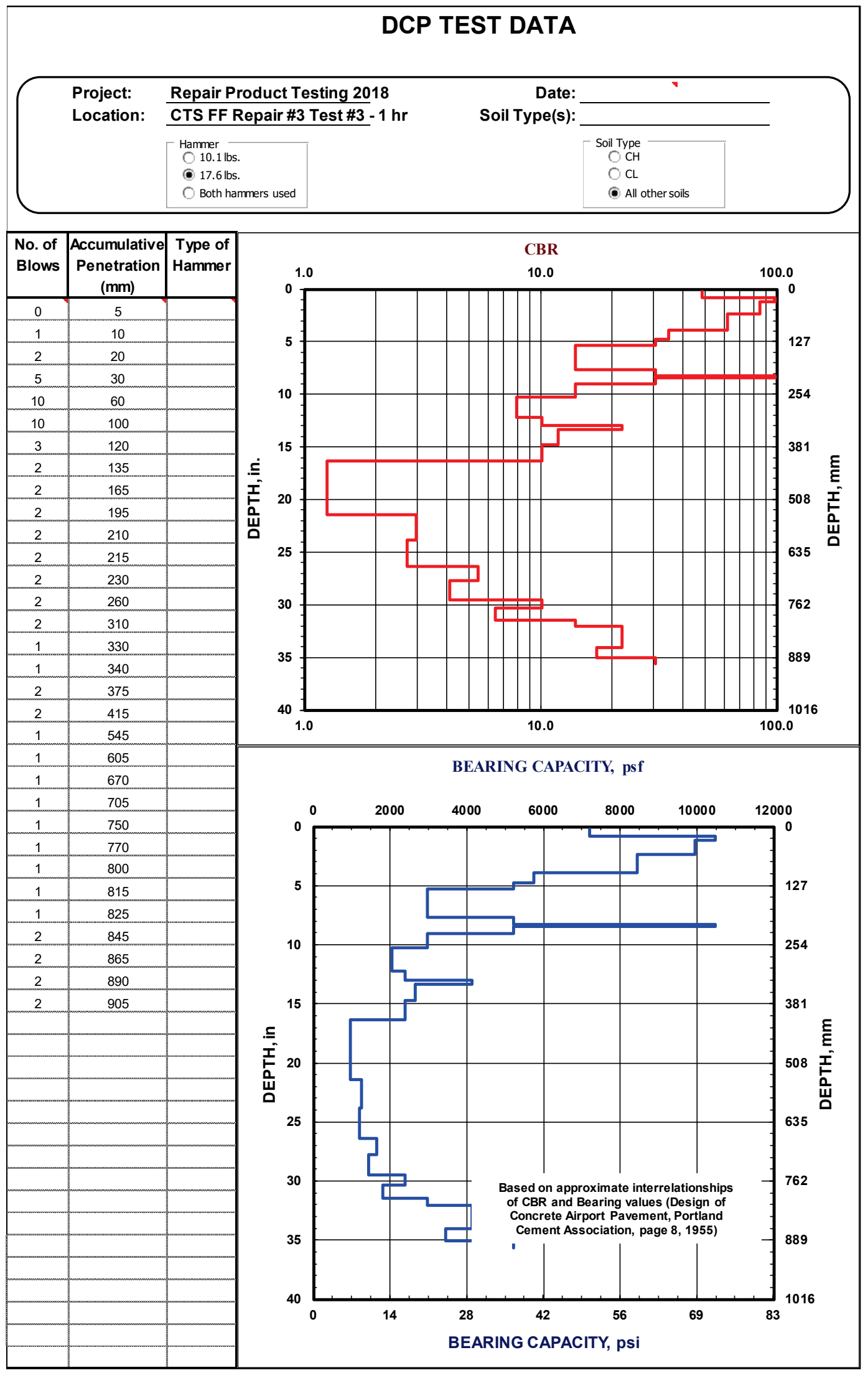


Figure B37. Repair FF-1, Test 1, DCP data at $2 \mathrm{hr}$ cure time.

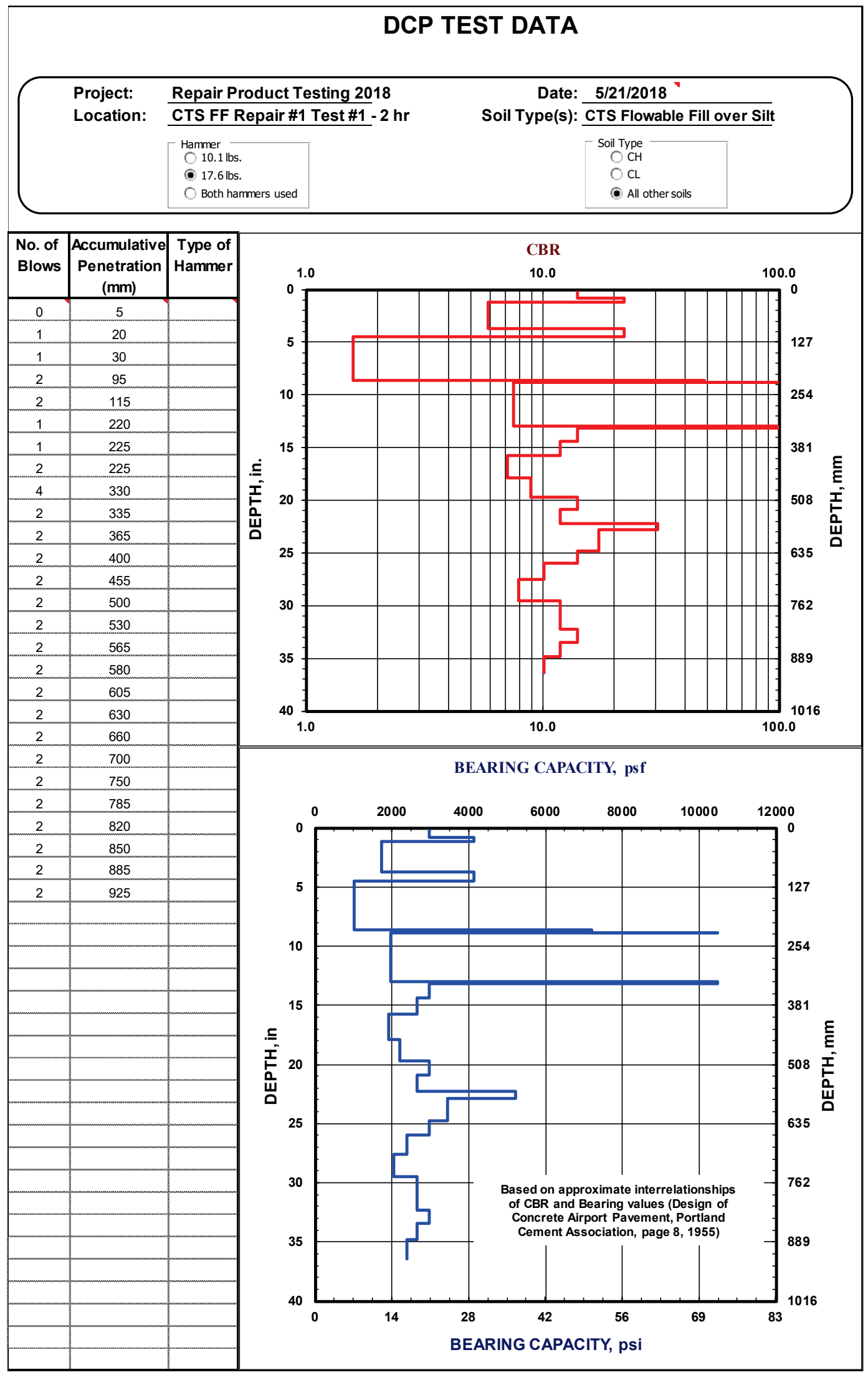


Figure B38. Repair FF-1, Test 2, DCP data at $2 \mathrm{hr}$ cure time.

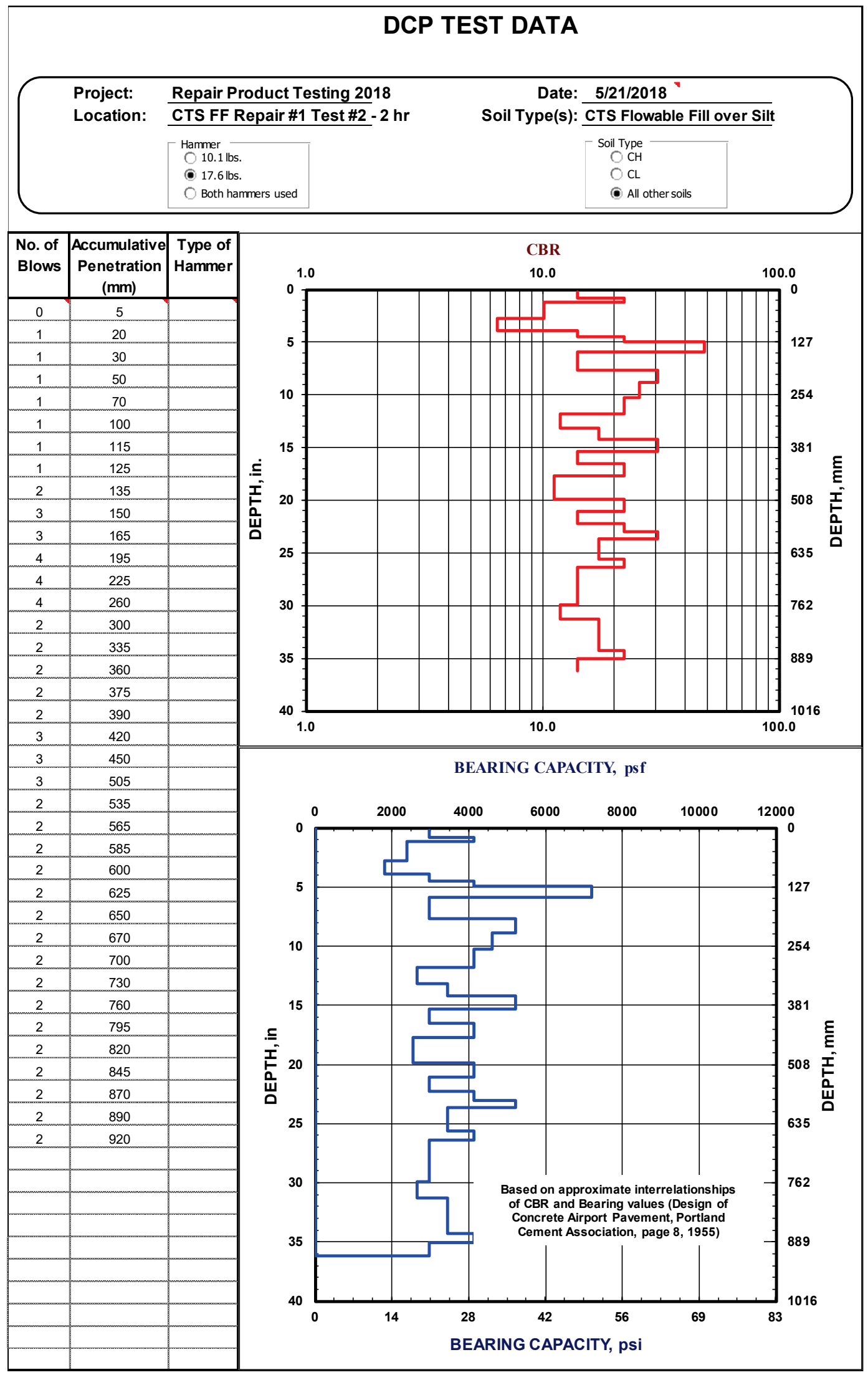


Figure B39. Repair FF-1, Test 3, DCP data at $2 \mathrm{hr}$ cure time.

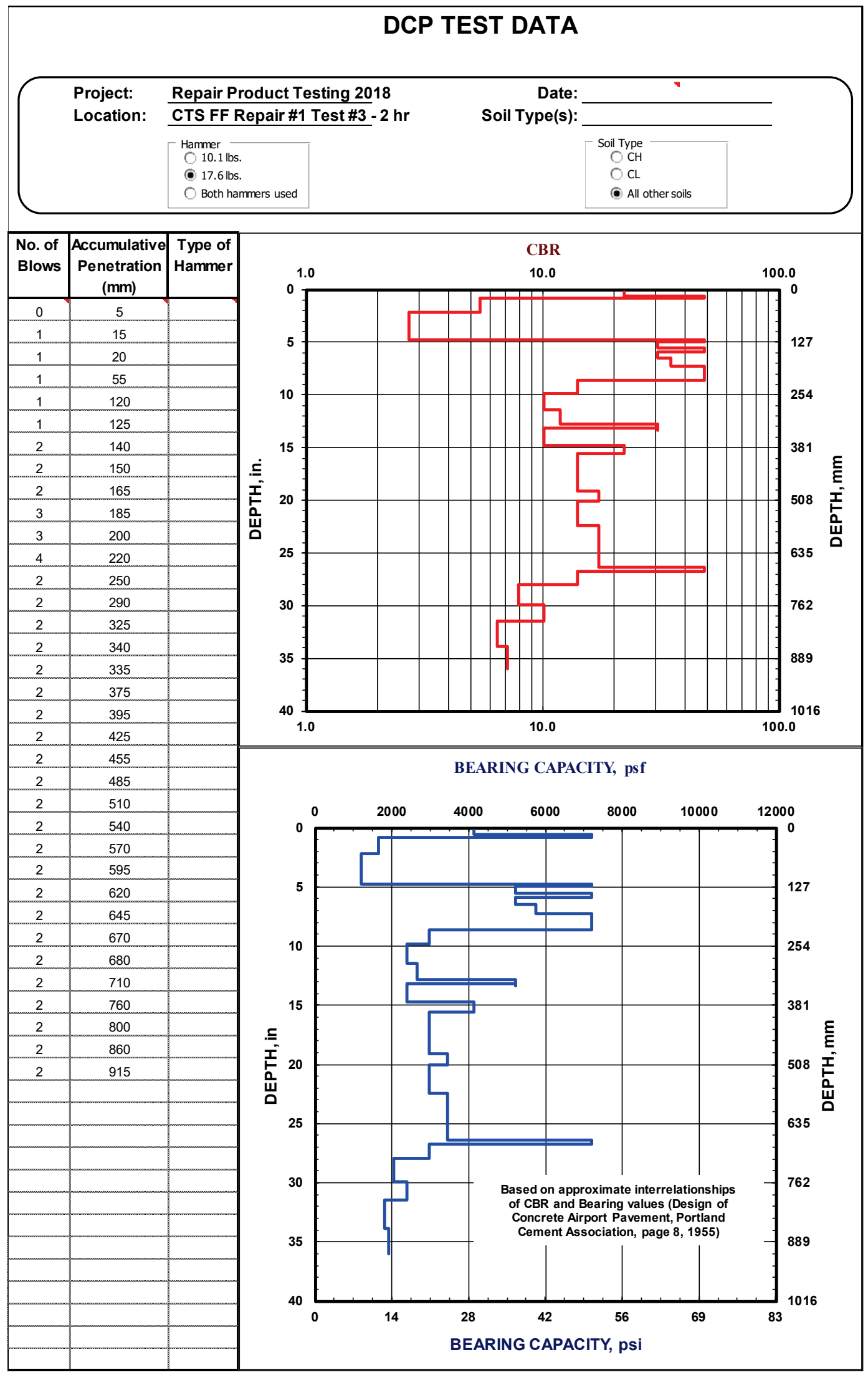


Figure B40. Repair FF-2, Test 1, DCP data at $2 \mathrm{hr}$ cure time.

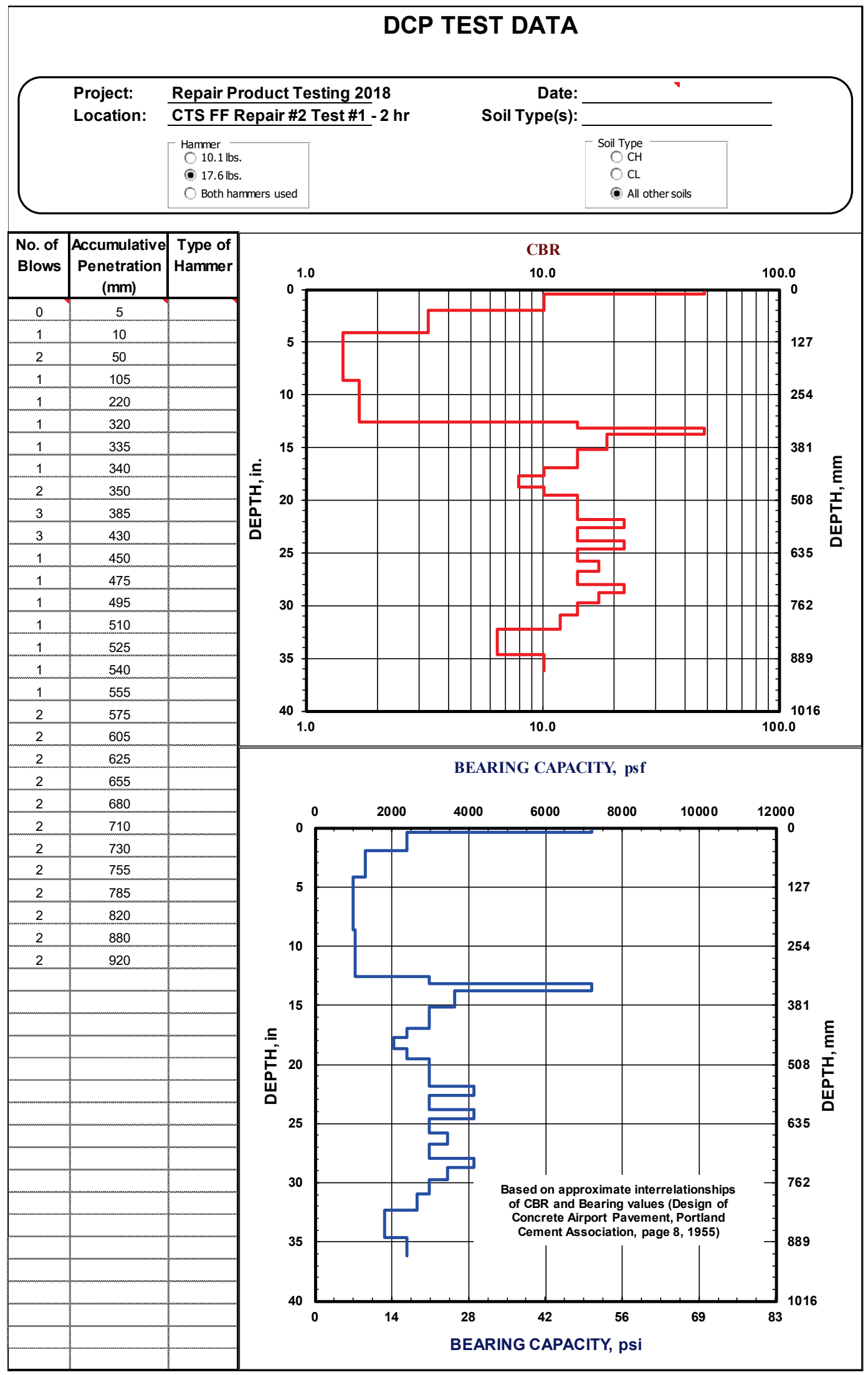


Figure B41. Repair FF-2, Test 2, DCP data at $2 \mathrm{hr}$ cure time.

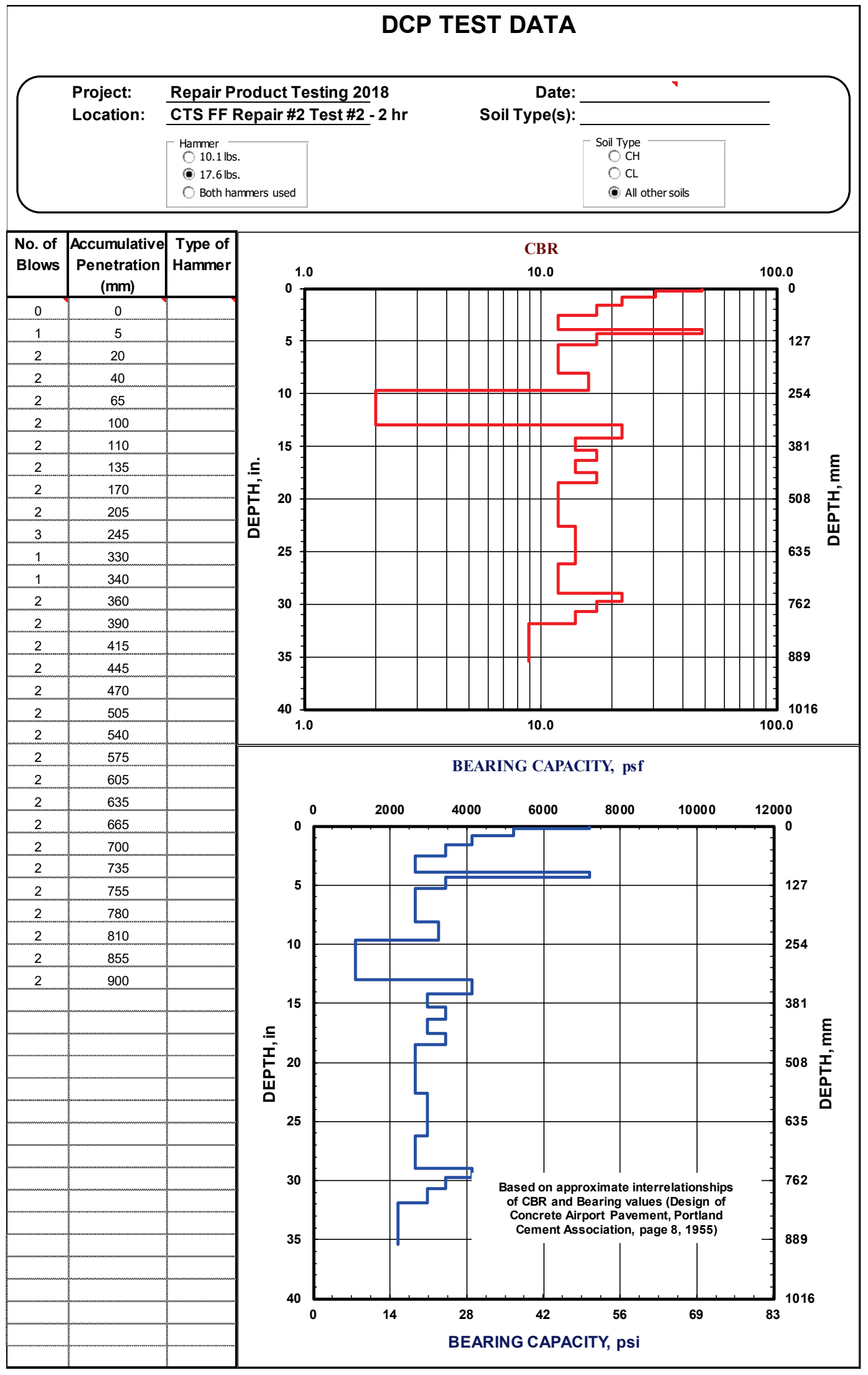


Figure B42. Repair FF-2, Test 3, DCP data at $2 \mathrm{hr}$ cure time.

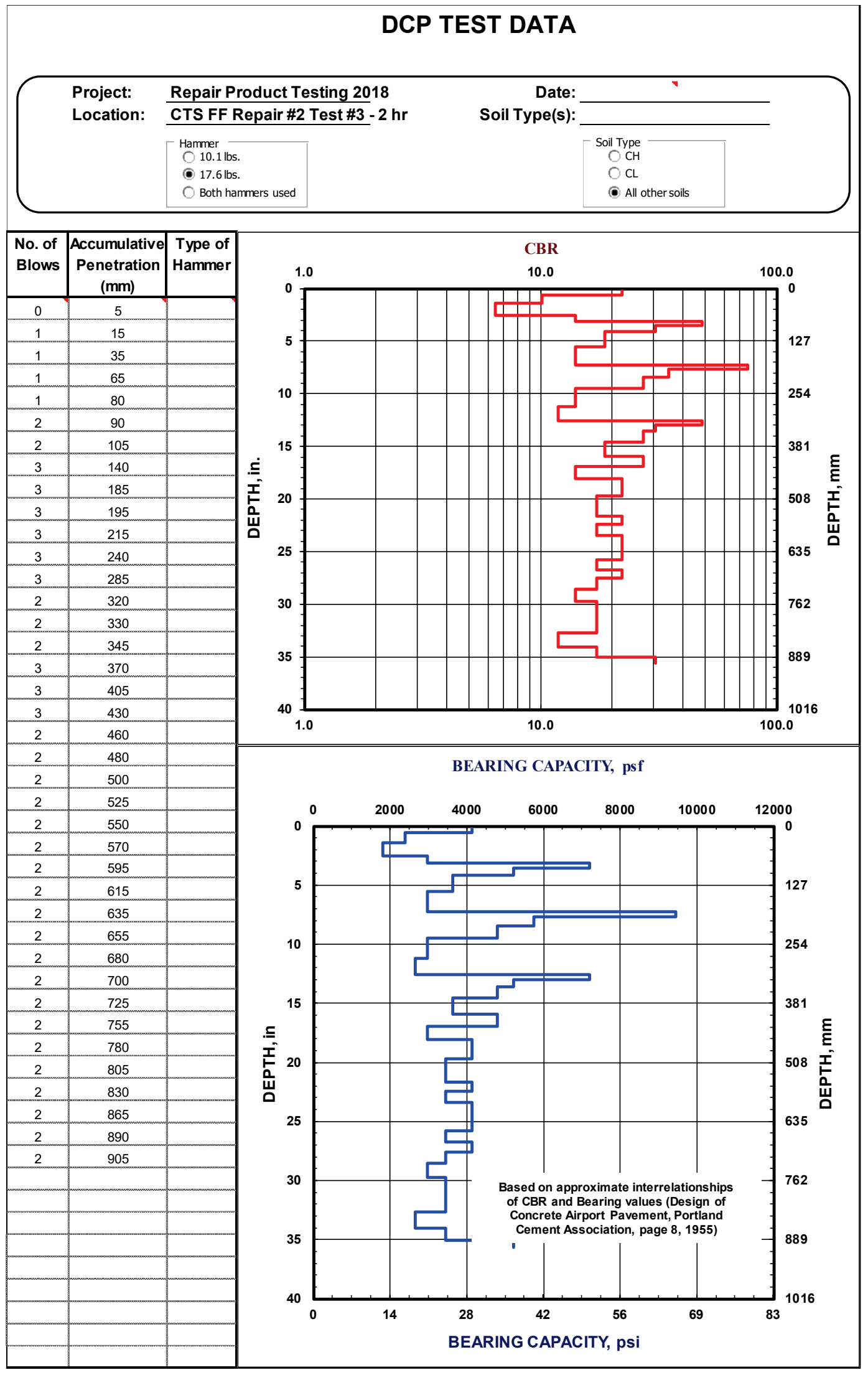


Figure B43. Repair FF-3, Test 1, DCP data at $2 \mathrm{hr}$ cure time.

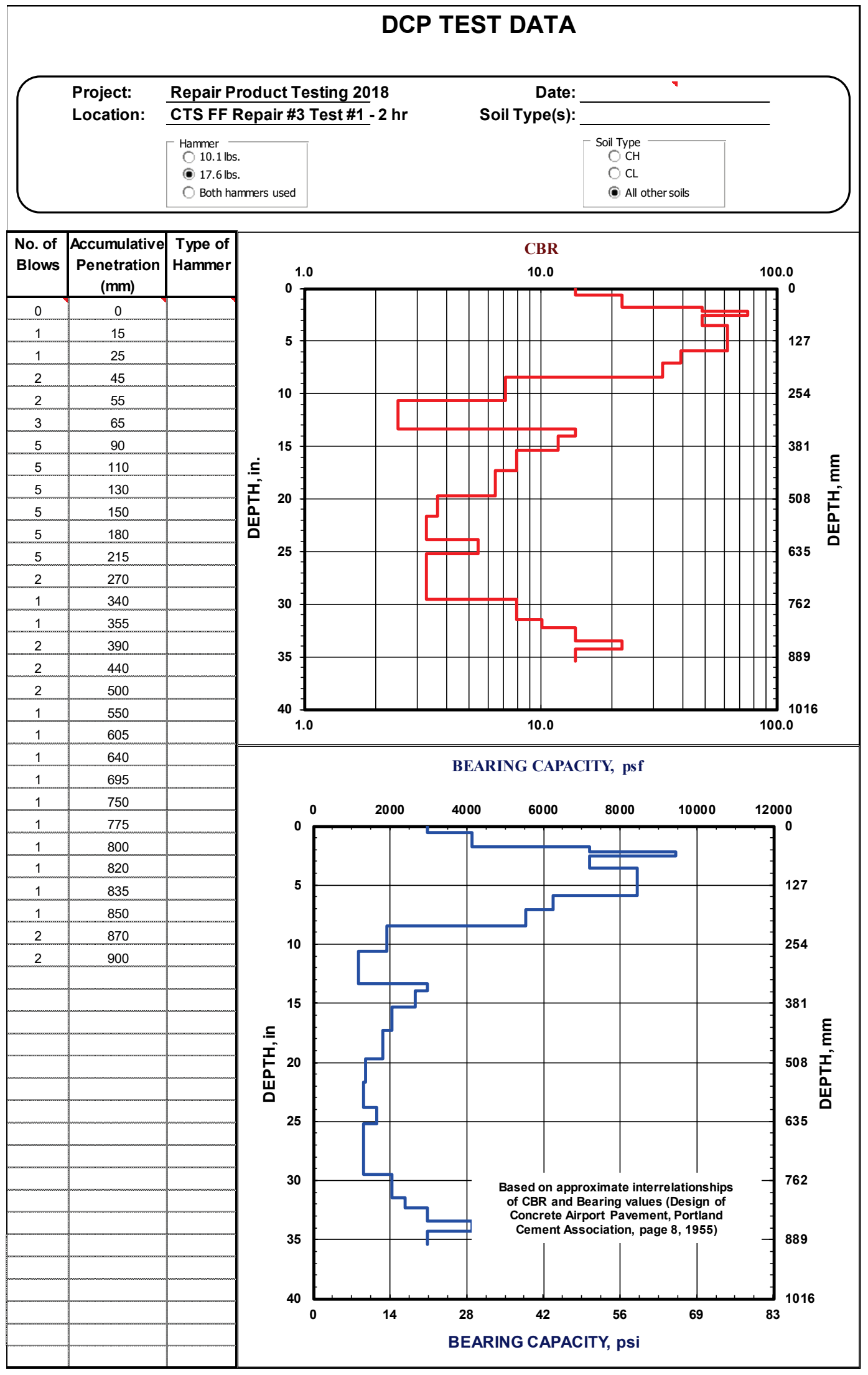


Figure B44. Repair FF-3, Test 2, DCP data at $2 \mathrm{hr}$ cure time.

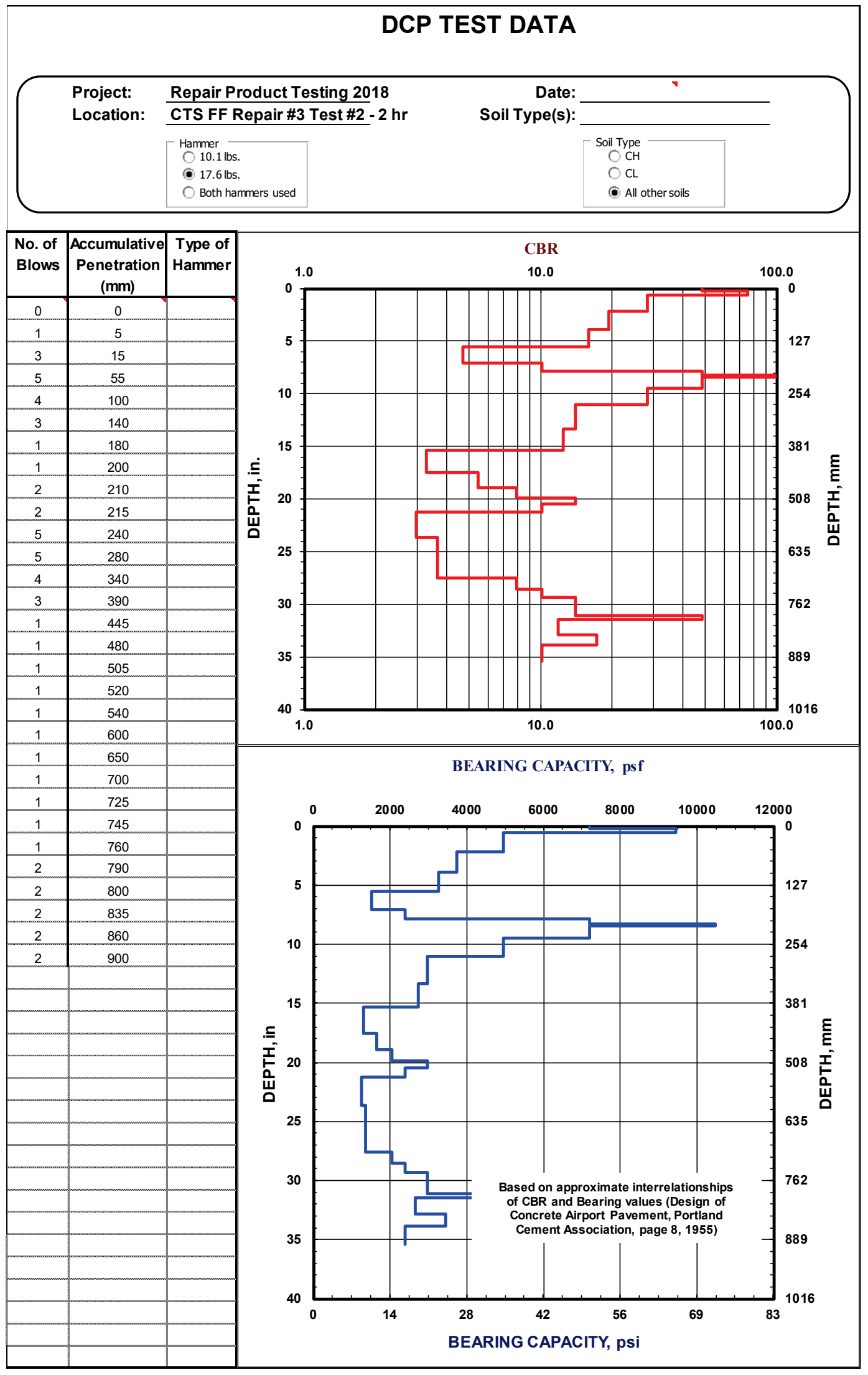


Figure B45. Repair FF-3, Test 3, DCP data at $2 \mathrm{hr}$ cure time.

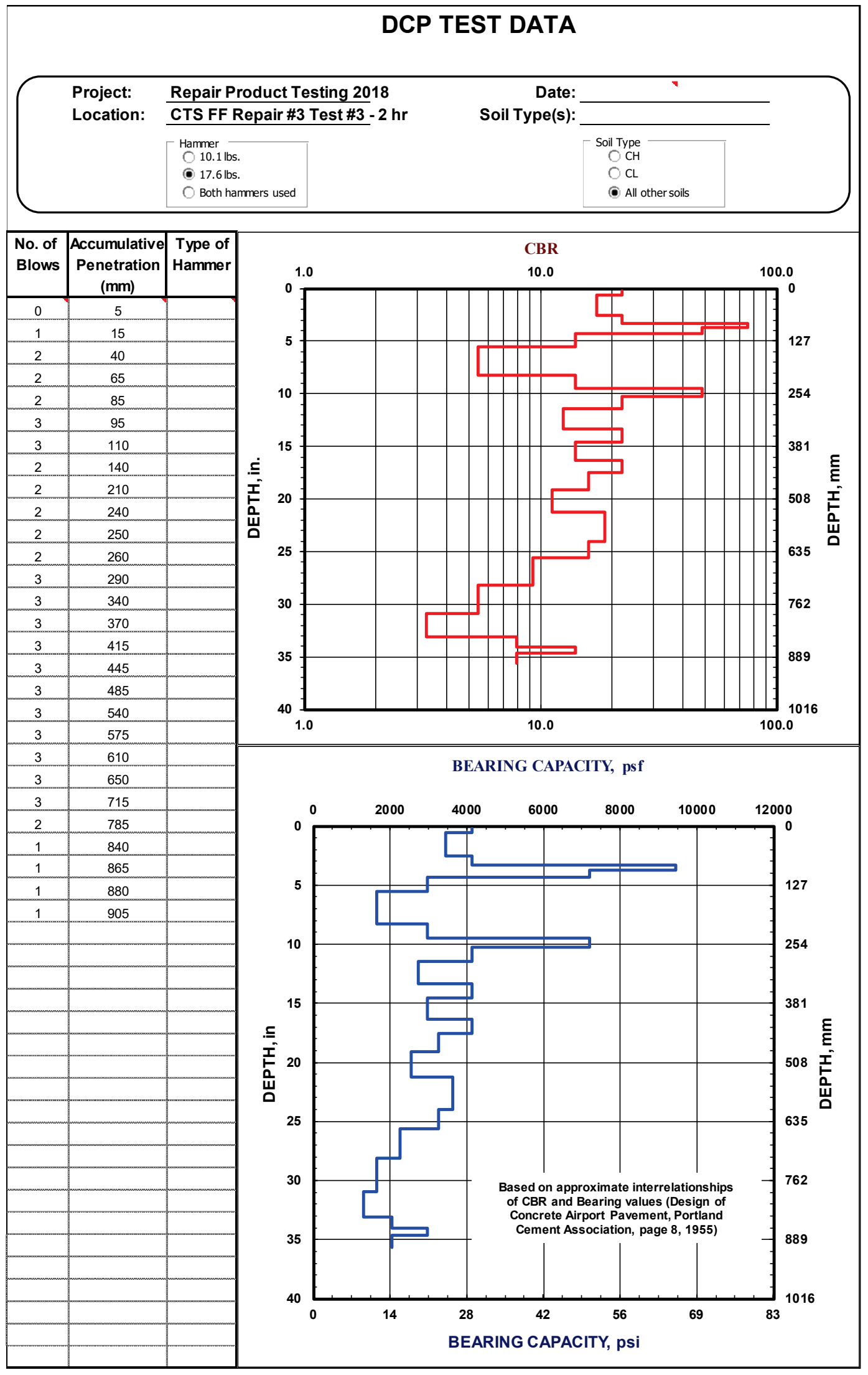


Figure B46. Repair FF-1, Test 1, DCP data at $24 \mathrm{hr}$ cure time.

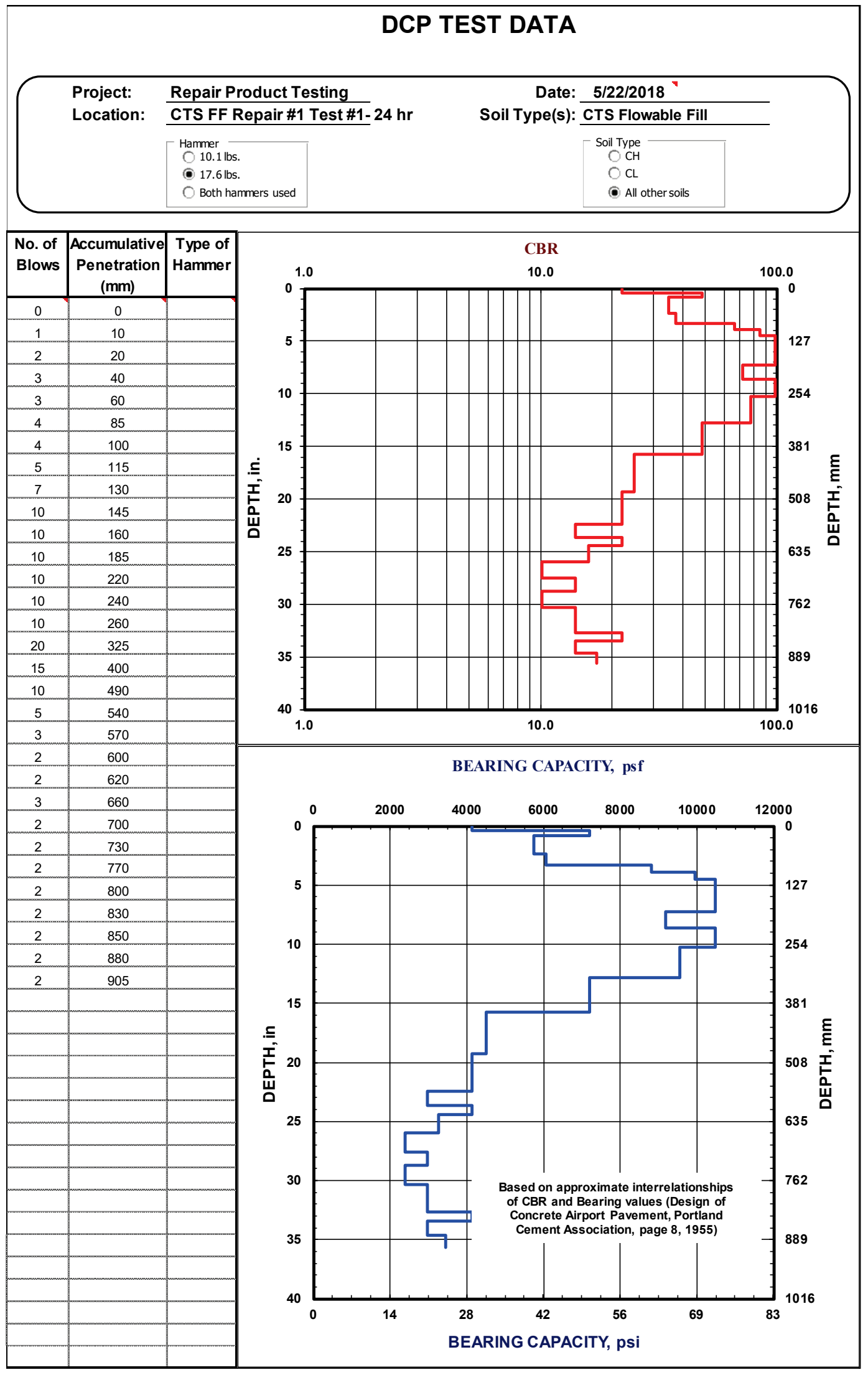


Figure B47. Repair FF-1, Test 2, DCP data at $24 \mathrm{hr}$ cure time.

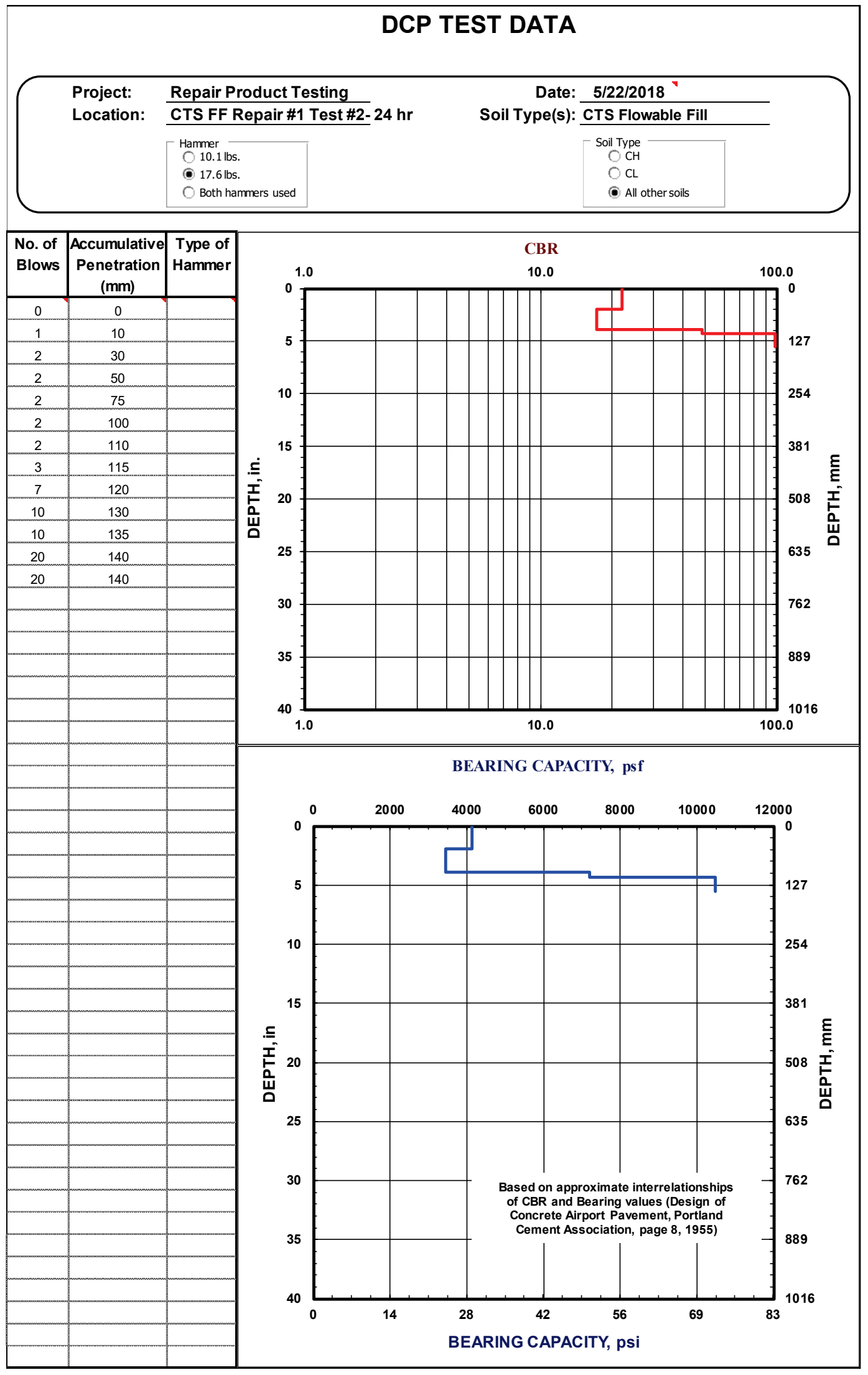


Figure B48. Repair FF-1, Test 3, DCP data at $24 \mathrm{hr}$ cure time.

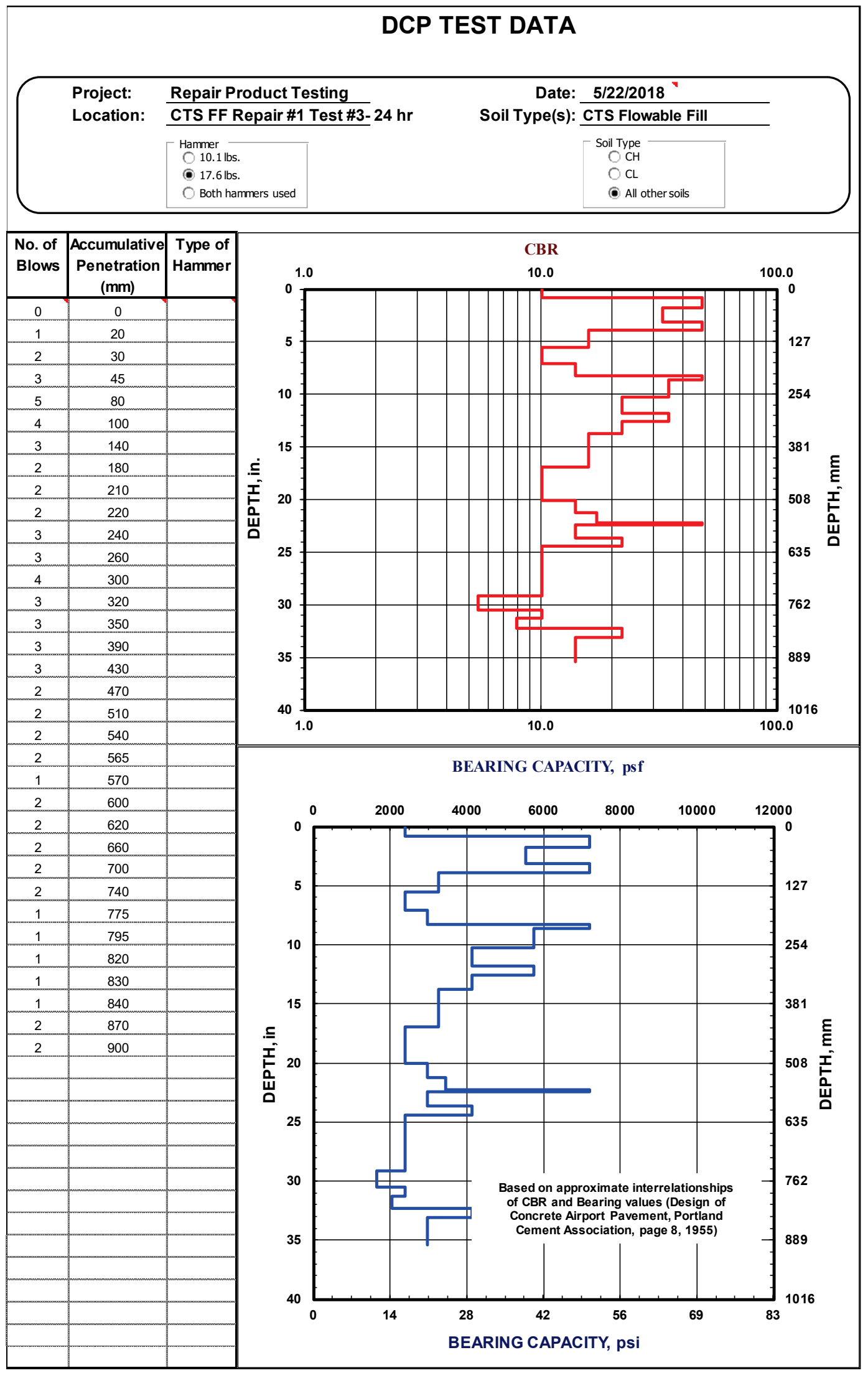


Figure B49. Repair FF-2, Test 1, DCP data at $24 \mathrm{hr}$ cure time.

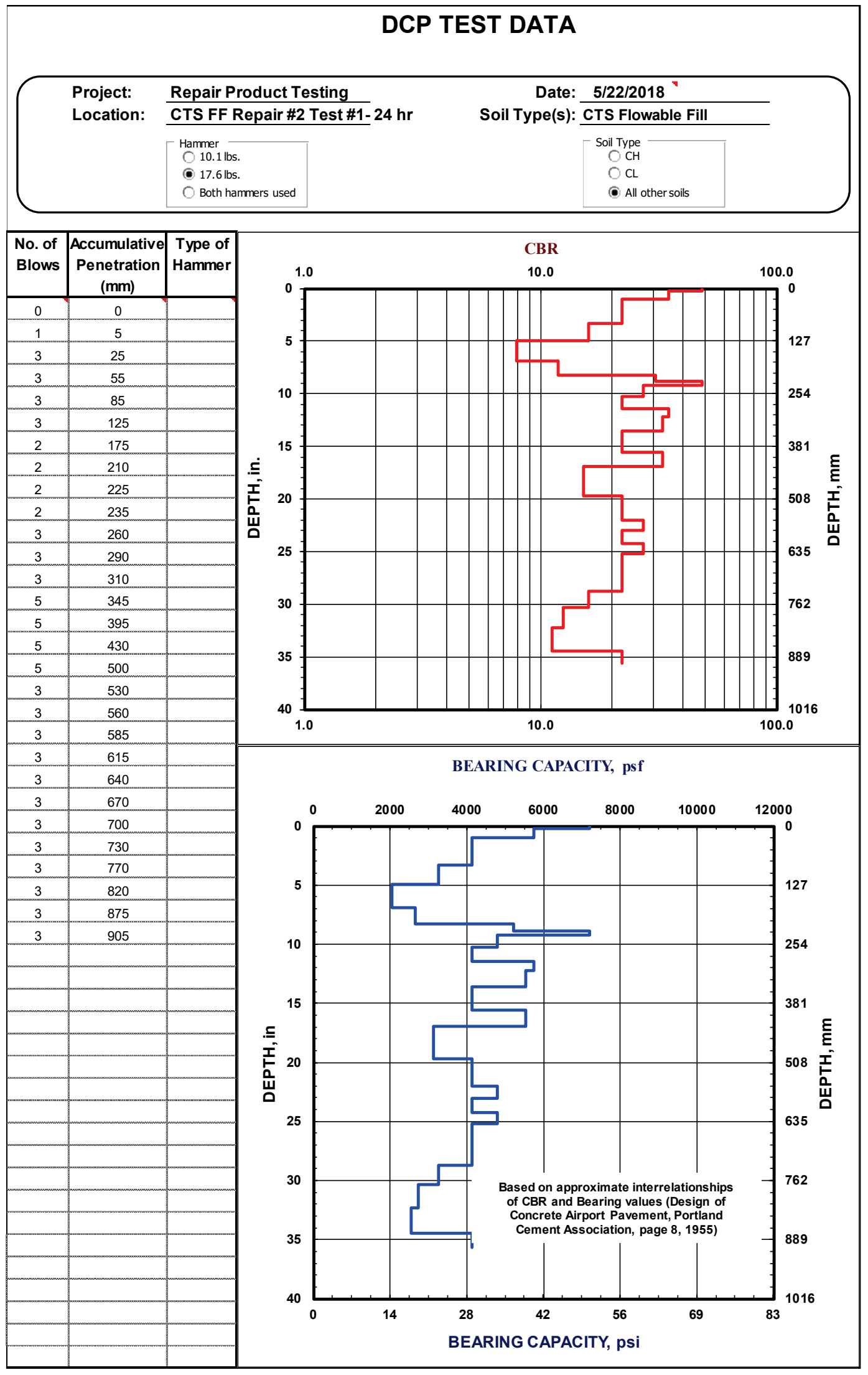


Figure B50. Repair FF-2, Test 2, DCP data at $24 \mathrm{hr}$ cure time.

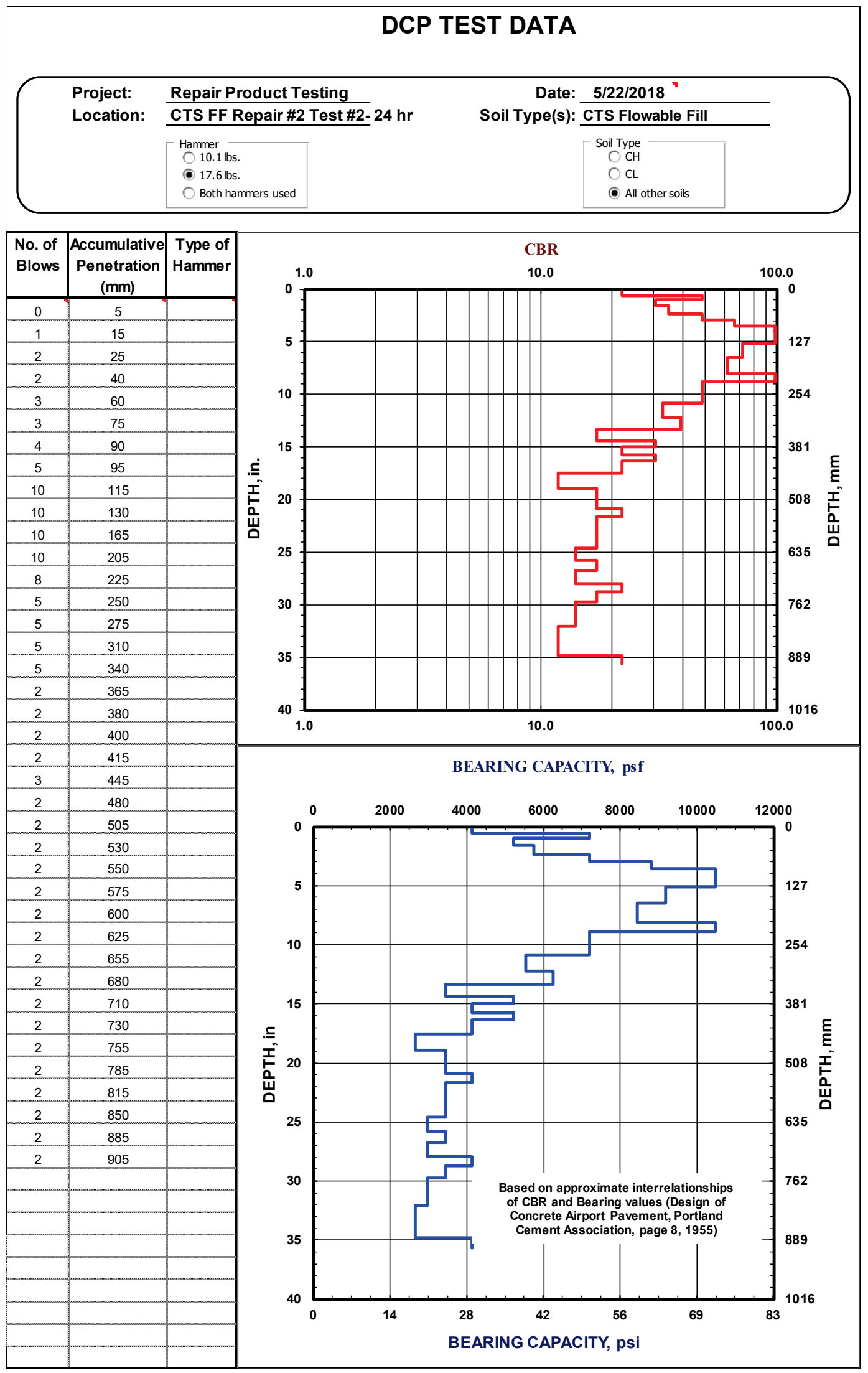


Figure B51. Repair FF-2, Test 3, DCP data at $24 \mathrm{hr}$ cure time.

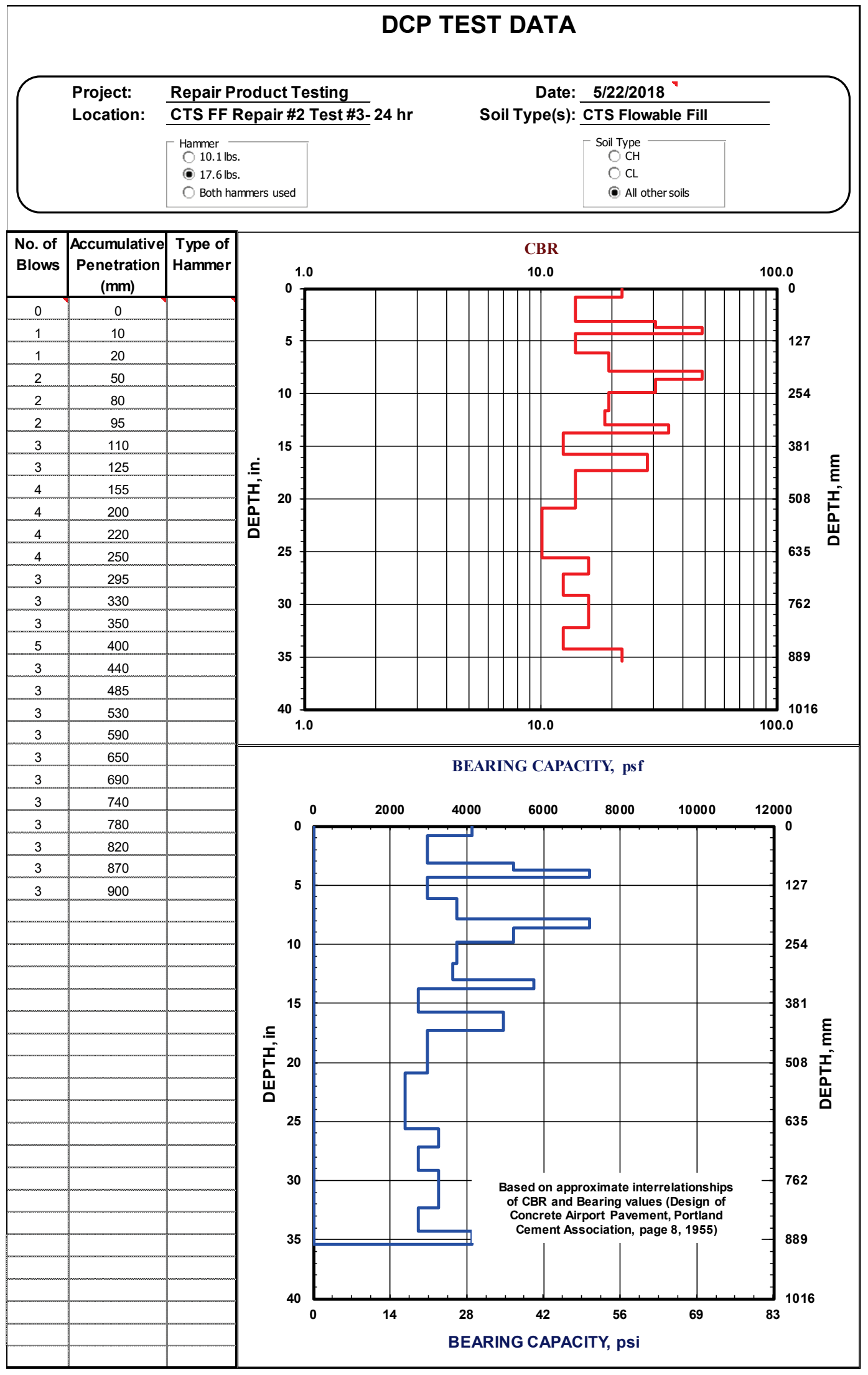


Figure B52. Repair FF-3, Test 1, DCP data at $24 \mathrm{hr}$ cure time.

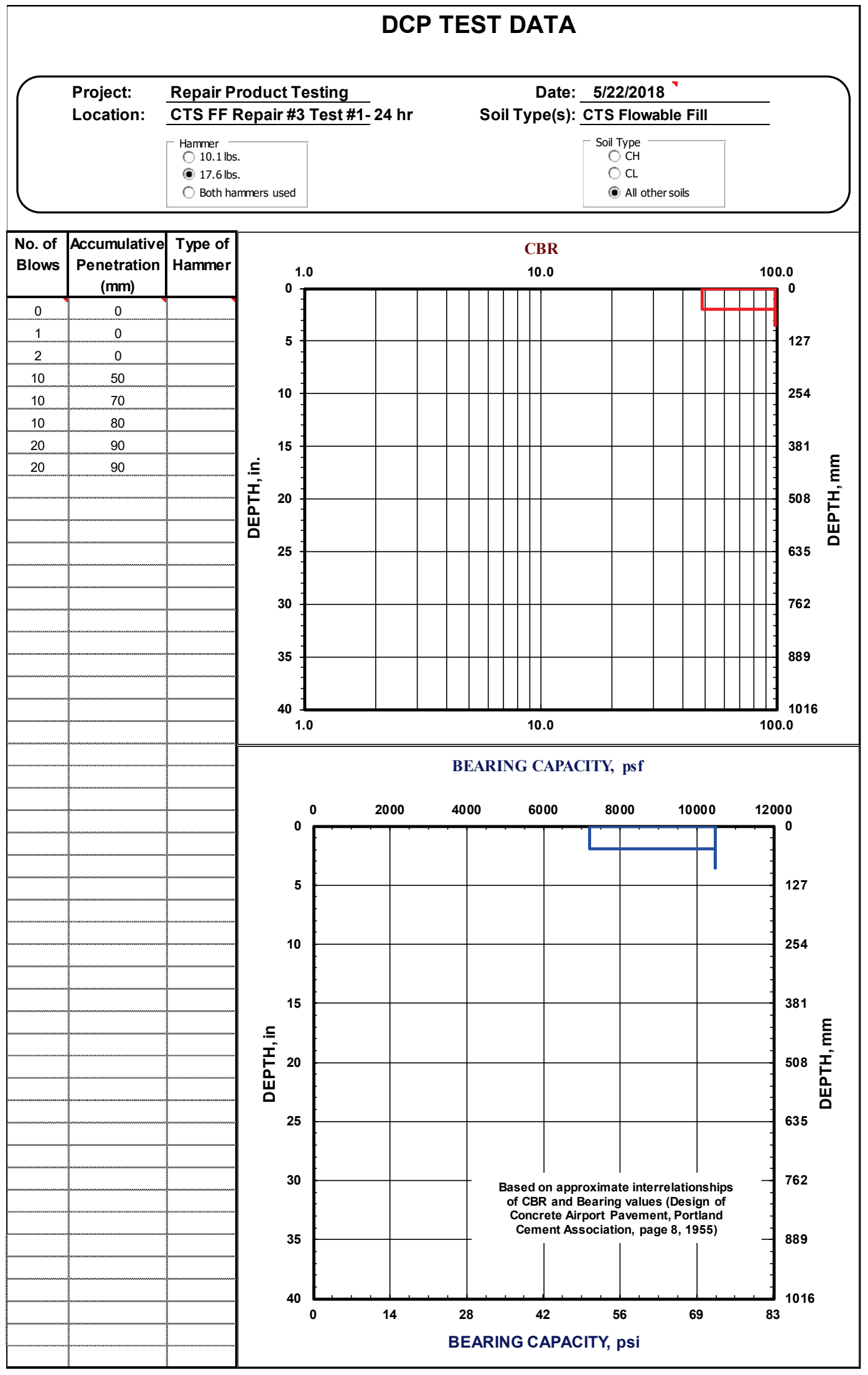


Figure B53. Repair FF-3, Test 2, DCP data at $24 \mathrm{hr}$ cure time.

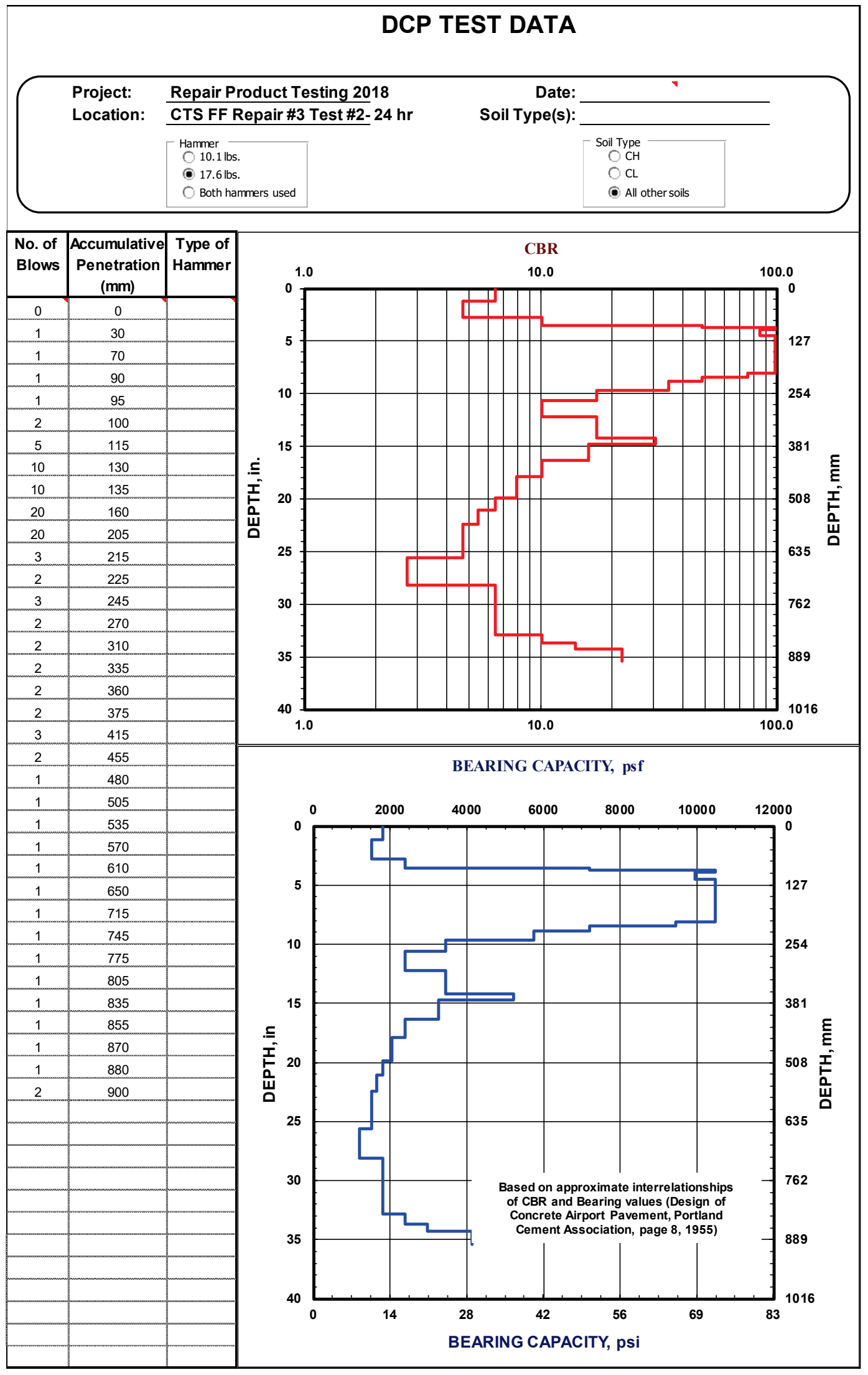


Figure B54. Repair FF-3, Test 3, DCP data at $24 \mathrm{hr}$ cure time.

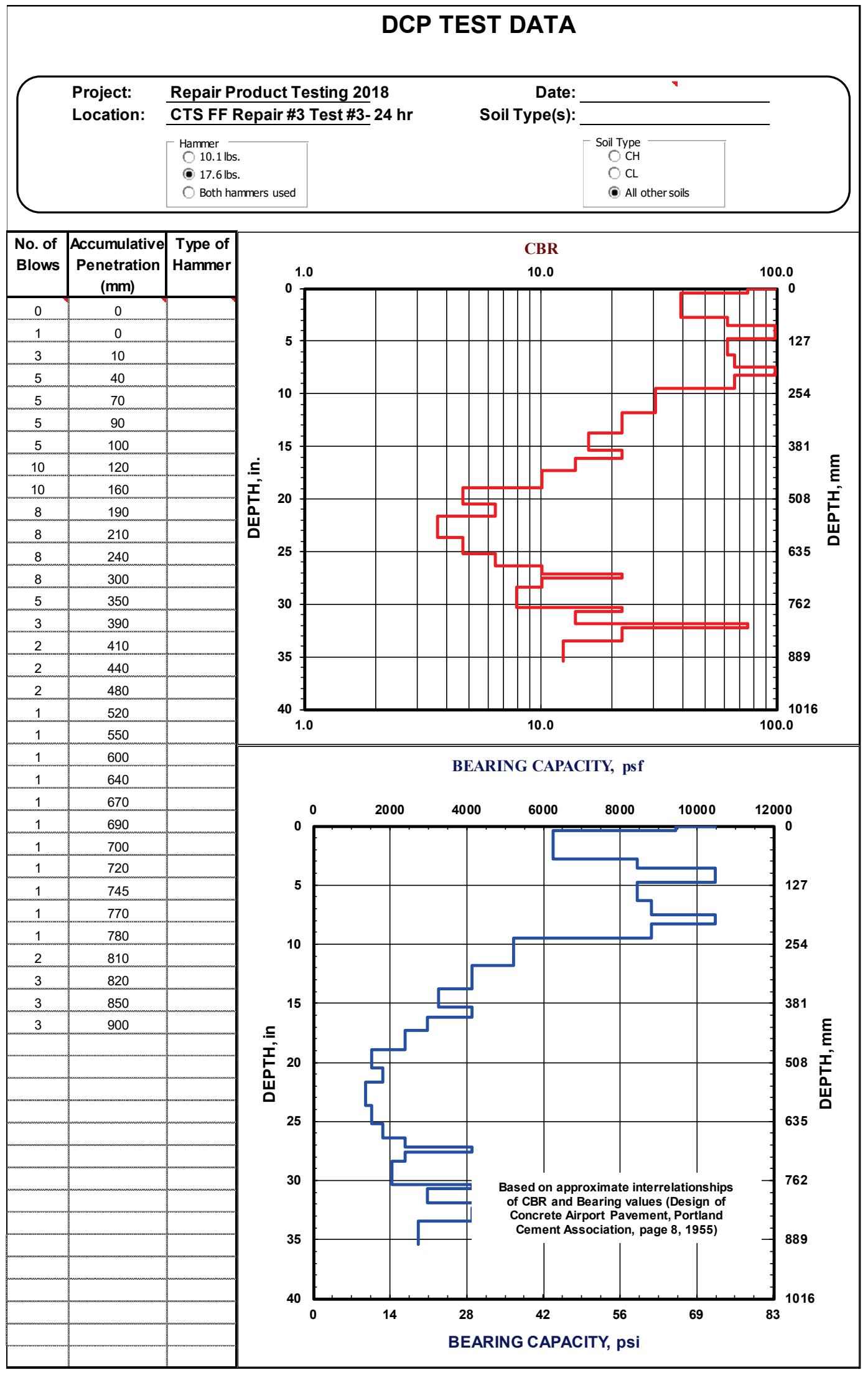




\section{Unit Conversion Factors}

\begin{tabular}{|l|c|l|}
\hline Multiply & By & To Obtain \\
\hline cubic feet & 0.02831685 & cubic meters \\
\hline cubic yards & 0.7645549 & cubic meters \\
\hline degrees (angle) & 0.01745329 & radians \\
\hline degrees Fahrenheit & (F-32)/1.8 & degrees Celsius \\
\hline feet & 0.3048 & meters \\
\hline gallons (US liquid) & $3.785412 \mathrm{E}-03$ & cubic meters \\
\hline inches & 0.0254 & meters \\
\hline ounces (US fluid) & $2.957353 \mathrm{E}-05$ & cubic meters \\
\hline pounds (force) & 4.448222 & newtons \\
\hline pounds (force) per square inch & 6.894757 & kilopascals \\
\hline square feet & 0.09290304 & square meters \\
\hline tons (force) & $8,896.443$ & newtons \\
\hline tons (2,000 pounds, mass) & 907.1847 & kilograms \\
\hline
\end{tabular}




\section{Acronyms}

$\begin{array}{ll}\text { AFCEC } & \text { Air Force Civil Engineer Center } \\ \text { RADR } & \text { Rapid Airfield Damage Recovery } \\ \text { RSFF } & \text { rapid-setting flowable fill } \\ \text { RSC } & \text { rapid-setting concrete } \\ \text { CBR } & \text { California Bearing Ratio } \\ \text { USAF } & \text { U.S. Air Force } \\ \text { CRATR } & \text { Critical Runway AssessmenT and Repair } \\ \text { JCTD } & \text { Joint Capabilities Technology Demonstration } \\ \text { LOUA } & \text { limited operational utility assessment } \\ \text { OUA } & \text { operational utility assessment } \\ \text { TTP } & \text { tactics, techniques, and procedures } \\ \text { RSC } & \text { rapid-setting concrete } \\ \text { SVM } & \text { simplified Volumetric Mixer } \\ \text { ADR } & \text { airfield damage repair } \\ \text { DCP } & \text { dynamic cone penetrometer } \\ \text { USCS } & \text { portland cement concrete } \\ \text { CTL } & \text { water-to-cement ratio } \\ \text { PCD } & \end{array}$


CSA calcium sulfoaluminate

DCP dynamic cone penetrometer 


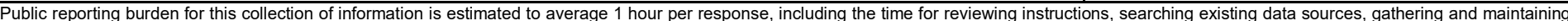

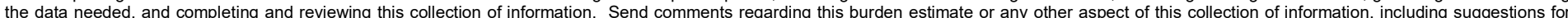

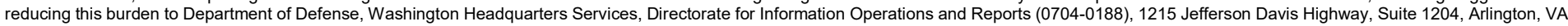

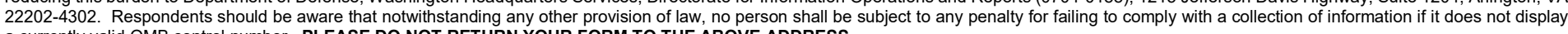
a currently valid OMB control number. PLEASE DO NOT RETURN YOUR FORM TO THE ABOVE ADDRESS.
1. REPORT DATE (DD-MM-YYYY)
May 2020

\section{TITLE AND SUBTITLE}

Full-Scale Testing of Commercially Available Cementitious Backfill and Surface Capping Materials for Crater Repairs

\section{DATES COVERED (From - To)}

5a. CONTRACT NUMBER

5b. GRANT NUMBER

5c. PROGRAM ELEMENT NUMBER

5d. PROJECT NUMBER

5e. TASK NUMBER

5f. WORK UNIT NUMBER

8. PERFORMING ORGANIZATION REPORT NUMBER

ERDC/GSL TR-20-17

Geotechnical and Structures Laboratory

U.S. Army Engineer Research and Development Center

3909 Halls Ferry Road

Vicksburg, MS 39180-6199

\section{SPONSORING / MONITORING AGENCY NAME(S) AND ADDRESS(ES)}

U.S. Air Force Civil Engineer Center

139 Barnes Drive, Suite 1

Tyndall AFB, FL 32403
10. SPONSOR/MONITOR'S ACRONYM(S)

11. SPONSOR/MONITOR'S REPORT NUMBER(S)

\section{DISTRIBUTION / AVAILABILITY STATEMENT}

Approved for public release; distribution is unlimited.

\section{SUPPLEMENTARY NOTES}

MIPR F4ATA77242GW01

\section{ABSTRACT}

The Air Force Civil Engineer Center (AFCEC) Rapid Airfield Damage Recovery (RADR) program currently utilizes rapid-setting flowable fill (RSFF) and rapid-setting concrete (RSC) for backfilling and capping crater repairs. These materials have been proven successful through many full-scale tests, troop demonstrations, and live flight trafficking. However, only one proprietary product is currently approved for each material. Two candidate capping materials and one backfill material were evaluated by conducting simulated crater repairs and collecting appropriate data. For capping products, both small $(8.5 \mathrm{ft} x 8.5 \mathrm{ft})$ and large $(15 \mathrm{ft} x 15 \mathrm{ft})$ repairs were conducted and trafficked with simulated F-15E aircraft traffic. For the backfill material, three small repairs were backfilled and the California Bearing Ratio (CBR) was estimated at cure times of 0.5, 2, and $24 \mathrm{hr}$. Overall, repairs capped with Western Materials Fastrac 246 failed after only 2,000 passes, so the material is not currently recommended for approval. Repairs capped with Buzzi Unicem UltiPave $3{ }^{\circledR}$ were able to sustain 3,500 passes before trafficking was ceased, so this material is recommended for approval as a crater repair capping material. CTS rapid-setting flowable fill backfill exhibited lower than expected CBR values and did not allow timely percolation of mix water, so it is not currently recommended for approval at this time.

\section{SUBJECT TERMS \\ Air bases}

Runways (Aeronautics) - Maintenance and repair Military bases

\section{SECURITY CLASSIFICATION OF:}

\section{a. REPORT}

Unclassified

\section{b. ABSTRACT}

Unclassified
Cratering

17. LIMITATION OF ABSTRACT

\section{c. THIS PAGE}

Fills (Earthwork)

Cement composites
Unclassified

Unclassified

SAR

18. NUMBER
OF PAGES
120

19a. NAME OF RESPONSIBLE PERSON

19b. TELEPHONE NUMBER (include area code) 